Does Assignment to Special Education Exacerbate Social, Emotional, and Academic Maladjustment among Students with Disabilities?

\author{
Adrienne D. Woods, $\mathrm{PhD}^{1}$ \\ Paul L. Morgan, $\mathrm{PhD}^{2}$ \\ George Farkas, $\mathrm{PhD}^{3}$ \\ Marianne M. Hillemeier, $\mathrm{PhD}^{2}$ \\ ${ }^{1}$ SRI International \\ ${ }^{2}$ Pennsylvania State University \\ ${ }^{3}$ University of California at Irvine
}

\begin{abstract}
Author Note:
Adrienne D. Woods (iD https://orcid.org/0000-0003-1101-6975

The authors have no conflicts of interest to disclose.

Correspondence should be addressed to Dr. Adrienne D. Woods, 1100 Wilson Blvd Suite 2800, Arlington, VA 22209 (adrienne.woods@sri.com).
\end{abstract}




\begin{abstract}
Prior work largely finds that students with disabilities (SWD) display more negative social, emotional, and academic attitudes than students without disabilities. Yet it is unclear to what extent this maladjustment is attributable to how recently and for how long students received special education services. We examined the predictive effects of the number of years and the recency of the last grade the SWD had an individualized education program (IEP). We evaluated 16 self-reported measures of early adolescent social, emotional, and academic attitudes in two national cohorts. We observed small and mostly non-significant relations between IEPs and social, emotional, and academic attitudes, indicating limited empirical support for the hypothesis that being assigned to special education exacerbates more negative attitudes among SWD. Keywords: Special education; social-emotional adjustment; academic attitudes; longitudinal analyses; students with disabilities
\end{abstract}




\section{Does Assignment to Special Education Exacerbate Negative Social, Emotional, and Academic Attitudes among Students with Disabilities?}

Students with disabilities (SWD) frequently display lower social and emotional adjustment and more negative attitudes including more emotional and interpersonal difficulties, lower motivation, greater peer rejection, delinquency, victimization, academic failure, and school dropout (e.g., Bender \& Wall, 1994; Rose et al., 2011). SWD are more likely to self-report feeling different than their peers as well as feeling victimized or excluded due to being in special education, thereby increasing their risk for lower social or emotional adjustment (Demchuk, 2001). Particularly among SWD who also experience other stigmatization, including on the basis of racial or ethnic identity, concerns regarding the labeling of SWD have resulted in suggestions that "special education may be unwarranted and harmful and rightly avoided" (Sullivan \& Proctor, 2016, p. 282) except possibly for students with complex or severe disabilities.

Students whose disabilities interfere with learning, including students with learning disabilities (LD) or emotional disorders (ED), report lower academic self-concepts (Zeleke, 2004), more negative behavioral engagement in learning tasks (Gans et al., 2003), and feeling less included, valued by, and bonded with peers, teachers, and schools (Gans et al., 2003; Lackaye \& Margalit, 2006; Murray \& Greenberg, 2001; Stiefel et al., 2018). Teachers perceive students with autism spectrum disorder (ASD) and ED as having lower academic motivation than students with LD or speech or language impairments (SLI) (Daniel \& Cooc, 2018). SWD report a lower or more external locus of control, indicating that they believe that events in their life are shaped more by external factors and less by their own abilities (Bishara \& Kaplan, 2018; Shogren et al., 2010). SWD, especially those with ASD, are more likely to experience more negative peer relationships, less peer support, loneliness, and bullying victimization (Lasgaard et 
al., 2010; O’Brennan et al., 2015; Rose et al., 2012). Students with LD also report more anxiety and loneliness than peers without LD (Lackaye \& Margalit, 2006; Nelson \& Harwood, 2011). SWD have been reported to have lower educational attainment aspirations than SWOD (Gutman \& Schoon, 2018). In turn, social-emotional maladjustment and more negative academic selfconcept and motivation are associated with fewer educational and societal opportunities over the life course (Durlak et al., 2011; Osborne \& Jones, 2011).

Yet it is currently unclear whether and the extent to which the more negative social, emotional, and academic attitudes displayed by SWD are exacerbated by assignment to special education. Special education services are designed to provide support to SWD for whom typical education practices have not been fully successful given neurological or physical differences. However, assignment to special education could exacerbate negative social, emotional, and academic attitudes of SWD in several ways. First, special education services may not be delivered in ways that successfully support SWD's learning needs. Even evidence-based practices may be ineffective if they are not well-implemented (Burns \& Ysseldyke, 2009). For instance, observational studies indicate that the majority of instructional time for students with LD is spent on low-level tasks that do not promote engaged learning, suggesting that the provided instruction may be insufficiently intensive to accelerate learning growth to grade level (Vaughn \& Wanzek, 2014). It is possible that SWD experiencing academic and behavioral difficulties that are inadequately addressed may experience poorer social or emotional adjustment as well as more negative academic attitudes (Bender \& Wall, 1994; Morgan et al., 2010). Among SWOD, experiencing academic difficulties in early elementary school predicts poorer task engagement and self-control (Morgan et al., 2008) as well as feelings of anger, sadness, loneliness, distractibility, and social isolation (Morgan et al., 2012). This link may 
similarly operate among SWD, who are especially likely to experience academic difficulties. Moreover, being "labeled" as having special needs by being assigned an IEP may signal to parents and teachers that they should have lower academic and behavioral expectations for SWD (Shifrer, 2013). Among SWOD, lower educational expectations have been theorized to threaten self-identity and so negatively impact self-esteem, academic self-concept, and peer relationships (e.g., Major \& O’Brien, 2005). This labeling could result in behavior aligned with self-fulfilling prophecies of lower expected educational attainment and academic work ethic, resulting in both lower educational performance and more negative social, emotional, and academic attitudes.

However, it could also be that associations between assignment to special education and more negative social, emotional, and academic attitudes is confounded by unmeasured factors. For example, the best predictor of having an Individualized Education Program (IEP) in elementary school is previously experiencing academic difficulties (Hibel et al., 2010). Federal special education legislation requires that SWD receive services when their disabilities adversely affect their educational performance (IDEA, 34 CFR $§ 300.8(c), 2007)$ so students in special education are highly likely to have had previous academic and behavioral difficulties (Morgan et al., 2010). Experiencing academic and behavioral difficulties is known to increase risk for lower social or emotional functioning (Morgan et al., 2012) regardless of IEP status. To illustrate, SWD are often involved in bullying as both victims and as perpetrators (Rose et al., 2011). Although educational placement decisions and teacher practices can contribute to bullying involvement (Rose et al., 2012), SWD might also become involved with bullying due to impaired social competencies resulting from underlying disabilities (e.g., Krull et al., 2014). Regardless of special education receipt, experiencing social rejection or peer bullying can result in internalizing problem behaviors, anxiety, depression, low self-esteem, and lower social or 
academic engagement (Marini et al., 2006; Rose et al., 2011). Thus, there may be alternative explanations for hypothesized relations between being assigned to special education and the lower social, emotional, and academic attitudes of SWD.

Better understanding the role of assignment to special education for SWD in social, emotional, and academic attitudes is important for both special education research and practice. Some researchers argue that schools should limit special education enrollment to students with severe disabilities (Sullivan \& Proctor, 2016). Yet the evidence base for such suggestions is very limited, and researchers typically investigate differences in social, emotional, or academic attitudes between SWD and SWOD rather than investigating assignment to special education among SWD as a mechanism that may or may not exacerbate maladjustment.

We identified only five studies that investigated the relations between social, emotional, and academic attitudes and characteristics of special education service receipt in elementary and middle school. Results from these findings were mixed, reporting negative (Chesmore et al., 2016; O’Brennan et al., 2015), neutral (Chesmore et al., 2016; Lackaye \& Margalit, 2006; Zach et al., 2016), or positive relations (Morgan et al., 2010) between receiving special education services and social-emotional and academic functioning. Each study contrasted SWD to SWOD. Any observed differences in such a contrast may reflect differences in social, emotional, and academic attitudes between students who do or do not have a disability, rather than indicating whether assignment to special education exacerbates these potentially pre-existing differences. This distinction is important to avoid mischaracterizations of assignment to special education as inherently ineffective or harmful. To our knowledge, no studies have investigated the link between special education services and social or emotional functioning that leverage variation in assignment to special education among SWD instead of comparing SWD to SWOD. 


\section{Purpose of Study}

We evaluated two mechanisms through which being assigned an IEP could exacerbate the more negative social, emotional, or academic attitudes documented among SWD. These mechanisms are 1) the timing of the most recent IEP, a proxy for the relative recency that SWD were assigned to receive special education services; and 2) the duration of time a student was reported to have an IEP, a proxy for the length of time that SWD received special education services. Our operationalization of treatment as assignment to special education through an IEP is consistent with an intent-to-treat paradigm (Gross \& Fogg, 2004). We evaluate the combined effects of these mechanisms in two nationally representative datasets, one of which measured social, emotional, and academic attitudes in $8^{\text {th }}$ grade and the other in $5^{\text {th }}$ grade.

Theoretically, if being assigned an IEP was harmful for social, emotional, and academic attitudes, then having an IEP (and thus receiving special education services) for a longer duration would be associated with more negative adjustment than having an IEP for a shorter duration. Similarly, if being assigned an IEP was harmful because being placed in special education increases the likelihood of experiencing stigmatization or lowered educational expectations, then having an IEP more recently would be associated with more negative adjustment (i.e., because there are fewer years to overcome any negative IEP effects). This might be especially true for SWD who are older and so more sensitive to their social standing amongst peers.

Though this non-causal approach does not remove all selection bias, we attempt to lessen this bias by controlling for disability type and prior academic and behavioral performance. This should better account for disability severity and provide more accurate estimates of whether assignment to special education exacerbates negative social, emotional, and academic attitudes. We restricted our sample to only those students who were reported to ever have an IEP. We then 
contrasted the predicted effects of having an IEP for more or fewer years as well as more or less recently. If these effects are significantly and meaningfully negative, this would substantiate claims that assignment to special education may exacerbate social, emotional, and academic maladjustment. Obtaining null or neutral coefficients would indicate that other factors associated with disability status may explain SWD's more negative social, emotional, and academic attitudes. Obtaining positive coefficients would indicate that assignment to special education may have a protective or remediating effect for SWD.

\section{Method}

We analyzed data from the Early Childhood Longitudinal Studies: Kindergarten Cohort of 1998-1999 (ECLS-K: 1998) and 2010-2011 (ECLS-K: 2011), which are sponsored by the National Center for Education Statistics (NCES). The ECLS-K datasets each consist of nationally representative samples of $\sim 20,000$ students, for whom comprehensive information about schooling experiences was repeatedly collected. The ECLS-K: 1998 collected data in kindergarten, first, third, fifth, and eighth grade. The ECLS-K: 2011 collected data in each grade from kindergarten to fifth grade. These datasets provide complementary but distinct measures of social, emotional, and academic attitudes, thus allowing for a broad assessment of how these outcomes are related to special education. The majority of SWD in these datasets received services for LD (57.6\% and 42.0\% in the ECLS-K: 1998 and 2011, respectively) or SLI (56.7\% and $73.4 \%)$ and were primarily educated in general education classrooms $(70.9 \%$ and $73.3 \%)$.

\section{Measures}

Self-reported social, emotional, and academic attitudes. We used 16 student selfreported measures of social, emotional, and academic attitudes as dependent variables (eight from each ECLS-K dataset). Our measures are similar to those used in prior research (e.g., 
Chesmore et al., 2016; Lackaye \& Margalit, 2006; Morgan et al., 2010; O’Brennan et al., 2015; Shifrer, 2013; Zach et al., 2016), although we assess a greater number of variables than these studies. In the ECLS-K: 1998, these were student self-reports of perceived reading and mathematics competency, educational attainment expectations, internalizing behavior problems, feelings of school belonging and peer relationships, and measures of self-concept and locus of control. In the ECLS-K: 2011, these were self-reports of peer victimization, social anxiety, behavioral engagement, peer support, loneliness, school belonging, grit, and worries about school. Collectively, these measures capture aspects of identity and behavior that may be negatively impacted by being labeled as needing special education (e.g., Daniel \& Cooc, 2018; Gans et al., 2003; Gutman \& Schoon, 2018; Lackaye \& Margalit, 2006; Rose et al., 2011, 2012; Shifrer, 2013; Shogren, 2010; Zeleke, 2004). We z-scored all outcome variables so that results are reported in standard deviation units.

ECLS-K: 1998 Outcomes. Eighth grade students in the ECLS-K: 1998 completed surveys assessing multiple dimensions of academic, social, and emotional adjustment. Four scales were created with items from the Self-Description Questionnaire II (SDQ). Students rated statements from $1=$ Not at all true to $4=$ Very true. The SDQ Perceived Interest/Competence in Reading and Mathematics subscales each consisted of four items assessing self-reported grades in English and mathematics and the student's interest in and enjoyment of reading and mathematics. Internal reliabilities within the ECLS-K: 1998 dataset were relatively high ( $\alpha_{\text {Reading }}$ $=.76 ; \alpha_{\text {Mathematics }}=.89$ ). The SDQ Internalizing Behavior subscale used eight items to measure internalizing problems like feeling "sad a lot of the time," feeling lonely, feeling ashamed of mistakes, feeling frustrated, and worrying about school and friendships $(\alpha=.75)$.

Two scales measuring self-concept and locus of control were adapted from the National 
Education Longitudinal Study of 1988 (NELS:88) for the ECLS-K: 1998 at eighth grade. These scales asked students to rate their agreement with 13 statements about themselves, ranging from 1=Strongly agree to 4=Strongly disagree. The NELS: 88 Self-Concept scale, adapted from the Rosenberg Self-Esteem Scale (RSE), asked students about self-perceptions $(\alpha=.81)$. The Locus of Control subscale asked students how much control they felt they had in their lives $(\alpha=.75)$.

We included three other measures at eighth grade. School belonging was computed by averaging responses from five questions asking students how often they fit in, felt close to classmates and teachers, enjoyed school, and felt safe at school (where 1=Never, 2=Sometimes, 3=Often, $4=$ Always; $\alpha=.71$ ). Expected educational attainment was derived from one survey item asking how far the student believed they would go in school (where $1=$ not completing high school, 7 = obtaining a professional degree). We measured perceptions of value among peers by averaging three questions asking whether students thought their classmates found it important to be their friend, whether they liked them as a person, and if they cared about them (with 1=Never, 2=Seldom, 3=Sometimes, 4=Often, 5=Always; $\alpha=.79)$.

ECLS-K: 2011 Outcomes. Fifth grade students in the ECLS-K: 2011 completed surveys assessing multiple dimensions of academic, social, and emotional adjustment. Peer victimization items were adapted from a 21-item scale created by Espelage and Holt (2001). Four questions assessed the frequency that other students (a) "teased you, made fun of you, or called you names?" (b) “told lies or untrue stories about you?” (c) “pushed, shoved, slapped, hit, or kicked you?" and (d) "left you out from playing with them on purpose?" during the current school year. Response options were $1=$ Never, $2=$ Rarely, $3=$ Sometimes, $4=$ Often, and $5=$ Very Often $(\alpha=.81)$.

The social anxiety or fear of negative evaluation scale was adapted from the Social Anxiety Scale for Children (La Grecca \& Stone, 2001). Students reported the extent to which 
they worried what other students thought about them, worried that other students did not like them, or were afraid other students would not like them ( $1=$ Never to $5=$ Very Often; $\alpha=.88)$. Peer social support was adapted from Vandell's (2000) Peer Social Support, Bullying, and Victimization form. Children were asked to think about themselves and their experiences that school year, and whether other children in their class "make me feel better if I'm having a bad day," "let me play with them," "make me feel happy," "would help me if I hurt myself at school," "tell me I'm their friend," and "would help me if other kids were being mean to me" $(\alpha$ $=.87$ ). The Loneliness form was adapted from Parker and Asher (1993). Students were asked to rate their agreement with the statements, "I feel lonely at school," "I feel left out at school," "I feel alone at school," from $1=$ Never to $5=$ Very Often $(\alpha=.89)$. The School Belonging scale was the same as that used in the ECLS-K: $1998(\alpha=.70)$.

The Behavioral Engagement scale included items created by Skinner et al. (2009). Students reported how often $(1=$ Never to $5=$ Very Often $)$ they try hard to do well in school, work as hard as they can in class, participate in class discussions, pay attention in class, and listen very carefully in class $(\alpha=.73)$. The Grit scale was adapted for the ECLS-K: 2011 from the Short Grit Scale (Duckworth \& Quinn, 2009). Students evaluated the extent to which 6 questions describe a person like them on a scale from 1=Not at all true to 4=Very True: "I finish whatever I begin," "I try very hard even after making mistakes," "I continue to work toward my goals, even when they take a long time to complete," I keep working hard even when I feel like quitting," "I continue working on what I set out to do, even when it takes a long time to complete," and "I keep trying to improve myself, even when it takes a long time to get there" $(\alpha=.83)$. The Worry/Stress about School scale was developed from the Internalizing Problems Scale used in the ECLS-K: 1998. Four items assessed whether students find it hard to finish their schoolwork, feel ashamed when 
they make mistakes at school, and worry about doing well in school and finishing their work $(1=$ Not at all true, to $4=$ Very True, $\alpha=.71)$.

Special education service receipt. We considered two mechanisms through which having an IEP may negatively impact social, emotional, and academic attitudes among a sample of SWD. The first was the number of prior years that the student had an IEP. The second was how recently the student last had an IEP. Both variables were created using all available waves of data while treating missing values as zero (i.e., using pairwise deletion methods). Our estimates were therefore conservative regarding both the length of time and the most recent grade that SWD received special education services.

The number of years the student had an IEP was computed by summing binary items at each spring wave asking school staff to indicate whether the student had an IEP. This variable ranged from a score of one, indicating that the student had an IEP during only one grade, to high scores of five in the ECLS-K: 1998 and six in the ECLS-K: 2011 (indicating that the student had an IEP in all five or all six waves, respectively). The most recent IEP was measured by the most recent grade with available data at which SWD were reported to have an IEP, on a scale from 1-5 in the ECLS-K: $1998(1=$ kindergarten, $2=$ first grade, $3=$ third grade, $4=$ fifth grade, and $5=$ eighth grade $)$ and on a scale from 1-6 in the ECLS-K: $2011(1=$ kindergarten, $2=$ first grade, $3=$ second grade, $4=$ third grade, $5=$ fourth grade, and $6=$ fifth grade).

Supplementary Table S1 shows a cross-tabulation of the total number of IEP years and the last IEP variables across each grade. Table S2 shows that the number of IEP years and the last IEP variables were positively correlated at $r=.45$ in the ECLS-K: 1998 and $r=.52$ in the ECLS-K: 2011. There appears to be sufficient variation across combinations of these variables that their relationships with social, emotional, and academic attitudes in eighth and fifth grade 
could be empirically separated by regression analysis. However, because these variables share about half of their variance, it is possible that they may also "share the effect" and thus diminish each other's coefficient in regression analysis. We found this to be the case. As demonstrated in Supplementary Table S3-S4, the magnitude and/or statistical significance of each variable was often reduced when entered into the regression analysis together without covariate adjustment. For example, in Table S3, both variables were significantly and negatively related to locus of control when entered into separate regression analyses (Last IEP: $\mathrm{B}=-0.17, p<.05 ;$ IEP Years: $\mathrm{B}=-0.15, p<.01)$. However, when included together, both coefficients were reduced in size and dropped to statistical non-significance (Last IEP: $\mathrm{B}=-0.12, p=\mathrm{ns} ;$ IEP Years: $\mathrm{B}=-0.11, p=$ ns). This was the case for 9 of the 16 coefficients for Last-IEP and for 9 of the 16 coefficients for IEP-Years. Including these two IEP variables together in analyses tends to "knock out" their effects, with zero significant effects following correction for comparisons across 8 outcomes in the ECLS-K: 1998 and 7 significant effects of 16 in the ECLS-K: 2011.

To surmount the challenge of this shared effect, we averaged these IEP variables into a single scale so that the highest values corresponded to students with both the greatest and most recent number of years with an IEP, while the lowest values corresponded to students with both the smallest and least recent number of years with an IEP. We did so by z-scoring both IEP variables, averaging them together, and then z-scoring once more. This variable thus allows us to test whether students with greater IEP experience showed more negative subsequent attitudes than students with less IEP experience, controlling for confounds measured in kindergarten.

In addition to IEP experience, we tested for differences in disability type by adding 5 binary disability indicators. This allows us to better account for the relative severity of IEP accommodations across disability type. In each year, the SWD's special education teacher 
answered the question, "During this school year, for which of the following disabilities has this child received special education or related services, whether for the child's primary disability or another of his/her disabilities?" We recoded responses into the following categories: learning disability (LD), speech or language impairment (SLI), emotional disturbance (ED), autism or developmental delay (ASD), or low incidence disabilities (LI), which included blind or visually impaired, Deaf/deaf or hard of hearing, physical or orthopedic impairment, multiple disabilities, or traumatic brain injury. These categories are not mutually exclusive.

Covariate adjustment. We adjusted each model for the same covariates from each ECLS-K dataset. These included fall kindergarten measures of teacher-reported behaviors (internalizing problem behaviors $\left[\alpha_{1998}=.80, \alpha_{2011}=.79\right]$, externalizing problem behaviors $\left[\alpha_{1998}\right.$ $=.90,2011 \alpha=.88]$, interpersonal relationship skills $\left[\alpha_{1998}=.89, \alpha_{2011}=.86\right]$, and positive learning-related behaviors $\left.\left[\alpha_{1998}=.89, \alpha_{2011}=.91\right]\right)$. We also included fall kindergarten measures of general reading $\left(M_{1998}=31.6, S D=10.3, \alpha=.93 ; M_{2011}=54.1, S D=11.5, \alpha=.95\right)$ and mathematics achievement $\left(M_{1998}=27.1, S D=8.8, \alpha=.92 ; M_{2011}=35.6, S D=11.6, \alpha=.92\right)$, which were averaged together to reduce collinearity and to indicate general academic achievement during the fall of kindergarten.

\section{Missing Data, Samples, and Weighting}

Cases with missing data tended to fall along similar demographic patterns. Children with missing data tended to be Black and/or to have young or single parents. Their families reported lower maternal education, lower socioeconomic status, and that their children more often were born prematurely or attended Head Start. These measures were included along with other nonanalytical measures as auxiliary variables in the imputation model (see Table S5 for a complete list). With data that are missing at random, including a rich selection of demographic auxiliary 
variables that might help explain missingness has been theorized to lessen bias (Davis-Kean et al., 2015).

We addressed missingness by multiply imputing 40 datasets in Stata/SE v. 14.2 using multivariate chained-equations (MICE) for each ECLS-K dataset following the recommendations outlined in Woods et al. (2021). MICE fills in missing values multiple times for each variable to create several complete datasets for analysis (Rubin, 1978; Van Buuren \& Groothuis-Oudshoorn, 2011). Data are analyzed in each imputed dataset and estimates are pooled together using Rubin's (1978) formulas to account for between- and within-imputation variance. Although imputations in the social sciences have historically been conducted with $m=$ 3 to 5 imputed datasets (Spratt et al., 2010), decreasing $m$ imputed datasets tends to reduce power and increase errors (Graham et al., 2007), and there is no negative impact of increasing $m$ (White et al., 2011). Moreover, some have suggested imputing at least as many datasets as the highest fraction of missing information (FMI) (Allison, 2012; White et al., 2011; Graham et al., 2007).

Each dataset was conservatively restricted to those with complete, non-missing data on whether they had ever experienced special education services. This resulted in unweighted sample sizes of $N=17,120$ in the ECLS-K: 1998 and $N=17,130$ in the ECLS-K: 2011. Applying the longitudinal weights for analyses using data from fall of kindergarten and the final wave of data collection ( $8^{\text {th }}$ grade in the ECLS-K: 1998 and $5^{\text {th }}$ grade in the ECLS-K: 2011) further reduced the sample sizes to $n=7,800$ in the ECLS-K: 1998 and $n=10,310$ in the ECLSK: 2011. Finally, attention was restricted to the counterfactual subsamples of students with disabilities (SWD) for regression analyses by dropping students who were never reported to have an IEP on file from these imputed datasets, producing weighted sample sizes of $n=1,340$ SWD in the ECLS-K: 1998 and $n=2,430$ SWD in the ECLS-K: 2011. See Stata code (available with 
the online supplementary materials) for data setup, cleaning, imputation model syntax, and analyses.

Data were weighted to account for clustered sampling designs and attrition using the longitudinal weights constructed by ECLS-K. Table S6 shows weighted and unweighted descriptive statistics for the imputed samples in each ECLS cohort. The weighted samples align with the U.S. population in biological sex, race and ethnicity, and family background (Table 1). SWD displayed more negative attitudes than SWOD in each dataset. More students in the ECLSK: 2011 were Hispanic and fewer were white than in the ECLS-K: 1998. The average SES was lower in the ECLS-K: 2011 than the ECLS-K: 1998, and SWD came from lower SES households than SWOD. We detected no issues with normality or collinearity through the collin program in Stata. Zero-order correlations are reported in Supplemental Table S2. Appropriate procedures for Human Subjects Research were approved by a university Institutional Review Board. Per NCES restricted data regulations, sample sizes are rounded to the nearest 10.

\section{Analysis Plan}

We used multiple regression to analyze whether assignment to an IEP predicts 16 social, emotional, and academic attitudes. We corrected for multiple comparisons across the eight outcomes in each dataset using the Benjamini-Hochberg correction. All continuous variables were standardized, and so results may be interpreted in standard deviation units. Our analysis plan was as follows. We first evaluated whether SWD in the ECLS-K datasets report more negative social, emotional, and academic attitudes than SWOD. To do so, we assessed whether ever having an IEP between kindergarten and fifth grade (ECLS-K: $2011 ; n=10,310$ ) or eighth grade (ECLS-K: 1998; $n=7,800$ ) was negatively related to social, emotional, and academic attitudes, without (Model 1) and with (Model 2) covariate control. We considered this binary 
indicator of whether the student ever had an IEP to be a proxy for ever being identified as a SWD. We also evaluated whether ever receiving services for LD, SLI, ED, ASD, or LI was differentially related to SWD social, emotional, and academic outcomes, both without (Model 3) and with (Model 4) covariate control. These results are shown in Tables 2-3.

Following these checks, we then pursued our primary research aim of investigating whether being assigned an IEP exacerbates or mitigates social, emotional, and academic maladjustment among SWD. We restricted our analytic sample to only those SWD who were assigned an IEP at least once between kindergarten and eighth grade in the ECLS-K: 1998 ( $n=$ 1,340) or between kindergarten and fifth grade in the ECLS-K: $2011(n=2,430)$. We conducted regression analyses without and then with covariate control, and again adjusted for multiple comparisons across the 8 outcomes in each dataset using the Benjamini-Hochberg method. All Stata code is available with the supplementary materials.

\section{Results}

We first evaluated whether SWD reported significantly more negative social, emotional, and academic attitudes than SWOD (Tables 2-3). Fifteen of the 16 coefficients for ever-IEP were statistically significant and negative in effect in Model 1 prior to covariate adjustment. The magnitudes of these negative coefficients were reduced but 13 of the 15 remained statistically significant with a median absolute size of .18 SD following covariate control in Model 2, suggesting that additional explanatory factors only partially explain SWD's more negative social, emotional, and academic attitudes. In Model 3, students who ever received services for LD had especially more negative social, emotional, and academic attitudes than SWOD. Seven of the 16 LD coefficients were statistically significant following covariate control. Positively, students who ever received services for ASD reported higher but nonsignificant reading $(.24 S D)$ and 
mathematics competencies (.20 SD), loci of control (.20 SD), and educational attainment aspirations (.43 SD) than students who did not receive services for ASD.

Next, we evaluated whether being assigned an IEP exacerbated or mitigated these negative social, emotional, or academic attitudes among SWD. Tables 4 and 5 present weighted regression analyses for the ECLS-K: 1998 and ECLS-K: 2011, respectively. In contrast to results from traditional analyses comparing SWD to SWOD (Tables 2-3), restricting attention to SWD who had more or less experience with an IEP yielded coefficients that were much smaller and that less frequently attained statistical significance. Although 10 of the 16 IEP variables were statistically significant following correction for multiple comparisons and negative in effect when control variables were not included in the model (row 1 of each table), including control variables like prior achievement, behavior, and sociodemographic information reduced these coefficients in magnitude and all but one became statistically non-significant. SWD who had greater experience with IEPs reported significantly lower behavioral engagement in the classroom (-0.10 SD). They also reported less peer support (-0.09 SD) and a lower locus of control (-0.12 SD), yet higher feelings of competency in mathematics $(0.10 S D)$, though none of these three coefficients were statistically significant following correction for multiple comparisons. The median absolute value for IEP experience was small at $0.08 S D$. Supplementary Tables S7-S8 show estimated models in which the dummy variables for specific disabilities were interacted with IEP experience. Of the resulting 80 interaction coefficients (5 disabilities x 16 outcomes), none were statistically significant following correction for multiple comparisons. These data do not appear to have the statistical power to detect interaction effects.

Overall, the results suggest that assignment to special education may neither exacerbate nor mitigate the negative social, emotional, or academic attitudes commonly displayed by SWD. 
More than $85 \%$ of the variance in our outcome variables was unexplained by our predictors (see the model $R^{2}$ at the bottom of Tables 4 and 5), including IEP experience, prior achievement and behavior, and sociodemographic variables. Thus, other factors likely explain the negative relation between assignment to IEP and social, emotional, and academic attitudes among SWD.

\section{Discussion}

We analyzed whether and to what extent variation in how long and how recently SWD received special education services was related to self-reported attitudinal measures in two national cohorts. We found little evidence that having greater experience with special education was related to more negative social, emotional, and academic attitudes among SWD. Control variables including socio-demographics as well as kindergarten behaviors and achievement strongly and consistently predicted the attitudinal outcomes. This suggests that these covariates may explain the more negative social, emotional, and academic attitudes among SWD relative to SWOD. Evaluating 16 social, emotional, and academic attitudes in two independent samples of SWD revealed only 1 coefficient that remained statistically significant and negative following covariate adjustment at $-0.10 S D$. Overall, this suggests that being assigned to special education may not independently result in much additional maladjustment for SWD over and above what these students may have already experienced as a result of their disabilities and the resulting academic or behavioral difficulties in school, which the IEP was likely designed to address.

\section{Limitations and Directions for Future Research}

The two ECLS-K cohorts are not directly comparable because they completed data collection in different years of schooling, and collected information on different social, emotional, and academic indicators in both their final wave of data collection (apart from school belonging) and in the $5^{\text {th }}$ grade wave. Data collection did not continue into high school and so 
our results are not generalizable to those grades. Because the ECLS-K: 1998 collected data in non-consecutive years, direct comparison of the effects of having an IEP across the two cohorts through their $5^{\text {th }}$ grade wave of data would be difficult, so we were unable to evaluate for cohort differences in the relations between these attitudes and having an IEP. There were also important policy changes that occurred between the two ECLS-K cohorts whose effects we were unable to test for. Instead, and to maximize the complementary nature of these datasets, we framed our study as providing evidence for the effects of having an IEP on a several distinct but related components of social, emotional, or academic attitudes across two cohorts of SWD followed through the middle grades. Estimates obtained in each dataset were similar in magnitude across the 1998 and 2011 cohorts, lending confidence to the comprehensive effects of having an IEP on social-emotional adjustment and academic attitudes among SWD.

Our results are consistent with prior findings that social, emotional, and academic attitudes differ by disability type (Murray \& Greenberg, 2001; Martínez \& Semrud-Clikeman, 2004; Kasari et al., 2011). We were unable to assess students who received early intervention services at ages 3-5. Because we cannot verify whether and how special education services were delivered in the ECLS-K datasets, we consider our measures capturing the timing of the most recent IEP and the duration of having an IEP as proxies for length of time and relative recency that SWD received special education services. However, the number of years SWD have an IEP and the timing of their last IEP are not randomly distributed among SWD. Effects may vary by disability type, severity of impairment, or by the quality of special education services received. Including indicators for whether the SWD ever received services for certain disability categories as well as whether students were experiencing academic or behavioral difficulties should have better controlled for this confounding by both disability type and impairment severity. 
Nonetheless, we believe that capitalizing on variation in IEP experience represents a better attempt to measure how assignment to special education impacts social, emotional, and academic attitudes among SWDs.

Our estimates were based on staff-reported receipt of special education services and SWD's self-reported social, emotional, or academic attitudes. This limitation is typical of observational research using national samples. There has been criticism of self-report measures given individuals' tendencies to respond in socially desirable ways (Donaldson \& Grant-Vallone, 2002). However, self-report measures function as well as non-self-report measures, particularly in studies assessing subjective wellbeing (Sandvik et al., 1993). Future research should disentangle the extent to which parent-, teacher-, and SWD-reported social, emotional, or academic attitudes are correlated and how these reports may be influenced by special education receipt. In addition, the survey measures used in the ECLS-K capture beliefs and attitudes about the students themselves (e.g., "I am good at math") instead of potentially stereotypical beliefs about a group as a whole (which would be assessed by utilizing generic noun phrases; for example, "I think boys are good at math"). In other words, it is possible that SWD may hold these potentially stereotypical beliefs even though they do not personally endorse more social or emotional maladjustment relative to their peers.

Our study focused on self-reported attitudinal risk and did not directly estimate predicted effects of special education on achievement. Prior work that has done so by comparing SWD outcomes before and after special education has noted positive effects on academic outcomes (Hanushek et al., 2002; Hurwitz et al. 2020; Schwartz et al. 2021). This contrasts with largely null findings in studies comparing SWD to SWOD (e.g., Morgan et al. 2010). Our findings join these other studies in suggesting that when selection bias is reduced by comparing SWD among 
themselves rather than to SWOD, special education may generate positive academic benefits with relatively minor negative attitudinal outcomes.

\section{Contributions and Implications}

It has been suggested that special education exacerbates often-observed negative social, emotional, or academic attitudes of SWD. Our findings suggest that the risk of experiencing more negative social, emotional, or academic attitudes following assignment of an IEP is fairly limited in scope, small in magnitude, and typically observed only when academic, behavioral, and sociodemographic confounders are not accounted for. That is, the estimated risks to the social, emotional, and academic attitudes of SWD that are often attributed to having an IEP may instead be explained by the maladjustment arising from experiencing the disability-related academic or behavioral difficulties, which special education services are designed to address.

In our study, SWD with greater experience with IEPs were significantly less engaged in the classroom. They also reported less peer support and the sense that events in their life more often occurred outside their control. Yet, SWD who had greater experience with IEPs also reported higher feelings of mathematics competency. These findings are consistent with the hypothesis that receiving special education has both positive and negative effects. Viewed in combination with prior research, our findings support that the effects of special education may be positively oriented toward academic achievement yet negatively influence some social or emotional attitudes. Our result that SWD who have more experience with an IEP report higher mathematics competency aligns with these findings, though it did not attain statistical significance following correction for multiple comparisons.

At the same time, SWD with an IEP report that they do not try as hard to do well in school, do not work as hard as they can in class, do not participate in class discussions, do not 
pay attention in class, or do not listen very carefully in class relative to SWD who receive fewer services. This may represent a "self-fulfilling prophecy" in which SWD who are assigned an IEP report a lower academic work ethic because of being labeled as needing services. For example, Shifrer (2013) reported that high school students with LD reported lower educational expectations partly through parents' and teachers' reduced educational expectations following IEP receipt. Future research should evaluate the extent to which classroom engagement is influenced by modifiable factors related to special education. Although we found that special education services as measured by IEP status were related to more negative classroom engagement, we did not replicate Shifrer's finding that having an IEP was linked to lower educational attainment expectations. Instead, there was a trend toward higher educational attainment expectations $(\sim .40 S D)$ among students with ASD. Our analyses also found that the negative effects of having an IEP were small at .10 SD, and the majority of the other social, emotional, and academic attitudes were not significantly or largely related to IEP experience. A variety of mitigating circumstances may influence the impact of having an IEP on social, emotional, or academic attitudes. Low academic performance and the need for academic assistance through special education are not the sole determinants of students' self-esteem. Peer judgments may be more strongly determined by the student's personality and social skills than by academic performance. Thus, future research designed to estimate the negative effects of special education on social-emotional adjustment should carefully separate these effects from the effects of the lower academic achievement that qualified the student for services. It has been reported in descriptive analyses that SWD who are Black experience greater stigmatization as a consequence of receiving special education services and/or being segregated from peers in selfcontained classrooms (e.g., a "double jeopardy" of being both racially minoritized and having a 
disability; Fierros \& Conroy, 2002). Our results suggest that students who are Black including those with disabilities rate themselves higher than otherwise similar students who are White on some social, emotional, or academic measures, and that this is especially true in the areas of mathematics competency, educational attainment, and peer relations. The degree to which these results are related to special education or other school services should be further explored.

Perhaps the most important implication of this study is that it is critical to pay attention to the contrasts used to assess whether special education services are associated with negative attitudes. If there were a relation between special education identification and more negative social, emotional, or academic attitudes, we would expect that students who had an IEP for more years or who had an IEP more recently would demonstrate more negative attitudes than students who had an IEP for fewer years or who had an IEP less recently. Yet we observed little evidence for such effects in our analyses across 16 measures of social, emotional, and academic attitudes. We also noted that failure to account for confounding factors like disability type and prior academic or behavioral difficulties may inflate estimates of the relation between special education and more negative social, emotional, and academic attitudes. Failing to account for such confounds could lead to misattributions of special education as inherently stigmatizing and harmful. Accounting for these possibilities, we found little empirical support for the hypothesis that how long or how recently SWD had an IEP was negatively related to their social, emotional, or academic attitudes. Instead, our results indicate that being assigned to special education has few significant predictive effects on social-emotional adjustment and academic attitudes. 
Table 1.

Weighted sample mean values following multiple imputation procedures

\begin{tabular}{|c|c|c|c|c|}
\hline & \multicolumn{2}{|c|}{ ECLS-K: 1998} & \multicolumn{2}{|c|}{ ECLS-K: 2011} \\
\hline & $\begin{array}{c}\text { All Students } \\
n=7,800 \\
\% \text { or } \mathbf{M}\end{array}$ & $\begin{array}{c}\text { Ever IEP } \\
n=1,340 \\
\% \text { or } \mathbf{M}\end{array}$ & $\begin{array}{c}\text { All Students } \\
n=10,310 \\
\% \text { or } \mathbf{M}\end{array}$ & $\begin{array}{c}\text { Ever IEP } \\
n=2,430 \\
\% \text { or } \mathbf{M}\end{array}$ \\
\hline \multicolumn{5}{|l|}{ Predictors } \\
\hline K Approaches & 3.00 & 2.69 & 2.96 & 2.63 \\
\hline K Externalizing & 1.61 & 1.77 & 1.60 & 1.80 \\
\hline K Internalizing & 1.52 & 1.61 & 1.46 & 1.58 \\
\hline K Achievement & 30.78 & 27.02 & 45.10 & 40.54 \\
\hline Ever IEP \% & 20.4 & 100.0 & 21.4 & 100.0 \\
\hline IEP Years & 2.18 & 2.18 & 2.78 & 2.78 \\
\hline Last IEP & 4.07 & 4.08 & 4.80 & 4.80 \\
\hline LD Services \% & 11.7 & 57.6 & 9.0 & 42.0 \\
\hline SLI Services \% & 11.6 & 56.7 & 15.7 & 73.4 \\
\hline ED Services \% & 1.5 & 7.6 & 2.0 & 9.2 \\
\hline ASD Services \% & 2.0 & 10.0 & 5.5 & 25.5 \\
\hline LI Services \% & 1.5 & 7.4 & 2.4 & 11.3 \\
\hline Male \% & 51.9 & 68.8 & 51.4 & 64.7 \\
\hline \multicolumn{5}{|l|}{ Race/Ethnicity \% } \\
\hline White & 57.5 & 61.4 & 51.9 & 49.6 \\
\hline Black & 17.1 & 16.8 & 13.3 & 14.6 \\
\hline Hispanic & 18.1 & 17.4 & 24.8 & 27.2 \\
\hline Asian & 3.6 & 1.6 & 4.7 & 2.5 \\
\hline Other & 3.7 & 2.8 & 5.2 & 6.1 \\
\hline SES & 0.01 & -0.12 & -0.09 & -0.25 \\
\hline \multicolumn{5}{|l|}{ Outcomes } \\
\hline Peer Victim & -- & -- & 2.02 & 2.16 \\
\hline Social Anxiety & -- & -- & 2.15 & 2.31 \\
\hline Behavioral Engage & -- & -- & 4.31 & 4.15 \\
\hline Peer Support & -- & -- & 4.04 & 3.82 \\
\hline Loneliness & -- & -- & 1.69 & 1.86 \\
\hline School Belonging & 3.06 & 2.93 & 3.26 & 3.17 \\
\hline Grit & -- & -- & 4.18 & 4.01 \\
\hline
\end{tabular}




\begin{tabular}{lcccc} 
School Worries & -- & -- & 2.28 & 2.42 \\
Reading Comp. & 2.53 & 2.42 & -- & - \\
Math Competency & 2.60 & 2.57 & -- & - \\
Internalizing & 2.03 & 2.10 & -- & -- \\
Locus of Control & -0.03 & -0.25 & -- & -- \\
Self-Concept & -0.01 & -0.17 & -- & -- \\
Educ Attainment & 5.12 & 4.60 & -- & -- \\
Peer Relationships & 3.78 & 3.56 & -- & -- \\
\hline
\end{tabular}

Note: $\%$ or $\mathrm{M}=$ Percent or mean pooled across $m=40$ imputations. IEP = individualized education program; LD = learning disability; SLI = speech or language impairment; ED = emotional disturbance; ASD = autism spectrum disorder; LI = low incidence disability.

Source: U.S. Department of Education, National Center for Education Statistics (NCES), Early Childhood Longitudinal Study, Kindergarten Class of 1998-99 (ECLS-K: 1998), Kindergarten Through Eighth Grade Full Sample Restricted-Use Data File, and ECLS-K Kindergarten Class of 2010-2011 (ECLS-K: 2011), Kindergarten Through Fifth Grade Full Sample Restricted-Use Data File. 
Table 2.

Regression of ECLS-K: $19988^{\text {th }}$ grade self-reported social, emotional, and academic competencies on IEP status without and with full covariate control $(\mathrm{n}=7,800)$.

\begin{tabular}{|c|c|c|c|c|c|c|c|c|c|c|c|c|}
\hline & \multicolumn{4}{|c|}{ Reading Competency } & \multicolumn{4}{|c|}{ Math Competency } & \multicolumn{4}{|c|}{ Self-Concept } \\
\hline & Model 1 & Model 2 & Model 3 & Model 4 & Model 1 & Model 2 & Model 3 & Model 4 & Model 1 & Model 2 & Model 3 & Model 4 \\
\hline Ever IEP & $-0.21 * * *$ & 0.03 & & & -0.06 & 0.04 & & & $-0.31 * * *$ & $-0.21 * * *$ & & \\
\hline Ever LD & & & $-0.34 * * *$ & -0.10 & & & -0.12 & 0.01 & & & $-0.29 * * *$ & $-0.20 * *$ \\
\hline Ever SLI & & & 0.02 & 0.11 & & & 0.03 & 0.05 & & & -0.13 & -0.09 \\
\hline Ever ED & & & -0.35 & -0.14 & & & -0.11 & -0.05 & & & -0.41 & -0.28 \\
\hline Ever ASD & & & 0.17 & 0.24 & & & 0.12 & 0.20 & & & -0.41 & -0.33 \\
\hline Ever LI & & & 0.12 & -0.02 & & & 0.12 & 0.07 & & & 0.08 & 0.00 \\
\hline K Approach & & 0.03 & & 0.03 & & $0.08 * *$ & & $0.08^{* *}$ & & $0.07 * *$ & & $0.06^{*}$ \\
\hline K Extern. & & -0.01 & & -0.01 & & 0.00 & & 0.00 & & $-0.08^{* * *}$ & & $-0.08 * * *$ \\
\hline K Intern. & & 0.00 & & -0.01 & & -0.03 & & -0.04 & & -0.03 & & -0.02 \\
\hline K Achieve. & & $0.19^{* * *}$ & & $0.18^{* * *}$ & & $0.12 * * *$ & & $0.12 * * *$ & & $0.08^{* * *}$ & & $0.07 * *$ \\
\hline Male & & $-0.39 * * *$ & & $-0.38 * * *$ & & $0.19^{* * *}$ & & $0.19^{* * *}$ & & $0.18^{* * *}$ & & $0.18 * * *$ \\
\hline Black & & $0.21 * *$ & & $0.20 * *$ & & 0.08 & & 0.08 & & $0.32 * * *$ & & $0.31 * * *$ \\
\hline Hispanic & & -0.03 & & -0.03 & & 0.01 & & 0.01 & & -0.06 & & -0.07 \\
\hline Asian & & 0.06 & & 0.06 & & $0.20 * *$ & & $0.20 * *$ & & -0.09 & & -0.09 \\
\hline Other & & 0.06 & & 0.06 & & 0.11 & & 0.12 & & 0.14 & & 0.13 \\
\hline SES & & $0.14^{* * *}$ & & $0.14^{* * *}$ & & $0.08^{* *}$ & & $0.08^{* *}$ & & $0.14^{* * *}$ & & $0.13^{* * *}$ \\
\hline$R^{2}$ & 0.01 & 0.12 & 0.02 & 0.12 & 0.00 & 0.04 & 0.00 & 0.05 & 0.01 & 0.07 & 0.07 & 0.08 \\
\hline
\end{tabular}


(continued)

\begin{tabular}{|c|c|c|c|c|c|c|c|c|c|c|c|c|}
\hline & \multicolumn{4}{|c|}{ Educational Attainment } & \multicolumn{4}{|c|}{ Internalizing Feelings } & \multicolumn{4}{|c|}{ Locus of Control } \\
\hline & Model 1 & Model 2 & Model 3 & Model 4 & Model 1 & Model 2 & Model 3 & Model 4 & Model 1 & Model 2 & Model 3 & Model 4 \\
\hline Ever IEP & $-0.52 * * *$ & $-0.29 * * *$ & & & $0.17 * *$ & $0.17 * *$ & & & $-0.46 * * *$ & $-0.31 * * *$ & & \\
\hline Ever LD & & & $-0.53 * * *$ & $-0.29 * * *$ & & & $0.18^{*}$ & 0.16 & & & $-0.46^{* * *}$ & $-0.30 * * *$ \\
\hline Ever SLI & & & $-0.27 * *$ & -0.18 & & & 0.13 & 0.15 & & & $-0.24 * *$ & $-0.19 *$ \\
\hline Ever ED & & & -0.28 & -0.04 & & & 0.13 & 0.08 & & & -0.46 & -0.25 \\
\hline Ever ASD & & & 0.29 & $0.43+$ & & & 0.06 & 0.00 & & & 0.11 & 0.20 \\
\hline Ever LI & & & -0.07 & -0.24 & & & 0.14 & 0.17 & & & 0.01 & -0.08 \\
\hline K Approach & & $0.11 * * *$ & & $0.11 * * *$ & & -0.01 & & -0.01 & & $0.08 * * *$ & & $0.08 * * *$ \\
\hline K Extern. & & 0.00 & & -0.01 & & $0.07 * *$ & & $0.07 * *$ & & $-0.08 * * *$ & & $-0.08 * * *$ \\
\hline K Intern. & & -0.01 & & -0.02 & & 0.04 & & 0.03 & & 0.02 & & 0.01 \\
\hline K Achieve. & & $0.10 * * *$ & & $0.09 * * *$ & & -0.04 & & -0.04 & & $0.11 * * *$ & & $0.10 * * *$ \\
\hline Male & & $-0.25 * * *$ & & $-0.25 * * *$ & & $-0.33 * * *$ & & $-0.33 * * *$ & & 0.03 & & 0.03 \\
\hline Black & & 0.10 & & 0.10 & & -0.04 & & -0.03 & & -0.03 & & -0.03 \\
\hline Hispanic & & 0.06 & & 0.06 & & $0.10+$ & & $0.11+$ & & $-0.12 *$ & & $-0.12 *$ \\
\hline Asian & & $0.17^{*}$ & & $0.18^{*}$ & & $0.18^{* *}$ & & $0.18 * *$ & & $-0.21 * * *$ & & $-0.20 * *$ \\
\hline Other & & -0.01 & & 0.00 & & -0.07 & & -0.06 & & -0.04 & & -0.04 \\
\hline SES & & $0.33 * *$ & & $0.33 * * *$ & & $-0.13 * * *$ & & $-0.13 * * *$ & & $0.21 * * *$ & & $0.21 * * *$ \\
\hline$R^{2}$ & 0.04 & 0.16 & 0.04 & 0.17 & 0.01 & 0.06 & 0.01 & 0.06 & 0.03 & 0.13 & 0.04 & 0.13 \\
\hline
\end{tabular}


(continued)

\begin{tabular}{|c|c|c|c|c|c|c|c|c|}
\hline & \multicolumn{4}{|c|}{ School Belonging } & \multicolumn{4}{|c|}{ Peer Relationships } \\
\hline & Model 1 & Model 2 & Model 3 & Model 4 & Model 1 & Model 2 & Model 3 & Model 4 \\
\hline Ever IEP & $-0.31 * * *$ & $-0.20 * * *$ & & & $-0.32 * * *$ & $-0.17 * *$ & & \\
\hline Ever LD & & & $-0.27 * * *$ & $-0.18^{*}$ & & & $-0.23^{* *}$ & -0.12 \\
\hline Ever SLI & & & -0.06 & -0.02 & & & -0.14 & -0.06 \\
\hline Ever ED & & & $-0.34+$ & -0.16 & & & -0.21 & 0.02 \\
\hline Ever ASD & & & -0.38 & -0.30 & & & -0.32 & -0.25 \\
\hline Ever LI & & & -0.35 & -0.41 & & & -0.07 & -0.16 \\
\hline K Approach & & $0.08^{* *}$ & & $0.08^{* *}$ & & $0.06+$ & & $0.06^{*}$ \\
\hline K Extern. & & $-0.05+$ & & $-0.05+$ & & $-0.08 * *$ & & $-0.08^{* *}$ \\
\hline K Intern. & & -0.02 & & -0.01 & & -0.01 & & -0.01 \\
\hline K Achieve. & & 0.00 & & 0.00 & & 0.02 & & 0.02 \\
\hline Male & & $-0.13^{* *}$ & & $-0.13 * * *$ & & $-0.29 * * *$ & & $-0.29 * * *$ \\
\hline Black & & -0.13 & & -0.12 & & 0.12 & & 0.12 \\
\hline Hispanic & & -0.09 & & -0.09 & & -0.08 & & -0.08 \\
\hline Asian & & -0.03 & & -0.03 & & -0.02 & & -0.01 \\
\hline Other & & -0.03 & & -0.03 & & 0.03 & & 0.03 \\
\hline SES & & $0.12 * * *$ & & $0.12 * * *$ & & $0.09 * * *$ & & $0.09 * * *$ \\
\hline$R^{2}$ & 0.02 & 0.06 & 0.02 & 0.06 & 0.02 & 0.07 & 0.02 & 0.07 \\
\hline
\end{tabular}

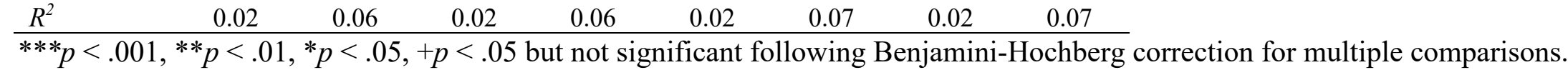

Note: $\mathrm{IEP}=$ individualized education program; $\mathrm{LD}=$ learning disability; $\mathrm{SLI}=$ speech or language impairment; $\mathrm{ED}=\mathrm{emotional}$

disturbance; ASD = autism spectrum disorder; LI = low incidence disability. Source: U.S. Department of Education, National Center 
for Education Statistics (NCES), Early Childhood Longitudinal Study, Kindergarten Class of 1998-99 (ECLS-K: 1998), Kindergarten Through Eighth Grade Full Sample Restricted-Use Data File. 
Table 3.

Regression of ECLS-K: $20115^{\text {th }}$ grade self-reported social, emotional, and academic attitudes on IEP status with and without additional covariate control $(\mathrm{n}=10,310)$.

\begin{tabular}{|c|c|c|c|c|c|c|c|c|c|c|c|c|}
\hline & \multicolumn{4}{|c|}{ Peer Victimization } & \multicolumn{4}{|c|}{ Social Anxiety } & \multicolumn{4}{|c|}{ Behavioral Engagement } \\
\hline & Model 1 & Model 2 & Model 3 & Model 4 & Model 1 & Model 2 & Model 3 & Model 4 & Model 1 & Model 2 & Model 3 & Model 4 \\
\hline Ever IEP & $0.20 * * *$ & 0.06 & & & $0.17 * * *$ & $0.14 * * *$ & & & $-0.38 * * *$ & $-0.22 * * *$ & & \\
\hline Ever LD & & & 0.12 & -0.04 & & & 0.10 & 0.05 & & & $-0.39 * * *$ & $-0.24 * * *$ \\
\hline Ever SLI & & & 0.07 & 0.07 & & & 0.07 & $0.09+$ & & & -0.09 & -0.04 \\
\hline Ever ED & & & $0.38 * *$ & 0.11 & & & 0.20 & 0.11 & & & $-0.38 * *$ & -0.23 \\
\hline Ever ASD & & & 0.15 & 0.06 & & & 0.11 & 0.08 & & & $-0.23+$ & -0.16 \\
\hline Ever LI & & & 0.01 & 0.01 & & & 0.07 & 0.06 & & & -0.18 & -0.16 \\
\hline K Approach & & -0.03 & & -0.03 & & $-0.06 * * *$ & & $-0.06^{* * *}$ & & $0.09 * * *$ & & $0.08 * * *$ \\
\hline K Extern. & & $0.20 * * *$ & & $0.20 * * *$ & & $0.09 * * *$ & & $0.09 * * *$ & & $-0.07 * * *$ & & $-0.06 * * *$ \\
\hline K Intern. & & -0.02 & & -0.02 & & 0.02 & & 0.02 & & -0.02 & & -0.02 \\
\hline K Achieve. & & -0.03 & & -0.03 & & 0.01 & & 0.01 & & $0.04 * *$ & & $0.04 * *$ \\
\hline Male & & -0.02 & & -0.02 & & $-0.33 * * *$ & & $-0.33 * * *$ & & $-0.22 * * *$ & & $-0.22 * * *$ \\
\hline Black & & $0.11 *$ & & $0.11^{*}$ & & $-0.23 * * *$ & & $-0.23 * * *$ & & -0.04 & & -0.04 \\
\hline Hispanic & & $-0.25 * * *$ & & $-0.25 * * *$ & & $-0.15 * * *$ & & $-0.14 * * *$ & & $-0.13 * * *$ & & $-0.13 * * *$ \\
\hline Asian & & $-0.10^{*}$ & & $-0.10^{*}$ & & -0.03 & & -0.03 & & $-0.21 * * *$ & & $-0.21 * * *$ \\
\hline Other & & 0.03 & & 0.03 & & -0.03 & & -0.03 & & -0.10 & & -0.11 \\
\hline SES & & $-0.15^{* * *}$ & & $-0.15 * * *$ & & $-0.06 * * *$ & & $-0.06^{* * *}$ & & $0.08 * * *$ & & $0.08 * * *$ \\
\hline$R^{2}$ & 0.01 & 0.08 & 0.01 & 0.08 & 0.01 & 0.05 & 0.01 & 0.05 & 0.03 & 0.08 & 0.04 & 0.09 \\
\hline
\end{tabular}


(continued)

\begin{tabular}{|c|c|c|c|c|c|c|c|c|c|c|c|c|}
\hline & \multicolumn{4}{|c|}{ Grit } & \multicolumn{4}{|c|}{ Peer Support } & \multicolumn{4}{|c|}{ School Belonging } \\
\hline & Model 1 & Model 2 & Model 3 & Model 4 & Model 1 & Model 2 & Model 3 & Model 4 & Model 1 & Model 2 & Model 3 & Model 4 \\
\hline Ever IEP & $-0.31 * * *$ & $-0.21 * * *$ & & & $-0.31 * * *$ & $-0.19 * * *$ & & & $-0.19 * * *$ & $-0.10 * * *$ & & \\
\hline Ever LD & & & $-0.23 * * *$ & $-0.15^{*}$ & & & $-0.20 * *$ & -0.07 & & & -0.11 & -0.02 \\
\hline Ever SLI & & & $0.09+$ & -0.07 & & & $-0.12+$ & $-0.10+$ & & & -0.06 & -0.04 \\
\hline Ever ED & & & $-0.34 *$ & -0.23 & & & $-0.34 * *$ & -0.16 & & & $-0.35 * *$ & -0.21 \\
\hline Ever ASD & & & $-0.24 * *$ & $-0.19+$ & & & $-0.27^{* *}$ & $-0.19+$ & & & -0.13 & -0.07 \\
\hline Ever LI & & & -0.16 & -0.15 & & & -0.04 & -0.03 & & & -0.05 & -0.04 \\
\hline K Approach & & $0.10^{* * *}$ & & $0.10 * * *$ & & $0.10 * * *$ & & $0.10 * * *$ & & $0.08 * * *$ & & $0.08 * * *$ \\
\hline K Extern. & & -0.03 & & -0.03 & & $-0.08 * * *$ & & $-0.08 * * *$ & & $-0.06^{* * *}$ & & $-0.06^{* *}$ \\
\hline K Intern. & & $-0.04+$ & & $-0.03+$ & & -0.03 & & -0.03 & & $-0.03+$ & & $-0.03+$ \\
\hline K Achieve. & & -0.02 & & -0.03 & & 0.01 & & 0.01 & & -0.02 & & -0.02 \\
\hline Male & & $-0.06^{*}$ & & $-0.06^{*}$ & & -0.04 & & -0.05 & & -0.02 & & -0.02 \\
\hline Black & & 0.07 & & 0.07 & & $-0.12 *$ & & $-0.12 *$ & & -0.08 & & -0.08 \\
\hline Hispanic & & -0.02 & & -0.03 & & 0.03 & & 0.03 & & 0.05 & & 0.05 \\
\hline Asian & & $-0.10+$ & & $-0.10+$ & & $-0.12 * *$ & & $-0.12 * *$ & & -0.08 & & -0.08 \\
\hline Other & & -0.09 & & -0.10 & & -0.04 & & -0.04 & & -0.07 & & -0.08 \\
\hline SES & & $0.07 * * *$ & & $0.07^{* * *}$ & & $0.08^{* * *}$ & & $0.08^{* * *}$ & & $0.09^{* * *}$ & & $0.08^{* * *}$ \\
\hline$R^{2}$ & 0.02 & 0.04 & 0.02 & 0.04 & 0.02 & 0.05 & & 0.05 & 0.01 & 0.03 & 0.01 & 0.03 \\
\hline
\end{tabular}


(continued)

\begin{tabular}{|c|c|c|c|c|c|c|c|c|}
\hline & \multicolumn{4}{|c|}{ Loneliness } & \multicolumn{4}{|c|}{ School Worries } \\
\hline & Model 1 & Model 2 & Model 3 & Model 4 & Model 1 & Model 2 & Model 3 & Model 4 \\
\hline Ever IEP & $0.24 * * *$ & $0.19^{* * *}$ & & & $0.26^{* * *}$ & $0.14 * * *$ & & \\
\hline Ever LD & & & $0.20 * *$ & $0.13+$ & & & $0.39 * * *$ & $0.21 * * *$ \\
\hline Ever SLI & & & 0.06 & 0.08 & & & 0.02 & 0.01 \\
\hline Ever ED & & & $0.28 *$ & 0.15 & & & $0.30^{*}$ & $0.24+$ \\
\hline Ever ASD & & & $0.22+$ & 0.18 & & & 0.01 & -0.04 \\
\hline Ever LI & & & 0.06 & 0.05 & & & 0.09 & 0.07 \\
\hline K Approach & & $-0.06^{* *}$ & & $-0.06 * *$ & & $-0.07 * * *$ & & $-0.06 * * *$ \\
\hline K Extern. & & $0.10 * * *$ & & $0.10^{* * *}$ & & $0.04^{* *}$ & & $0.04 *$ \\
\hline K Intern. & & $0.03+$ & & $0.03+$ & & 0.00 & & 0.00 \\
\hline K Achieve. & & 0.01 & & 0.01 & & $-0.12 * * *$ & & $-0.12 * * *$ \\
\hline Male & & $-0.23^{* * *}$ & & $-0.23 * * *$ & & $-0.18^{* * *}$ & & $-0.17 * * *$ \\
\hline Black & & $-0.14^{* *}$ & & $-0.14 * *$ & & $0.10+$ & & $0.09+$ \\
\hline Hispanic & & $-0.16^{* * *}$ & & $-0.15 * * *$ & & $0.14 * * *$ & & $0.14 * * *$ \\
\hline Asian & & -0.02 & & -0.02 & & 0.06 & & 0.06 \\
\hline Other & & 0.00 & & 0.00 & & 0.09 & & 0.09 \\
\hline SES & & $-0.07 * * *$ & & $-0.07 * * *$ & & $-0.09 * * *$ & & $-0.09 * * *$ \\
\hline$R^{2}$ & 0.01 & 0.04 & 0.01 & 0.04 & 0.01 & 0.07 & 0.02 & 0.07 \\
\hline
\end{tabular}

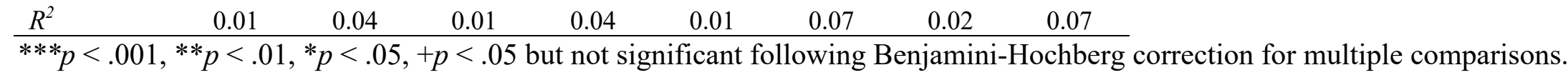

Note: IEP = individualized education program; $\mathrm{LD}=$ learning disability; $\mathrm{SLI}=$ speech or language impairment; $\mathrm{ED}=\mathrm{emotional}$ disturbance; $\mathrm{ASD}=$ autism spectrum disorder; $\mathrm{LI}=$ low incidence disability. Imputed data $(m=40)$ are weighted with $w 9 c 9 p \_20$. 
Source: U.S. Department of Education, National Center for Education Statistics (NCES), Early Childhood Longitudinal Study, Kindergarten Class of 2010-11 (ECLS-K: 2011), Kindergarten Through Fifth Grade Full Sample Restricted-Use Data File 
Table 4.

Regression of ECLS-K: $19988^{\text {th }}$ grade self-reported social, emotional, and academic attitudes on IEP characteristics without and with additional covariate control $(\mathrm{n}=1,340)$.

\begin{tabular}{lcccccccc}
\hline & $\begin{array}{c}\text { Reading } \\
\text { Competency }\end{array}$ & $\begin{array}{c}\text { Math } \\
\text { Competency }\end{array}$ & $\begin{array}{c}\text { Self- } \\
\text { Concept }\end{array}$ & $\begin{array}{c}\text { Educational } \\
\text { Attainment }\end{array}$ & $\begin{array}{c}\text { Internalizing } \\
\text { Feelings }\end{array}$ & $\begin{array}{c}\text { Locus of } \\
\text { Control }\end{array}$ & $\begin{array}{c}\text { School } \\
\text { Belonging }\end{array}$ & $\begin{array}{c}\text { Peer } \\
\text { Relationships }\end{array}$ \\
\hline Without covariates & & & & & & & & \\
IEP Experience & -0.07 & 0.08 & $-0.14^{* *}$ & -0.11 & $0.11+$ & $-0.19 * * *$ & $-0.11+$ & -0.04 \\
$\quad R^{2}$ & .00 & .01 & .02 & .01 & .01 & .03 & .01 & .00 \\
With covariates & & & & & & & & \\
IEP Experience & -0.02 & $0.10+$ & -0.08 & -0.07 & 0.04 & $-0.12+$ & -0.03 & -0.01 \\
LD Serv & -0.10 & -0.01 & -0.11 & -0.06 & 0.15 & -0.11 & -0.10 & 0.01 \\
SLI Serv & 0.08 & 0.09 & -0.06 & -0.02 & 0.20 & -0.10 & 0.06 & 0.05 \\
ED Serv & -0.21 & -0.11 & -0.29 & -0.04 & 0.11 & -0.23 & -0.18 & 0.07 \\
ASD Serv & 0.24 & 0.16 & -0.27 & $0.45+$ & -0.06 & 0.22 & -0.29 & -0.25 \\
LI Serv & 0.00 & -0.01 & 0.00 & -0.26 & 0.17 & 0.01 & -0.39 & -0.17 \\
Approaches & 0.02 & $0.16+$ & 0.09 & $0.18+$ & -0.01 & 0.05 & 0.08 & 0.03 \\
Externalizing & 0.02 & 0.02 & -0.02 & 0.05 & 0.04 & -0.04 & -0.01 & -0.09 \\
Internalizing & -0.01 & -0.03 & -0.08 & 0.00 & 0.07 & 0.06 & -0.05 & -0.04 \\
Achievement & $0.21 * * *$ & 0.06 & 0.05 & 0.12 & -0.09 & $0.17 * *$ & -0.02 & 0.06 \\
Male & $-0.20+$ & 0.19 & 0.18 & -0.11 & $-0.47 * * *$ & 0.11 & -0.04 & $-0.36 * *$ \\
Black & 0.20 & $0.42 * *$ & $0.41 * *$ & $0.51 * *$ & 0.05 & -0.17 & -0.10 & $0.44 * *$ \\
Hispanic & -0.05 & 0.12 & -0.02 & 0.04 & -0.03 & -0.13 & -0.27 & -0.26 \\
Asian & 0.39 & 0.02 & -0.04 & 0.06 & 0.17 & -0.44 & -0.09 & -0.24 \\
Other & -0.12 & -0.29 & -0.21 & -0.36 & -0.07 & -0.02 & -0.25 & -0.35 \\
& & & & & & &
\end{tabular}




\begin{tabular}{lcccccccc} 
SES & $0.15 *$ & 0.08 & $0.22 * *$ & $0.38 * * *$ & $-0.22 *$ & $0.21 * * *$ & 0.12 & 0.04 \\
$R^{2}$ & .13 & .09 & .11 & .15 & .10 & .14 & .06 & .08 \\
\hline$* * * p<.001, * * p<.01,{ }^{*} p<.05,+p<.05$ but not significant following Benjamini-Hochberg correction for multiple comparisons.
\end{tabular}

Note: $\mathrm{IEP}=$ individualized education program; $\mathrm{LD}=$ learning disability; $\mathrm{SLI}=$ speech or language impairment; $\mathrm{ED}=\mathrm{emotional}$ disturbance; ASD = autism spectrum disorder; LI = low incidence disability. Imputed data $(m=40)$ are weighted with $c 1 \_7 f c 0$. Source: U.S. Department of Education, National Center for Education Statistics (NCES), Early Childhood Longitudinal Study, Kindergarten Class of 1998-99 (ECLS-K: 1998), Kindergarten Through Eighth Grade Full Sample Restricted-Use Data File. 
Table 5.

Regression of ECLS-K: $20115^{\text {th }}$ grade self-reported social, emotional, and academic attitudes on IEP characteristics without and with additional covariate control $(\mathrm{n}=2,430)$.

\begin{tabular}{|c|c|c|c|c|c|c|c|c|}
\hline & $\begin{array}{c}\text { Peer } \\
\text { Victimization }\end{array}$ & $\begin{array}{c}\text { Social } \\
\text { Anxiety }\end{array}$ & $\begin{array}{c}\text { Behavioral } \\
\text { Engagement }\end{array}$ & Grit & $\begin{array}{c}\text { Peer } \\
\text { Support }\end{array}$ & $\begin{array}{c}\text { School } \\
\text { Belonging }\end{array}$ & Loneliness & $\begin{array}{c}\text { School } \\
\text { Worries }\end{array}$ \\
\hline \multicolumn{9}{|c|}{ Without covariates } \\
\hline IEP Experience & $0.13 * * *$ & $0.08 * *$ & $-0.20 * * *$ & $-0.13 * * *$ & $-0.16 * * *$ & $-0.07 * *$ & $0.14 * * *$ & $0.08 * *$ \\
\hline$R^{2}$ & .01 & .01 & .03 & .01 & .02 & .00 & .01 & .00 \\
\hline \multicolumn{9}{|l|}{ With covariates } \\
\hline IEP Experience & 0.07 & 0.02 & $-0.10 * *$ & -0.06 & $-0.09+$ & -0.02 & 0.07 & -0.01 \\
\hline LD Services & -0.12 & -0.07 & -0.05 & -0.02 & 0.11 & 0.08 & 0.01 & 0.11 \\
\hline SLI Services & 0.04 & 0.01 & 0.11 & 0.05 & 0.03 & 0.07 & -0.01 & -0.15 \\
\hline ED Services & 0.17 & 0.13 & -0.24 & -0.25 & -0.15 & -0.20 & 0.14 & $0.28+$ \\
\hline ASD Services & 0.04 & 0.08 & -0.13 & -0.17 & -0.16 & -0.06 & 0.17 & -0.03 \\
\hline LI Services & -0.01 & 0.05 & -0.14 & -0.13 & 0.00 & -0.02 & 0.04 & 0.08 \\
\hline K Approaches & -0.08 & -0.05 & $0.12 * *$ & $0.13 * *$ & $0.15 * * *$ & 0.07 & -0.02 & -0.06 \\
\hline K Externalizing & $0.14 * * *$ & $0.08+$ & 0.02 & 0.03 & -0.02 & -0.06 & $0.09+$ & 0.01 \\
\hline K Internalizing & $-0.07+$ & -0.01 & -0.04 & -0.03 & -0.02 & -0.02 & 0.03 & -0.02 \\
\hline Achievement & -0.07 & $-0.08+$ & 0.06 & -0.02 & 0.03 & 0.02 & -0.03 & $-0.15 * * *$ \\
\hline Male & -0.10 & $-0.38 * * *$ & $-0.20 * * *$ & -0.09 & 0.02 & -0.04 & $-0.27 * * *$ & $-0.22 * * *$ \\
\hline Black NH & 0.10 & $-0.30 * *$ & -0.06 & 0.08 & -0.14 & 0.12 & -0.19 & -0.02 \\
\hline Hispanic & $-0.31 * * *$ & $-0.20 * *$ & $-0.17 *$ & -0.12 & 0.05 & 0.06 & $-0.21 * *$ & $0.12+$ \\
\hline Asian & -0.01 & $-0.22+$ & $-0.50 * * *$ & -0.24 & $-0.30+$ & -0.21 & -0.18 & -0.16 \\
\hline
\end{tabular}


DO IEPS EXACERBATE NEGATIVE ATTITUDES?

\begin{tabular}{lcccccccc} 
Other & 0.04 & -0.09 & -0.22 & -0.13 & 0.03 & 0.11 & -0.11 & 0.24 \\
SES & $-0.13 * * *$ & $-0.11 * *$ & $0.11 * *$ & $0.09 *$ & $0.09 *$ & $0.09 *$ & $-0.12^{* *}$ & $-0.11^{* *}$ \\
$R^{2}$ & .07 & .07 & .09 & .05 & .06 & .03 & .05 & .09 \\
\hline$* * * p<.001, * * p<.01, * p<.05,+p<.05$ & but not significant following & Benjamini-Hochberg correction for multiple comparisons.
\end{tabular}

Note: $\mathrm{IEP}=$ individualized education program; $\mathrm{LD}=$ learning disability; $\mathrm{SLI}=$ speech or language impairment; $\mathrm{ED}=\mathrm{emotional}$ disturbance; ASD = autism spectrum disorder; LI = low incidence disability. Source: U.S. Department of Education, National Center for Education Statistics (NCES), Early Childhood Longitudinal Study, Kindergarten Class of 2010-11 (ECLS-K: 2011), Kindergarten Through Fifth Grade Full Sample Restricted-Use Data File. 


\section{References}

Allison, P. D. (2012). Missing data. Thousand Oaks, CA: Sage.

Bender, W. N., \& Wall, M. E. (1994). Social-emotional development of students with learning disabilities. Learning Disability Quarterly, 17(4), 323-341. DOI: 10.2307/1511128

Bishara, S. \& Kaplan, S. (2018) The relationship of locus of control and metacognitive knowledge of math with math achievements. International Journal of Disability, Development and Education, 65(6), 631-648, DOI: 10.1080/1034912X.2018.1432033

Burns, M. K., \& Ysseldyke, J. E. (2009). Reported prevalence of evidence-based instructional practices in special education. The Journal of Special Education, 43(1), 3-11. DOI: $10.1177 / 0022466908315563$

Chesmore, A. A., Ou, S., \& Reynolds, A. J. (2016). Childhood placement in special education and adult well-being. The Journal of Special Education, 1-12. DOI: 10.1177/ 0022466915624413

Davis-Kean, P. E., Jager, J., \& Maslowsky, J. (2015). Answering developmental questions using secondary data. Child Development Perspectives, 9(4), 256-261. https://doi.org/10.1111/cdep.12151

Daniel, J. R., \& Cooc, N. (2018). Teachers' perceptions of academic intrinsic motivation for students with disabilities. The Journal of Special Education, 52(2), 101-112. DOI: $10.1177 / 0022466918765276$

Demchuk, L. J. (2000). Children's perceptions and attitudes about special education. ProQuest Dissertations and Theses, 1-255. Retrieved from http://search.proquest.com

Donaldson, S. I., \& Grant-Vallone, E. J. (2002). Understanding self-report bias in organizational 
behavior research. Journal of business and Psychology, 17(2), 245-260. DOI:

10.1023/A:1019637632584

Duckworth, A. L., \& Quinn, P. D. (2009). Development and validation of the Short Grit Scale (GRIT-S). Journal of Personality Assessment, 91(2), 166-174. DOI: 10.1080/ 00223890802634290

Durlak, J. A., Weissberg, R. P., Dymnicki, A. B., Taylor, R. D., \& Schellinger, K. B. (2011). The impact of enhancing students' social and emotional learning: A meta-analysis of schoolbased universal interventions. Child Development, 82(1), 405-432. DOI: 10.1111/j.14678624.2010.01564.x

Espelage, D. L. and Holt, M. (2001). Bullying and victimization during early adolescence: Peer influences and psychosocial correlates. Journal of Emotional Abuse, 2: 123-142

Fierros, E. G., \& Conroy, J. W. (2002). Double jeopardy: An exploration of restrictiveness and race in special education. In D. J. Losen \& G. Orfield, Racial inequality in special education (pp. 39-70). Cambridge, MA: Harvard Education Press.

Gans, A. M., Kenny, M. C., \& Ghany, D. L. (2003). Comparing the self-concept of students with and without learning disabilities. Journal of Learning Disabilities, 36(3), 287-295. DOI: $10.1177 / 002221940303600307$

Graham, J. W., Olchowski, A. E., \& Gilreath, T. D. (2007). How many imputations are really needed? Some practical clarifications of multiple imputation theory. Prevention Science, 8(3), 206-213. https://doi.org/10.1007/s11121-007-0070-9

Gross, D., \& Fogg, L. (2004). A critical analysis of the intent-to-treat principle in prevention research. The Journal of Primary Prevention, 25, 475-489. DOI: 10.1023/B:JOPP. 
DO IEPS EXACERBATE NEGATIVE ATTITUDES?

0000048113.77939 .44

Gutman, L. M., \& Schoon, I. (2018). Aiming high, aiming low, not knowing where to go: Career aspirations and later outcomes of adolescents with special educational needs. International Journal of Educational Research, 89, 92-102. DOI: 10.1016/j.ijer.2017.10.002

Hanushek, E. A., Kain, J. F., \& Rivkin, S. G. (2002). Inferring program effects for special populations: Does special education raise achievement for students with disabilities? Review of Economics and Statistics, 84(4), 584-599. DOI: 10.1162/00346530 2760556431

Hibel, J., Farkas, G., \& Morgan, P. L. (2010). Who is placed into special education? Sociology of Education, 83(4), 312-332. DOI: 10.1177/0038040710383518

Hurwitz, S., Perry, B., Cohen, E. D., \& Skiba, R. (2020). Special education and individualized academic growth: A longitudinal assessment of outcomes for students with disabilities. American Educational Research Journal, 57(2), 576-611. DOI: 10.3102/ 0002831219857054

Kasari, C., Locke, J., Gulsrud, A., \& Rotheram-Fuller, E. (2011). Social networks and friendships at school: Comparing children with and without ASD. Journal of Autism and Developmental Disorders, 41(5), 533-544. DOI: 10.1007/s10803-010-1076-x

Krull, J., Wilbert, J., \& Hennemann, T. (2014). The social and emotional situation of first graders with classroom behavior problems and classroom learning difficulties in inclusive classes. Learning Disabilities: A Contemporary Journal, 12(2), 169-190. Retrieved from: http://www.ldam.org/

Lackaye, T. D., \& Margalit, M. (2006). Comparisons of achievement, effort, and self- 
DO IEPS EXACERBATE NEGATIVE ATTITUDES?

perceptions among students with learning disabilities and their peers from different achievement groups. Journal of Learning Disabilities, 39(5), 432-446. DOI:

$10.1177 / 00222194060390050501$

La Greca, A. M. and Stone, W. L. (1993). Social anxiety scale for children-revised: Factor structure and concurrent validity. Journal of Clinical Child Psychology, 22, 17-27.

Lasgaard, M., Nielsen, A., Eriksen, M. E., \& Goossens, L. (2010). Loneliness and social support in adolescent boys with autism spectrum disorders. Journal of Autism and Developmental Disorders, 40(2), 218-226. DOI: 10.1007/s10803-009-0851-z

Major, B, \& O’Brien, L. T. (2005). The social psychology of stigma. Annual Review of Psychology, 56, 393-421. DOI: 10.1146/annurev.psych.56.091103.070137

Marini, Z. A., Dane, A. V., Bosacki, S. L., \& Cura, Y. L. C. (2006). Direct and indirect bullyvictims: differential psychosocial risk factors associated with adolescents involved in bullying and victimization. Aggressive Behavior, 32(6), 551-569. DOI: 10.1002/ab.20155

Martínez, R. S., \& Semrud-Clikeman, M. (2004). Emotional adjustment and school functioning of young adolescents with multiple versus single learning disabilities. Journal of learning Disabilities, 37(5), 411-420. DOI: 10.1177/00222194040370050401

Morgan, P. L., Farkas, G., Tufis, P. A., \& Sperling, R. A. (2008). Are reading and behavior problems risk factors for each other? Journal of Learning Disabilities, 41(5), 417-436. DOI: $10.1177 / 0022219408321123$

Morgan, P. L., Farkas, G., \& Wu, Q. (2012). Do poor readers feel angry, sad, and unpopular? Scientific Studies of Reading, 16(4), 360-381. DOI: 10.1080/10888438.2011.570397

Morgan, P. L., Frisco, M. L., Farkas, G., \& Hibel, J. (2010). A propensity score matching 
DO IEPS EXACERBATE NEGATIVE ATTITUDES?

analysis of the effects of special education services. The Journal of Special Education, 43(4), 236-254. DOI: 10.1177/0022466908323007

Murray, C., \& Greenberg, M. T. (2001). Relationships with teachers and bonds with school:

Social emotional adjustment correlates for children with and without disabilities. Psychology in the Schools, 38(1), 25-41. DOI: 10.1002/1520-

6807(200101)38:1\%3C25::AID-PITS4\%3E3.0.CO;2-C

O’Brennan, L. M., Waasdorp, T. E., Pas, E. T., \& Bradshaw, C. P. (2015). Peer victimization and social-emotional functioning: A longitudinal comparison of students in general and special education. Remedial and Special Education, 36(5), 275-285. DOI: 10.1177/ 0741932515575615

Osborne, J. W., \& Jones, B. D. (2011). Identification with academics and motivation to achieve in school: How the structure of the self influences academic outcomes. Educational Psychology Review, 23(1), 131-158. DOI: 10.1007/s10648-011-9151-1

Parker, J. G. and Asher, S. R. (1993). Friendship and friendship quality in middle childhood: Links with peer group acceptance and feelings of loneliness and social dissatisfaction. Developmental Psychology, 29(4), 611-621.

Rose, C. A., Monda-Amaya, L. E., \& Espelage, D. L. (2011). Bullying perpetration and victimization in special education: A review of the literature. Remedial and Special Education, 32(2), 114-130. DOI: 10.1177/0741932510361247

Rose, C. A., Swearer, S. M., \& Espelage, D. L. (2012). Bullying and students with disabilities: The untold narrative. Focus on Exceptional Children, 45(2), 1-10. DOI: 10.17161/ 
fec.v45i2.6682

Rubin, D. B. (1978). Multiple imputations in sample surveys-a phenomenological Bayesian approach to nonresponse. In Proceedings of the survey research methods section of the American Statistical Association (Vol. 1, pp. 20-34). American Statistical Association.

Sandvik, E., Diener, E., \& Seidlitz, L. (1993). Subjective well-being: The convergence and stability of self-report and non-self-report measures. Journal of Personality, 61(3), 317342. DOI: 10.1111/j.1467-6494.1993.tb00283.x

Schwartz, A. E., Hopkins, B. G., \& Stiefel, L. (2021). The effects of special education on the academic performance of students with learning disabilities. Journal of Policy Analysis and Management. DOI: 10.1002/pam.22282

Shifrer, D. (2013). Stigma of a label: Educational expectations for high school students labeled with learning disabilities. Journal of Health and Social Behavior, 54(4), 462-480. DOI: $10.1177 / 0022146513503346$

Shogren, K. A., Bovaird, J. A., Palmer, S. B., \& Wehmeyer, M. L. (2010). Locus of control orientations in students with intellectual disability, learning disabilities, and no disabilities: A latent growth curve analysis. Research and Practice for Persons with Severe Disabilities, 35(3-4), 80-92. DOI: 10.2511/rpsd.35.3-4.80

Skinner, E. A., Kindermann, T. A., and Furrer, C. J. (2009). A motivational perspective on engagement and disaffection: Conceptualization and assessment of children's behavioral and emotional participation in academic activities in the classroom. Educational and Psychological Measurement, 69(3), 493-525.

Spratt, M., Carpenter, J., Sterne, J. A. C., Carlin, J. B., Heron, J., Henderson, J., \& Tilling, K. 
(2010). Strategies for multiple imputation in longitudinal studies. American Journal of Epidemiology, 172(4), 478-487. https://doi.org/10.1093/aje/kwq137

Stiefel, L., Shiferaw, M., Schwartz, A. E., \& Gottfried, M. (2018). Who feels included in school? Examining feelings of inclusion among students with disabilities. Educational Researcher, 47(2), 105-120. DOI: 10.3102/0013189X17738761

Sullivan, A. L., \& Proctor, S. L. (2016). The shield or the sword? Revisiting the debate on racial disproportionality in special education and implications for school psychologists. School Psychology Forum: Research in Practice, 10(3), 278-288.

Van Buuren, S., \& Groothuis-Oudshoorn, K. (2011). Multivariate imputation by chained equations. Journal of Statistical Software, 45(3), 1-67. DOI:10.1177/0962280206074463

Vandell, D. (2000). Peer Social Support, Bullying, and Victimization (Form FLV05GS: Kids in My Class at School) [measurement instrument]. NICHD Study of Early Child Care and Youth development: Phase III, 2000-2004.

Vaughn, S., \& Wanzek, J. (2014). Intensive interventions in reading for students with reading disabilities: Meaningful impacts. Learning Disabilities Research \& Practice, 29(2), 4653. DOI: $10.1111 / 1 \mathrm{drp} .12031$

White, I. R., Royston, P., \& Wood, A. M. (2011). Multiple imputation using chained equations: Issues and guidance for practice. Statistics in Medicine, 30(4), 377-399. https://doi.org/10.1002/sim.4067

Woods, A. D., Davis-Kean, P., Halvorson, M. A., King, K. M., Logan, J. A. R., Xu, M., Bainter, S., Brown, D. M. Y., Clay, J. M., Cruz, R. A., Elsherif, M. M., Gerasimova, D., Joyal-Desmarais, K., Moreau, D., Nissen, J., Schmidt, K., Uzdavines, A., \& Vasilev, M. 
R. (2021, August 2). Missing Data and Multiple Imputation Decision Tree. https://doi.org/10.31234/osf.io/mdw5r

Zach, S., Yazdi-Ugav, O., \& Zeev, A. (2016). Academic achievements, behavioral problems, and loneliness as predictors of social skills among students with and without learning disorders. School Psychology International, 37(4), 378-396. DOI:

$10.1177 / 0143034316649231$

Zeleke, S. (2004). Self-concepts of students with learning disabilities and their normally achieving peers: A review. European Journal of Special Needs Education, 19(2), 145170. DOI: $10.1080 / 08856250410001678469$ 
Table 1.

Weighted sample mean values following multiple imputation procedures

\begin{tabular}{|c|c|c|c|c|}
\hline & \multicolumn{2}{|c|}{ ECLS-K: 1998} & \multicolumn{2}{|c|}{ ECLS-K: 2011} \\
\hline & All Students & Ever IEP & All Students & Ever IEP \\
\hline & $n=7,800$ & $n=1,340$ & $n=10,310$ & $n=2,430$ \\
\hline & $\%$ or $\mathrm{M}$ & $\%$ or $\mathrm{M}$ & $\%$ or $\mathrm{M}$ & $\%$ or $\mathrm{M}$ \\
\hline \multicolumn{5}{|l|}{ Predictors } \\
\hline K Approaches & 3.00 & 2.69 & 2.96 & 2.63 \\
\hline K Externalizing & 1.61 & 1.77 & 1.60 & 1.80 \\
\hline $\mathrm{K}$ Internalizing & 1.52 & 1.61 & 1.46 & 1.58 \\
\hline K Achievement & 30.78 & 27.02 & 45.10 & 40.54 \\
\hline Ever IEP \% & 20.4 & 100.0 & 21.4 & 100.0 \\
\hline IEP Years & 2.18 & 2.18 & 2.78 & 2.78 \\
\hline Last IEP & 4.07 & 4.08 & 4.80 & 4.80 \\
\hline LD Services \% & 11.7 & 57.6 & 9.0 & 42.0 \\
\hline SLI Services \% & 11.6 & 56.7 & 15.7 & 73.4 \\
\hline ED Services \% & 1.5 & 7.6 & 2.0 & 9.2 \\
\hline ASD Services \% & 2.0 & 10.0 & 5.5 & 25.5 \\
\hline LI Services \% & 1.5 & 7.4 & 2.4 & 11.3 \\
\hline Male $\%$ & 51.9 & 68.8 & 51.4 & 64.7 \\
\hline \multicolumn{5}{|l|}{ Race/Ethnicity \% } \\
\hline White & 57.5 & 61.4 & 51.9 & 49.6 \\
\hline Black & 17.1 & 16.8 & 13.3 & 14.6 \\
\hline Hispanic & 18.1 & 17.4 & 24.8 & 27.2 \\
\hline Asian & 3.6 & 1.6 & 4.7 & 2.5 \\
\hline Other & 3.7 & 2.8 & 5.2 & 6.1 \\
\hline SES & 0.01 & -0.12 & -0.09 & -0.25 \\
\hline \multicolumn{5}{|l|}{ Outcomes } \\
\hline Peer Victim & -- & -- & 2.02 & 2.16 \\
\hline Social Anxiety & -- & -- & 2.15 & 2.31 \\
\hline Behavioral Engage & -- & -- & 4.31 & 4.15 \\
\hline Peer Support & -- & -- & 4.04 & 3.82 \\
\hline Loneliness & -- & -- & 1.69 & 1.86 \\
\hline School Belonging & 3.06 & 2.93 & 3.26 & 3.17 \\
\hline Grit & -- & -- & 4.18 & 4.01 \\
\hline
\end{tabular}




\begin{tabular}{lcccc} 
School Worries & -- & -- & 2.28 & 2.42 \\
Reading Comp. & 2.53 & 2.42 & -- & - \\
Math Competency & 2.60 & 2.57 & -- & - \\
Internalizing & 2.03 & 2.10 & -- & -- \\
Locus of Control & -0.03 & -0.25 & -- & -- \\
Self-Concept & -0.01 & -0.17 & -- & -- \\
Educ Attainment & 5.12 & 4.60 & -- & -- \\
Peer Relationships & 3.78 & 3.56 & -- & -- \\
\hline
\end{tabular}

Note: $\%$ or $\mathrm{M}=$ Percent or mean pooled across $m=40$ imputations. IEP = individualized education program; LD = learning disability; SLI = speech or language impairment; ED = emotional disturbance; ASD = autism spectrum disorder; LI = low incidence disability.

Source: U.S. Department of Education, National Center for Education Statistics (NCES), Early Childhood Longitudinal Study, Kindergarten Class of 1998-99 (ECLS-K: 1998), Kindergarten Through Eighth Grade Full Sample Restricted-Use Data File, and ECLS-K Kindergarten Class of 2010-2011 (ECLS-K: 2011), Kindergarten Through Fifth Grade Full Sample Restricted-Use Data File. 
Table 2.

Regression of ECLS-K: $19988^{\text {th }}$ grade self-reported social, emotional, and academic competencies on IEP status without and with full covariate control $(\mathrm{n}=7,800)$.

\begin{tabular}{|c|c|c|c|c|c|c|c|c|c|c|c|c|}
\hline & \multicolumn{4}{|c|}{ Reading Competency } & \multicolumn{4}{|c|}{ Math Competency } & \multicolumn{4}{|c|}{ Self-Concept } \\
\hline & Model 1 & Model 2 & Model 3 & Model 4 & Model 1 & Model 2 & Model 3 & Model 4 & Model 1 & Model 2 & Model 3 & Model 4 \\
\hline Ever IEP & $-0.21 * * *$ & 0.03 & & & -0.06 & 0.04 & & & $-0.31 * * *$ & $-0.21 * * *$ & & \\
\hline Ever LD & & & $-0.34 * * *$ & -0.10 & & & -0.12 & 0.01 & & & $-0.29 * * *$ & $-0.20 * *$ \\
\hline Ever SLI & & & 0.02 & 0.11 & & & 0.03 & 0.05 & & & -0.13 & -0.09 \\
\hline Ever ED & & & -0.35 & -0.14 & & & -0.11 & -0.05 & & & -0.41 & -0.28 \\
\hline Ever ASD & & & 0.17 & 0.24 & & & 0.12 & 0.20 & & & -0.41 & -0.33 \\
\hline Ever LI & & & 0.12 & -0.02 & & & 0.12 & 0.07 & & & 0.08 & 0.00 \\
\hline K Approach & & 0.03 & & 0.03 & & $0.08 * *$ & & $0.08^{* *}$ & & $0.07 * *$ & & $0.06^{*}$ \\
\hline K Extern. & & -0.01 & & -0.01 & & 0.00 & & 0.00 & & $-0.08^{* * *}$ & & $-0.08 * * *$ \\
\hline K Intern. & & 0.00 & & -0.01 & & -0.03 & & -0.04 & & -0.03 & & -0.02 \\
\hline K Achieve. & & $0.19^{* * *}$ & & $0.18^{* * *}$ & & $0.12 * * *$ & & $0.12 * * *$ & & $0.08^{* * *}$ & & $0.07 * *$ \\
\hline Male & & $-0.39 * * *$ & & $-0.38 * * *$ & & $0.19^{* * *}$ & & $0.19^{* * *}$ & & $0.18^{* * *}$ & & $0.18 * * *$ \\
\hline Black & & $0.21 * *$ & & $0.20 * *$ & & 0.08 & & 0.08 & & $0.32 * * *$ & & $0.31 * * *$ \\
\hline Hispanic & & -0.03 & & -0.03 & & 0.01 & & 0.01 & & -0.06 & & -0.07 \\
\hline Asian & & 0.06 & & 0.06 & & $0.20 * *$ & & $0.20 * *$ & & -0.09 & & -0.09 \\
\hline Other & & 0.06 & & 0.06 & & 0.11 & & 0.12 & & 0.14 & & 0.13 \\
\hline SES & & $0.14^{* * *}$ & & $0.14^{* * *}$ & & $0.08^{* *}$ & & $0.08^{* *}$ & & $0.14^{* * *}$ & & $0.13^{* * *}$ \\
\hline$R^{2}$ & 0.01 & 0.12 & 0.02 & 0.12 & 0.00 & 0.04 & 0.00 & 0.05 & 0.01 & 0.07 & 0.07 & 0.08 \\
\hline
\end{tabular}


(continued)

\begin{tabular}{|c|c|c|c|c|c|c|c|c|c|c|c|c|}
\hline & \multicolumn{4}{|c|}{ Educational Attainment } & \multicolumn{4}{|c|}{ Internalizing Feelings } & \multicolumn{4}{|c|}{ Locus of Control } \\
\hline & Model 1 & Model 2 & Model 3 & Model 4 & Model 1 & Model 2 & Model 3 & Model 4 & Model 1 & Model 2 & Model 3 & Model 4 \\
\hline Ever IEP & $-0.52 * * *$ & $-0.29 * * *$ & & & $0.17 * *$ & $0.17 * *$ & & & $-0.46^{* * *}$ & $-0.31 * * *$ & & \\
\hline Ever LD & & & $-0.53 * * *$ & $-0.29 * * *$ & & & $0.18 *$ & 0.16 & & & $-0.46^{* * *}$ & $-0.30 * * *$ \\
\hline Ever SLI & & & $-0.27 * *$ & -0.18 & & & 0.13 & 0.15 & & & $-0.24 * *$ & $-0.19^{*}$ \\
\hline Ever ED & & & -0.28 & -0.04 & & & 0.13 & 0.08 & & & -0.46 & -0.25 \\
\hline Ever ASD & & & 0.29 & $0.43+$ & & & 0.06 & 0.00 & & & 0.11 & 0.20 \\
\hline Ever LI & & & -0.07 & -0.24 & & & 0.14 & 0.17 & & & 0.01 & -0.08 \\
\hline K Approach & & $0.11 * * *$ & & $0.11 * * *$ & & -0.01 & & -0.01 & & $0.08 * * *$ & & $0.08 * * *$ \\
\hline K Extern. & & 0.00 & & -0.01 & & $0.07 * *$ & & $0.07 * *$ & & $-0.08 * * *$ & & $-0.08 * * *$ \\
\hline K Intern. & & -0.01 & & -0.02 & & 0.04 & & 0.03 & & 0.02 & & 0.01 \\
\hline K Achieve. & & $0.10 * * *$ & & $0.09 * * *$ & & -0.04 & & -0.04 & & $0.11 * * *$ & & $0.10 * * *$ \\
\hline Male & & $-0.25 * * *$ & & $-0.25 * * *$ & & $-0.33 * * *$ & & $-0.33 * * *$ & & 0.03 & & 0.03 \\
\hline Black & & 0.10 & & 0.10 & & -0.04 & & -0.03 & & -0.03 & & -0.03 \\
\hline Hispanic & & 0.06 & & 0.06 & & $0.10+$ & & $0.11+$ & & $-0.12 *$ & & $-0.12 *$ \\
\hline Asian & & $0.17 *$ & & $0.18^{*}$ & & $0.18^{* *}$ & & $0.18 * *$ & & $-0.21 * * *$ & & $-0.20 * *$ \\
\hline Other & & -0.01 & & 0.00 & & -0.07 & & -0.06 & & -0.04 & & -0.04 \\
\hline SES & & $0.33 * *$ & & $0.33 * * *$ & & $-0.13 * * *$ & & $-0.13 * * *$ & & $0.21 * * *$ & & $0.21 * * *$ \\
\hline$R^{2}$ & 0.04 & 0.16 & 0.04 & 0.17 & 0.01 & 0.06 & 0.01 & 0.06 & 0.03 & 0.13 & 0.04 & 0.13 \\
\hline
\end{tabular}


(continued)

\begin{tabular}{|c|c|c|c|c|c|c|c|c|}
\hline & \multicolumn{4}{|c|}{ School Belonging } & \multicolumn{4}{|c|}{ Peer Relationships } \\
\hline & Model 1 & Model 2 & Model 3 & Model 4 & Model 1 & Model 2 & Model 3 & Model 4 \\
\hline Ever IEP & $-0.31 * * *$ & $-0.20 * * *$ & & & $-0.32 * * *$ & $-0.17 * *$ & & \\
\hline Ever LD & & & $-0.27 * * *$ & $-0.18 *$ & & & $-0.23 * *$ & -0.12 \\
\hline Ever SLI & & & -0.06 & -0.02 & & & -0.14 & -0.06 \\
\hline Ever ED & & & $-0.34+$ & -0.16 & & & -0.21 & 0.02 \\
\hline Ever ASD & & & -0.38 & -0.30 & & & -0.32 & -0.25 \\
\hline Ever LI & & & -0.35 & -0.41 & & & -0.07 & -0.16 \\
\hline K Approach & & $0.08^{* *}$ & & $0.08 * *$ & & $0.06+$ & & $0.06^{*}$ \\
\hline K Extern. & & $-0.05+$ & & $-0.05+$ & & $-0.08 * *$ & & $-0.08 * *$ \\
\hline K Intern. & & -0.02 & & -0.01 & & -0.01 & & -0.01 \\
\hline K Achieve. & & 0.00 & & 0.00 & & 0.02 & & 0.02 \\
\hline Male & & $-0.13 * *$ & & $-0.13 * * *$ & & $-0.29 * * *$ & & $-0.29 * * *$ \\
\hline Black & & -0.13 & & -0.12 & & 0.12 & & 0.12 \\
\hline Hispanic & & -0.09 & & -0.09 & & -0.08 & & -0.08 \\
\hline Asian & & -0.03 & & -0.03 & & -0.02 & & -0.01 \\
\hline Other & & -0.03 & & -0.03 & & 0.03 & & 0.03 \\
\hline SES & & $0.12 * * *$ & & $0.12 * * *$ & & $0.09 * * *$ & & $0.09 * * *$ \\
\hline$R^{2}$ & 0.02 & 0.06 & 0.02 & 0.06 & 0.02 & 0.07 & 0.02 & 0.07 \\
\hline
\end{tabular}

Note: IEP = individualized education program; LD = learning disability; SLI = speech or language impairment; ED = emotional disturbance; ASD = autism spectrum disorder; LI = low incidence disability. Source: U.S. Department of Education, National Center for Education Statistics (NCES), Early Childhood Longitudinal Study, Kindergarten Class of 1998-99 (ECLS-K: 1998), Kindergarten Through Eighth Grade Full Sample Restricted-Use Data File. 
Table 3.

Regression of ECLS-K: $20115^{\text {th }}$ grade self-reported social, emotional, and academic attitudes on IEP status with and without additional covariate control $(\mathrm{n}=10,310)$.

\begin{tabular}{|c|c|c|c|c|c|c|c|c|c|c|c|c|}
\hline & \multicolumn{4}{|c|}{ Peer Victimization } & \multicolumn{4}{|c|}{ Social Anxiety } & \multicolumn{4}{|c|}{ Behavioral Engagement } \\
\hline & Model 1 & Model 2 & Model 3 & Model 4 & Model 1 & Model 2 & Model 3 & Model 4 & Model 1 & Model 2 & Model 3 & Model 4 \\
\hline Ever IEP & $0.20 * * *$ & 0.06 & & & $0.17 * * *$ & $0.14 * * *$ & & & $-0.38 * * *$ & $-0.22 * * *$ & & \\
\hline Ever LD & & & 0.12 & -0.04 & & & 0.10 & 0.05 & & & $-0.39 * * *$ & $-0.24 * * *$ \\
\hline Ever SLI & & & 0.07 & 0.07 & & & 0.07 & $0.09+$ & & & -0.09 & -0.04 \\
\hline Ever ED & & & $0.38 * *$ & 0.11 & & & 0.20 & 0.11 & & & $-0.38 * *$ & -0.23 \\
\hline Ever ASD & & & 0.15 & 0.06 & & & 0.11 & 0.08 & & & $-0.23+$ & -0.16 \\
\hline Ever LI & & & 0.01 & 0.01 & & & 0.07 & 0.06 & & & -0.18 & -0.16 \\
\hline K Approach & & -0.03 & & -0.03 & & $-0.06^{* * *}$ & & $-0.06 * * *$ & & $0.09 * * *$ & & $0.08 * * *$ \\
\hline K Extern. & & $0.20 * * *$ & & $0.20 * * *$ & & $0.09 * * *$ & & $0.09 * * *$ & & $-0.07 * * *$ & & $-0.06 * * *$ \\
\hline K Intern. & & -0.02 & & -0.02 & & 0.02 & & 0.02 & & -0.02 & & -0.02 \\
\hline K Achieve. & & -0.03 & & -0.03 & & 0.01 & & 0.01 & & $0.04 * *$ & & $0.04 * *$ \\
\hline Male & & -0.02 & & -0.02 & & $-0.33 * * *$ & & $-0.33 * * *$ & & $-0.22 * * *$ & & $-0.22 * * *$ \\
\hline Black & & $0.11 *$ & & $0.11 *$ & & $-0.23 * * *$ & & $-0.23 * * *$ & & -0.04 & & -0.04 \\
\hline Hispanic & & $-0.25 * * *$ & & $-0.25 * * *$ & & $-0.15 * * *$ & & $-0.14 * * *$ & & $-0.13 * * *$ & & $-0.13 * * *$ \\
\hline Asian & & $-0.10^{*}$ & & $-0.10^{*}$ & & -0.03 & & -0.03 & & $-0.21 * * *$ & & $-0.21 * * *$ \\
\hline Other & & 0.03 & & 0.03 & & -0.03 & & -0.03 & & -0.10 & & -0.11 \\
\hline SES & & $-0.15 * * *$ & & $-0.15 * * *$ & & $-0.06^{* * *}$ & & $-0.06 * * *$ & & $0.08 * * *$ & & $0.08 * * *$ \\
\hline$R^{2}$ & 0.01 & 0.08 & 0.01 & 0.08 & 0.01 & 0.05 & 0.01 & 0.05 & 0.03 & 0.08 & 0.04 & 0.09 \\
\hline
\end{tabular}


(continued)

\begin{tabular}{|c|c|c|c|c|c|c|c|c|c|c|c|c|}
\hline & \multicolumn{4}{|c|}{ Grit } & \multicolumn{4}{|c|}{ Peer Support } & \multicolumn{4}{|c|}{ School Belonging } \\
\hline & Model 1 & Model 2 & Model 3 & Model 4 & Model 1 & Model 2 & Model 3 & Model 4 & Model 1 & Model 2 & Model 3 & Model 4 \\
\hline Ever IEP & $-0.31 * * *$ & $-0.21 * * *$ & & & $-0.31 * * *$ & $-0.19 * * *$ & & & $-0.19 * * *$ & $-0.10 * * *$ & & \\
\hline Ever LD & & & $-0.23 * * *$ & $-0.15^{*}$ & & & $-0.20^{* *}$ & -0.07 & & & -0.11 & -0.02 \\
\hline Ever SLI & & & $0.09+$ & -0.07 & & & $-0.12+$ & $-0.10+$ & & & -0.06 & -0.04 \\
\hline Ever ED & & & $-0.34 *$ & -0.23 & & & $-0.34^{* *}$ & -0.16 & & & $-0.35^{* *}$ & -0.21 \\
\hline Ever ASD & & & $-0.24^{* *}$ & $-0.19+$ & & & $-0.27 * *$ & $-0.19+$ & & & -0.13 & -0.07 \\
\hline Ever LI & & & -0.16 & -0.15 & & & -0.04 & -0.03 & & & -0.05 & -0.04 \\
\hline K Approach & & $0.10^{* * *}$ & & $0.10 * * *$ & & $0.10 * * *$ & & $0.10 * * *$ & & $0.08^{* * *}$ & & $0.08 * * *$ \\
\hline K Extern. & & -0.03 & & -0.03 & & $-0.08 * * *$ & & $-0.08 * * *$ & & $-0.06^{* * *}$ & & $-0.06^{* *}$ \\
\hline K Intern. & & $-0.04+$ & & $-0.03+$ & & -0.03 & & -0.03 & & $-0.03+$ & & $-0.03+$ \\
\hline K Achieve. & & -0.02 & & -0.03 & & 0.01 & & 0.01 & & -0.02 & & -0.02 \\
\hline Male & & $-0.06^{*}$ & & $-0.06^{*}$ & & -0.04 & & -0.05 & & -0.02 & & -0.02 \\
\hline Black & & 0.07 & & 0.07 & & $-0.12^{*}$ & & $-0.12^{*}$ & & -0.08 & & -0.08 \\
\hline Hispanic & & -0.02 & & -0.03 & & 0.03 & & 0.03 & & 0.05 & & 0.05 \\
\hline Asian & & $-0.10+$ & & $-0.10+$ & & $-0.12^{* *}$ & & $-0.12 * *$ & & -0.08 & & -0.08 \\
\hline Other & & -0.09 & & -0.10 & & -0.04 & & -0.04 & & -0.07 & & -0.08 \\
\hline SES & & $0.07 * * *$ & & $0.07 * * *$ & & $0.08^{* * *}$ & & $0.08^{* * *}$ & & $0.09^{* * *}$ & & $0.08^{* * *}$ \\
\hline$R^{2}$ & 0.02 & 0.04 & 0.02 & 0.04 & 0.02 & 0.05 & & 0.05 & 0.01 & 0.03 & 0.01 & 0.03 \\
\hline
\end{tabular}


(continued)

\begin{tabular}{|c|c|c|c|c|c|c|c|c|}
\hline & \multicolumn{4}{|c|}{ Loneliness } & \multicolumn{4}{|c|}{ School Worries } \\
\hline & Model 1 & Model 2 & Model 3 & Model 4 & Model 1 & Model 2 & Model 3 & Model 4 \\
\hline Ever IEP & $0.24 * * *$ & $0.19 * * *$ & & & $0.26^{* * *}$ & $0.14 * * *$ & & \\
\hline Ever LD & & & $0.20 * *$ & $0.13+$ & & & $0.39 * * *$ & $0.21 * * *$ \\
\hline Ever SLI & & & 0.06 & 0.08 & & & 0.02 & 0.01 \\
\hline Ever ED & & & $0.28^{*}$ & 0.15 & & & $0.30^{*}$ & $0.24+$ \\
\hline Ever ASD & & & $0.22+$ & 0.18 & & & 0.01 & -0.04 \\
\hline Ever LI & & & 0.06 & 0.05 & & & 0.09 & 0.07 \\
\hline K Approach & & $-0.06^{* *}$ & & $-0.06^{* *}$ & & $-0.07 * * *$ & & $-0.06^{* * *}$ \\
\hline K Extern. & & $0.10 * * *$ & & $0.10^{* * *}$ & & $0.04 * *$ & & $0.04^{*}$ \\
\hline K Intern. & & $0.03+$ & & $0.03+$ & & 0.00 & & 0.00 \\
\hline K Achieve. & & 0.01 & & 0.01 & & $-0.12 * * *$ & & $-0.12 * * *$ \\
\hline Male & & $-0.23 * * *$ & & $-0.23 * * *$ & & $-0.18 * * *$ & & $-0.17 * * *$ \\
\hline Black & & $-0.14^{* *}$ & & $-0.14 * *$ & & $0.10+$ & & $0.09+$ \\
\hline Hispanic & & $-0.16 * * *$ & & $-0.15 * * *$ & & $0.14 * * *$ & & $0.14 * * *$ \\
\hline Asian & & -0.02 & & -0.02 & & 0.06 & & 0.06 \\
\hline Other & & 0.00 & & 0.00 & & 0.09 & & 0.09 \\
\hline SES & & $-0.07 * * *$ & & $-0.07 * * *$ & & $-0.09 * * *$ & & $-0.09 * * *$ \\
\hline$R^{2}$ & 0.01 & 0.04 & 0.01 & 0.04 & 0.01 & 0.07 & 0.02 & 0.07 \\
\hline
\end{tabular}

Note: IEP $=$ individualized education program; $\mathrm{LD}=$ learning disability $; \mathrm{SLI}=$ speech or language impairment $\mathrm{ED}=\mathrm{emotional}$ disturbance; ASD = autism spectrum disorder; LI = low incidence disability. Imputed data $(m=40)$ are weighted with $w 9 c 9 p \_20$. Source: U.S. Department of Education, National Center for Education Statistics (NCES), Early Childhood Longitudinal Study, Kindergarten Class of 2010-11 (ECLS-K: 2011), Kindergarten Through Fifth Grade Full Sample Restricted-Use Data File 
Table 4.

Regression of ECLS-K: $19988^{\text {th }}$ grade self-reported social, emotional, and academic attitudes on IEP characteristics without and with additional covariate control $(\mathrm{n}=1,340)$.

\begin{tabular}{lcccccccc}
\hline & $\begin{array}{c}\text { Reading } \\
\text { Competency }\end{array}$ & $\begin{array}{c}\text { Math } \\
\text { Competency }\end{array}$ & $\begin{array}{c}\text { Self- } \\
\text { Concept }\end{array}$ & $\begin{array}{c}\text { Educational } \\
\text { Attainment }\end{array}$ & $\begin{array}{c}\text { Internalizing } \\
\text { Feelings }\end{array}$ & $\begin{array}{c}\text { Locus of } \\
\text { Control }\end{array}$ & $\begin{array}{c}\text { School } \\
\text { Belonging }\end{array}$ & $\begin{array}{c}\text { Peer } \\
\text { Relationships }\end{array}$ \\
\hline Without covariates & & & & & & & & \\
IEP Experience & -0.07 & 0.08 & $-0.14^{* *}$ & -0.11 & $0.11+$ & $-0.19 * * *$ & $-0.11+$ & -0.04 \\
$\quad R^{2}$ & .00 & .01 & .02 & .01 & .01 & .03 & .01 & .00 \\
With covariates & & & & & & & & \\
IEP Experience & -0.02 & $0.10+$ & -0.08 & -0.07 & 0.04 & $-0.12+$ & -0.03 & -0.01 \\
LD Serv & -0.10 & -0.01 & -0.11 & -0.06 & 0.15 & -0.11 & -0.10 & 0.01 \\
SLI Serv & 0.08 & 0.09 & -0.06 & -0.02 & 0.20 & -0.10 & 0.06 & 0.05 \\
ED Serv & -0.21 & -0.11 & -0.29 & -0.04 & 0.11 & -0.23 & -0.18 & 0.07 \\
ASD Serv & 0.24 & 0.16 & -0.27 & $0.45+$ & -0.06 & 0.22 & -0.29 & -0.25 \\
LI Serv & 0.00 & -0.01 & 0.00 & -0.26 & 0.17 & 0.01 & -0.39 & -0.17 \\
Approaches & 0.02 & $0.16+$ & 0.09 & $0.18+$ & -0.01 & 0.05 & 0.08 & 0.03 \\
Externalizing & 0.02 & 0.02 & -0.02 & 0.05 & 0.04 & -0.04 & -0.01 & -0.09 \\
Internalizing & -0.01 & -0.03 & -0.08 & 0.00 & 0.07 & 0.06 & -0.05 & -0.04 \\
Achievement & $0.21 * * *$ & 0.06 & 0.05 & 0.12 & -0.09 & $0.17 * *$ & -0.02 & 0.06 \\
Male & $-0.20+$ & 0.19 & 0.18 & -0.11 & $-0.47 * * *$ & 0.11 & -0.04 & $-0.36 * *$ \\
Black & 0.20 & $0.42 * *$ & $0.41 * *$ & $0.51 * *$ & 0.05 & -0.17 & -0.10 & $0.44 * *$ \\
Hispanic & -0.05 & 0.12 & -0.02 & 0.04 & -0.03 & -0.13 & -0.27 & -0.26 \\
Asian & 0.39 & 0.02 & -0.04 & 0.06 & 0.17 & -0.44 & -0.09 & -0.24 \\
Other & -0.12 & -0.29 & -0.21 & -0.36 & -0.07 & -0.02 & -0.25 & -0.35 \\
& & & & & & &
\end{tabular}




\begin{tabular}{lcccccccc} 
SES & $0.15 *$ & 0.08 & $0.22 * *$ & $0.38 * * *$ & $-0.22 *$ & $0.21 * * *$ & 0.12 & 0.04 \\
$R^{2}$ & .13 & .09 & .11 & .15 & .10 & .14 & .06 & .08 \\
\hline$* * * p<.001, * * p<.01,{ }^{*} p<.05,+p<.05$ but not significant following Benjamini-Hochberg correction for multiple comparisons.
\end{tabular}

Note: $\mathrm{IEP}=$ individualized education program; $\mathrm{LD}=$ learning disability; $\mathrm{SLI}=$ speech or language impairment; $\mathrm{ED}=\mathrm{emotional}$ disturbance; ASD = autism spectrum disorder; LI = low incidence disability. Imputed data $(m=40)$ are weighted with $c 1 \_7 f c 0$. Source: U.S. Department of Education, National Center for Education Statistics (NCES), Early Childhood Longitudinal Study, Kindergarten Class of 1998-99 (ECLS-K: 1998), Kindergarten Through Eighth Grade Full Sample Restricted-Use Data File. 
Table 5.

Regression of ECLS-K: $20115^{\text {th }}$ grade self-reported social, emotional, and academic attitudes on IEP characteristics without and with additional covariate control $(\mathrm{n}=2,430)$.

\begin{tabular}{|c|c|c|c|c|c|c|c|c|}
\hline & $\begin{array}{c}\text { Peer } \\
\text { Victimization }\end{array}$ & $\begin{array}{c}\text { Social } \\
\text { Anxiety }\end{array}$ & $\begin{array}{c}\text { Behavioral } \\
\text { Engagement }\end{array}$ & Grit & $\begin{array}{c}\text { Peer } \\
\text { Support }\end{array}$ & $\begin{array}{c}\text { School } \\
\text { Belonging }\end{array}$ & Loneliness & $\begin{array}{c}\text { School } \\
\text { Worries }\end{array}$ \\
\hline \multicolumn{9}{|c|}{ Without covariates } \\
\hline IEP Experience & $0.13 * * *$ & $0.08 * *$ & $-0.20 * * *$ & $-0.13 * * *$ & $-0.16 * * *$ & $-0.07 * *$ & $0.14 * * *$ & $0.08 * *$ \\
\hline$R^{2}$ & .01 & .01 & .03 & .01 & .02 & .00 & .01 & .00 \\
\hline \multicolumn{9}{|l|}{ With covariates } \\
\hline IEP Experience & 0.07 & 0.02 & $-0.10 * *$ & -0.06 & $-0.09+$ & -0.02 & 0.07 & -0.01 \\
\hline LD Services & -0.12 & -0.07 & -0.05 & -0.02 & 0.11 & 0.08 & 0.01 & 0.11 \\
\hline SLI Services & 0.04 & 0.01 & 0.11 & 0.05 & 0.03 & 0.07 & -0.01 & -0.15 \\
\hline ED Services & 0.17 & 0.13 & -0.24 & -0.25 & -0.15 & -0.20 & 0.14 & $0.28+$ \\
\hline ASD Services & 0.04 & 0.08 & -0.13 & -0.17 & -0.16 & -0.06 & 0.17 & -0.03 \\
\hline LI Services & -0.01 & 0.05 & -0.14 & -0.13 & 0.00 & -0.02 & 0.04 & 0.08 \\
\hline K Approaches & -0.08 & -0.05 & $0.12 * *$ & $0.13 * *$ & $0.15 * * *$ & 0.07 & -0.02 & -0.06 \\
\hline K Externalizing & $0.14 * * *$ & $0.08+$ & 0.02 & 0.03 & -0.02 & -0.06 & $0.09+$ & 0.01 \\
\hline K Internalizing & $-0.07+$ & -0.01 & -0.04 & -0.03 & -0.02 & -0.02 & 0.03 & -0.02 \\
\hline Achievement & -0.07 & $-0.08+$ & 0.06 & -0.02 & 0.03 & 0.02 & -0.03 & $-0.15 * * *$ \\
\hline Male & -0.10 & $-0.38 * * *$ & $-0.20 * * *$ & -0.09 & 0.02 & -0.04 & $-0.27 * * *$ & $-0.22 * * *$ \\
\hline Black NH & 0.10 & $-0.30 * *$ & -0.06 & 0.08 & -0.14 & 0.12 & -0.19 & -0.02 \\
\hline Hispanic & $-0.31 * * *$ & $-0.20 * *$ & $-0.17 *$ & -0.12 & 0.05 & 0.06 & $-0.21 * *$ & $0.12+$ \\
\hline Asian & -0.01 & $-0.22+$ & $-0.50 * * *$ & -0.24 & $-0.30+$ & -0.21 & -0.18 & -0.16 \\
\hline
\end{tabular}


DO IEPS EXACERBATE NEGATIVE ATTITUDES?

\begin{tabular}{lcccccccc} 
Other & 0.04 & -0.09 & -0.22 & -0.13 & 0.03 & 0.11 & -0.11 & 0.24 \\
SES & $-0.13 * * *$ & $-0.11 * *$ & $0.11 * *$ & $0.09 *$ & $0.09 *$ & $0.09 *$ & $-0.12^{* *}$ & $-0.11^{* *}$ \\
$R^{2}$ & .07 & .07 & .09 & .05 & .06 & .03 & .05 & .09 \\
\hline$* * * p<.001, * * p<.01, * p<.05,+p<.05$ & but not significant following & Benjamini-Hochberg correction for multiple comparisons.
\end{tabular}

Note: $\mathrm{IEP}=$ individualized education program; $\mathrm{LD}=$ learning disability; $\mathrm{SLI}=$ speech or language impairment; $\mathrm{ED}=\mathrm{emotional}$ disturbance; ASD = autism spectrum disorder; LI = low incidence disability. Source: U.S. Department of Education, National Center for Education Statistics (NCES), Early Childhood Longitudinal Study, Kindergarten Class of 2010-11 (ECLS-K: 2011), Kindergarten Through Fifth Grade Full Sample Restricted-Use Data File. 


\section{Supplemental Material}

\section{Table S1.}

Cross-tabulation of the wave at which SWD most recently had an IEP by the proportion (\%) of students with varying IEP dosages (number of years assigned an IEP).

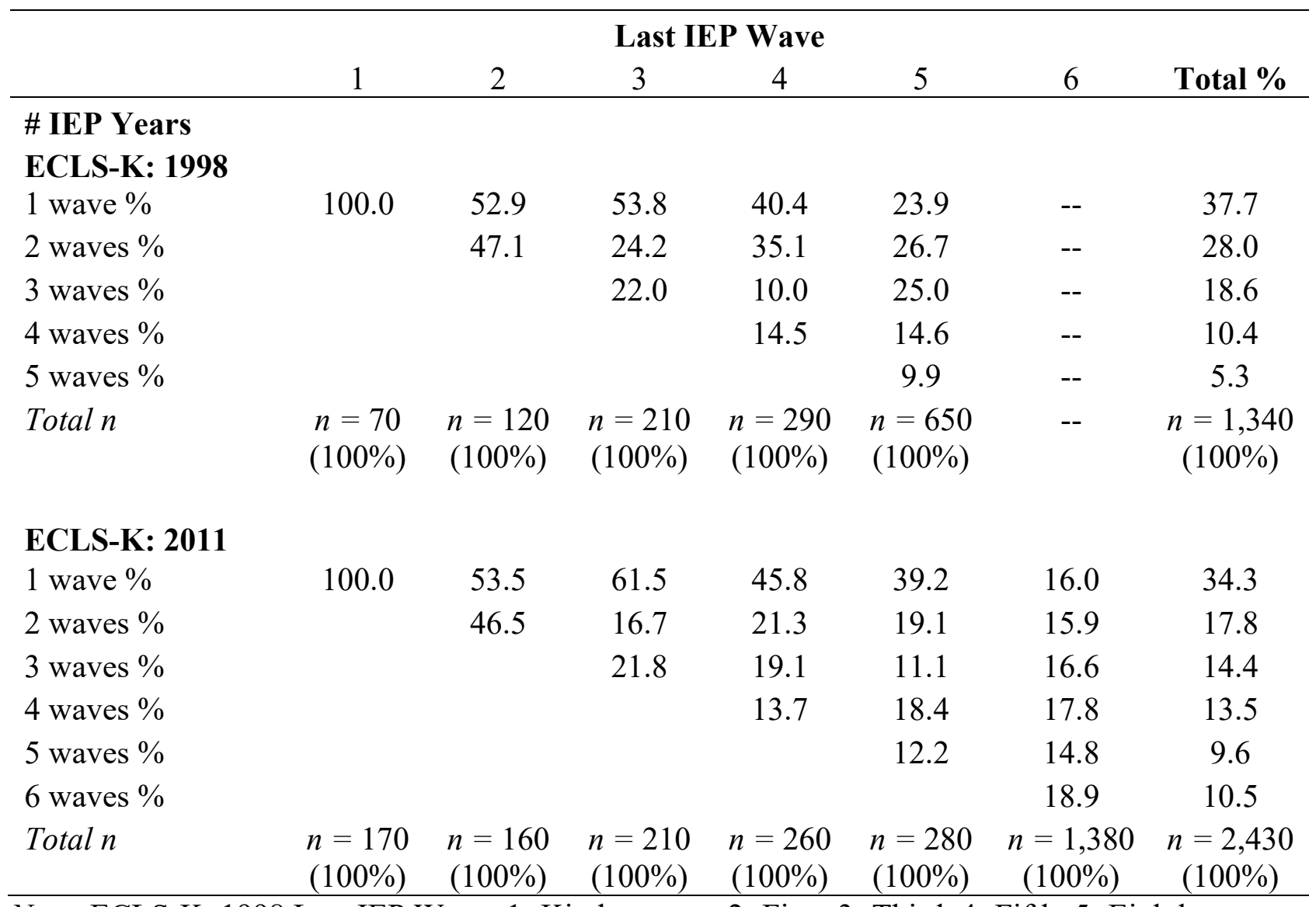

Note: ECLS-K: 1998 Last IEP Wave: 1=Kindergarten, 2=First, 3=Third, 4=Fifth, 5=Eighth;

ECLS-K: 2011 Last IEP Wave: 1=Kindergarten, 2=First, 3=Second, 4=Third, 5=Fourth, 6=Fifth.

Source: U.S. Department of Education, National Center for Education Statistics (NCES), Early Childhood Longitudinal Study, Kindergarten Class of 1998-99 (ECLS-K: 1998), Kindergarten Through Eighth Grade Full Sample Restricted-Use Data File, and ECLS-K Kindergarten Class of 2010-2011 (ECLS-K: 2011), Kindergarten Through Fifth Grade Full Sample Restricted-Use Data File. 
Table S2. Heat map and weighted zero-order correlations between outcomes and predictors (below diagonal = ECLS-K: 1998, above diagonal $=E C L S-K: 2011)$.

\begin{tabular}{|c|c|c|c|c|c|c|c|c|c|c|c|c|c|c|c|c|}
\hline & & 1 & 2 & 3 & 4 & 5 & 6 & 7 & 8 & 9 & 10 & 11 & 12 & 13 & 14 & 15 \\
\hline 1 & IEP Years & 1 & 0.52 & 0.34 & 0.06 & 0.10 & 0.24 & 0.12 & 0.10 & 0.08 & -0.14 & -0.15 & 0.12 & -0.06 & -0.10 & 0.03 \\
\hline 2 & Last IEP & 0.45 & 1 & 0.36 & -0.17 & 0.09 & 0.09 & 0.08 & 0.07 & 0.04 & -0.13 & -0.10 & 0.08 & -0.03 & -0.09 & 0.08 \\
\hline 3 & LD Services & 0.22 & 0.38 & 1 & -0.37 & 0.07 & 0.06 & 0.05 & 0.02 & 0.04 & -0.16 & -0.07 & 0.06 & -0.03 & -0.10 & 0.16 \\
\hline 4 & SLI Services & 0.13 & -0.24 & -0.49 & 1 & -0.10 & 0.12 & 0.05 & -0.02 & 0.00 & 0.07 & 0.02 & -0.03 & 0.04 & 0.02 & -0.12 \\
\hline 5 & ED Services & 0.11 & 0.12 & 0.01 & -0.14 & 1 & 0.07 & 0.11 & 0.11 & 0.05 & -0.09 & -0.08 & 0.11 & -0.08 & -0.07 & 0.08 \\
\hline 6 & ASD Services & 0.18 & 0.04 & -0.05 & 0.11 & 0.02 & 1 & 0.24 & 0.05 & 0.06 & -0.12 & -0.10 & 0.09 & -0.05 & -0.12 & 0.01 \\
\hline 7 & LI Services & 0.15 & 0.02 & -0.06 & 0.09 & 0.00 & 0.23 & 1 & 0.02 & 0.04 & -0.08 & -0.04 & 0.03 & -0.02 & -0.08 & 0.02 \\
\hline 8 & Outcome 1 & -0.05 & -0.08 & -0.17 & 0.12 & -0.08 & 0.07 & 0.03 & 1 & 0.49 & -0.17 & -0.40 & 0.58 & -0.38 & -0.15 & 0.29 \\
\hline 9 & Outcome 2 & 0.04 & -0.01 & -0.03 & 0.05 & 0.01 & 0.01 & 0.03 & 0.13 & 1 & -0.13 & -0.32 & 0.59 & -0.30 & -0.15 & 0.42 \\
\hline 10 & Outcome 3 & 0.09 & 0.10 & 0.11 & -0.02 & 0.00 & 0.02 & 0.00 & 0.17 & 0.00 & 1 & 0.39 & -0.17 & 0.40 & 0.59 & -0.12 \\
\hline 11 & Outcome 4 & -0.16 & -0.16 & -0.15 & 0.02 & -0.06 & -0.03 & 0.00 & 0.11 & 0.13 & -0.36 & 1 & -0.51 & 0.59 & 0.42 & -0.15 \\
\hline 12 & Outcome 5 & -0.11 & -0.11 & -0.11 & 0.01 & -0.03 & -0.05 & 0.02 & 0.17 & 0.23 & -0.38 & 0.54 & 1 & -0.47 & -0.21 & 0.33 \\
\hline 13 & Outcome 6 & -0.13 & -0.14 & -0.15 & 0.02 & -0.06 & -0.01 & 0.00 & 0.27 & 0.19 & -0.03 & 0.26 & 0.27 & 1 & 0.47 & -0.16 \\
\hline 14 & Outcome 7 & -0.02 & -0.05 & -0.01 & 0.00 & -0.06 & -0.05 & -0.01 & 0.16 & 0.25 & -0.14 & 0.23 & 0.42 & 0.15 & 1 & -0.06 \\
\hline 15 & Outcome 8 & -0.06 & -0.05 & 0.00 & -0.01 & -0.06 & -0.04 & -0.03 & 0.10 & 0.10 & -0.09 & 0.19 & 0.36 & 0.12 & 0.55 & 1 \\
\hline 16 & Male & 0.03 & 0.01 & 0.02 & -0.03 & 0.09 & 0.00 & -0.01 & -0.14 & 0.10 & -0.17 & 0.07 & 0.10 & -0.02 & -0.04 & -0.14 \\
\hline 17 & White & 0.01 & -0.06 & -0.09 & 0.03 & 0.00 & 0.02 & 0.05 & 0.02 & -0.01 & -0.08 & 0.17 & 0.08 & 0.09 & 0.09 & 0.04 \\
\hline 18 & Black & 0.04 & 0.08 & 0.02 & -0.02 & 0.06 & 0.05 & -0.02 & 0.04 & 0.05 & 0.05 & -0.09 & 0.03 & -0.01 & -0.05 & 0.04 \\
\hline 19 & Hispanic & -0.04 & 0.00 & 0.06 & -0.02 & -0.02 & -0.05 & -0.05 & -0.06 & -0.01 & 0.02 & -0.10 & -0.08 & -0.07 & -0.07 & -0.07 \\
\hline 20 & Asian & -0.03 & -0.01 & -0.03 & 0.04 & -0.01 & -0.01 & 0.01 & 0.02 & 0.01 & 0.02 & -0.02 & -0.02 & 0.00 & 0.02 & 0.02 \\
\hline 21 & Other & 0.01 & 0.03 & 0.10 & -0.04 & -0.04 & -0.02 & -0.02 & -0.02 & -0.05 & 0.04 & -0.06 & -0.06 & -0.08 & -0.02 & -0.05 \\
\hline 22 & SES & -0.10 & -0.09 & -0.14 & 0.05 & -0.08 & 0.01 & 0.12 & 0.14 & 0.07 & -0.10 & 0.21 & 0.19 & 0.28 & 0.11 & 0.06 \\
\hline 23 & K Approach & -0.21 & -0.27 & -0.19 & 0.10 & -0.11 & -0.16 & -0.03 & 0.09 & 0.15 & -0.14 & 0.20 & 0.18 & 0.24 & 0.13 & 0.12 \\
\hline 24 & K Externaliz. & 0.16 & 0.12 & -0.02 & -0.08 & 0.23 & 0.09 & 0.05 & -0.07 & -0.05 & 0.08 & -0.12 & -0.09 & -0.09 & -0.13 & -0.16 \\
\hline 25 & K Internaliz. & 0.08 & 0.09 & 0.00 & -0.01 & 0.11 & 0.15 & 0.01 & -0.04 & -0.06 & 0.12 & -0.07 & -0.12 & -0.09 & -0.08 & -0.07 \\
\hline
\end{tabular}


(continued)

\begin{tabular}{llccccccccccc}
\hline & & 16 & 17 & 18 & 19 & 20 & 21 & 22 & 23 & 24 & 25 \\
\hline 1 & IEP Years & 0.08 & 0.08 & 0.04 & -0.12 & -0.02 & 0.03 & -0.06 & -0.29 & 0.18 & 0.11 \\
2 & Last IEP & 0.01 & -0.01 & 0.02 & 0.00 & -0.05 & 0.02 & -0.05 & -0.26 & 0.16 & 0.12 \\
3 & LD Services & -0.01 & -0.09 & 0.06 & 0.08 & -0.05 & -0.01 & -0.21 & -0.33 & 0.13 & 0.11 \\
4 & SLI Services & 0.04 & 0.02 & -0.07 & -0.02 & 0.06 & 0.05 & 0.08 & 0.18 & -0.16 & -0.01 \\
5 & ED Services & 0.05 & 0.02 & 0.10 & -0.06 & -0.02 & -0.04 & -0.01 & -0.16 & 0.30 & 0.21 \\
6 & ASD Services & 0.10 & -0.01 & 0.02 & -0.02 & 0.03 & 0.01 & 0.00 & -0.18 & 0.12 & 0.06 \\
7 & LI Services & 0.01 & 0.00 & 0.00 & 0.00 & 0.01 & -0.02 & 0.05 & -0.12 & 0.07 & 0.01 \\
8 & Outcome 1 & 0.03 & 0.03 & 0.10 & -0.10 & -0.03 & 0.02 & -0.09 & -0.17 & 0.21 & 0.05 \\
9 & Outcome 2 & -0.11 & 0.07 & -0.06 & -0.03 & -0.03 & 0.00 & -0.07 & -0.12 & 0.10 & 0.06 \\
10 & Outcome 3 & -0.08 & 0.14 & -0.06 & -0.09 & -0.05 & -0.01 & 0.15 & 0.23 & -0.15 & -0.11 \\
11 & Outcome 4 & -0.05 & 0.06 & -0.06 & 0.01 & -0.05 & -0.03 & 0.09 & 0.20 & -0.15 & -0.12 \\
12 & Outcome 5 & -0.07 & 0.06 & -0.01 & -0.06 & -0.02 & 0.01 & -0.05 & -0.12 & 0.13 & 0.10 \\
13 & Outcome 6 & -0.04 & 0.01 & -0.01 & 0.00 & -0.03 & 0.01 & 0.06 & 0.14 & -0.14 & -0.08 \\
14 & Outcome 7 & -0.07 & 0.07 & -0.01 & -0.05 & -0.03 & -0.03 & 0.08 & 0.19 & -0.12 & -0.10 \\
15 & Outcome 8 & -0.08 & -0.10 & 0.01 & 0.10 & -0.05 & 0.03 & -0.18 & -0.13 & 0.08 & 0.06 \\
16 & Male & 1 & 0.00 & 0.03 & -0.02 & -0.01 & 0.00 & 0.02 & -0.17 & 0.18 & 0.01 \\
17 & White & 0.00 & 1 & -0.34 & -0.64 & -0.21 & -0.23 & 0.37 & 0.05 & -0.01 & 0.00 \\
18 & Black & 0.04 & -0.48 & 1 & -0.24 & -0.08 & -0.09 & -0.14 & -0.07 & 0.11 & -0.01 \\
19 & Hispanic & 0.01 & -0.58 & -0.15 & 1 & -0.14 & -0.16 & -0.36 & -0.04 & -0.05 & 0.00 \\
20 & Asian & -0.04 & -0.27 & -0.07 & -0.09 & 1 & -0.05 & 0.09 & 0.05 & -0.05 & -0.01 \\
21 & Other & -0.03 & -0.29 & -0.08 & -0.09 & -0.04 & 1 & 0.03 & 0.00 & 0.00 & 0.01 \\
22 & SES & 0.02 & 0.31 & -0.22 & -0.20 & 0.00 & -0.04 & 1 & 0.17 & -0.07 & -0.07 \\
23 & K Approach & -0.13 & 0.16 & -0.16 & -0.04 & 0.02 & -0.06 & 0.22 & 1 & -0.58 & -0.30 \\
24 & K Externaliz. & 0.19 & -0.09 & 0.14 & -0.01 & -0.03 & 0.04 & -0.09 & -0.49 & 1 & 0.25 \\
25 & K Internaliz. & 0.00 & -0.05 & 0.04 & 0.04 & 0.02 & -0.04 & -0.12 & -0.37 & 0.29 & 1 \\
\hline & & & & & & & & & & & \\
\hline
\end{tabular}


Note: Outcome 1 = Reading Competency (ECLS-K: 1998) or Peer Victimization (ECLS-K: 2011); Outcome 2 = Mathematics Competency (1998) or Social Anxiety (2011); Outcome 3 = Internalizing Feelings (1998) or Behavioral Engagement (2011); Outcome 4 = Locus of Control (1998) or Peer Support (2011); Outcome 5 = Self-Concept (1998) or Loneliness (2011); Outcome $6=$

Educational Attainment (1998) or School Belonging (2011); Outcome 7 = School Belonging (1998) or Grit (2011); Outcome 8 = Peer Relationships (1998) or School Worries (2011). Source: U.S. Department of Education, National Center for Education Statistics (NCES), Early Childhood Longitudinal Study, Kindergarten Class of 1998-99 (ECLS-K: 1998), Kindergarten Through Eighth Grade Full Sample Restricted-Use Data File, and ECLS-K Kindergarten Class of 2010-2011 (ECLS-K: 2011), Kindergarten Through Fifth Grade Full Sample Restricted-Use Data File. 


\section{Table S3.}

Separate and combined effects of IEP years (duration) and last IEP (timing) on outcomes from the ECLS-K: 1998 (n = 1,340) without covariate adjustment.

\begin{tabular}{|c|c|c|c|c|c|c|c|c|c|c|c|c|}
\hline & \multicolumn{12}{|c|}{ ECLS-K: 1998} \\
\hline & \multicolumn{3}{|c|}{ Reading Competency } & \multicolumn{3}{|c|}{ Math Competency } & \multicolumn{3}{|c|}{ Internalizing } & \multicolumn{3}{|c|}{ Locus of Control } \\
\hline & Model 1 & Model 2 & Model 3 & Model 1 & Model 2 & Model 3 & Model 1 & Model 2 & Model 3 & Model 1 & Model 2 & Model 3 \\
\hline Last IEP & -0.08 & -- & -0.07 & 0.01 & -- & -0.05 & $0.11+$ & -- & 0.09 & $-0.17 *$ & -- & -0.12 \\
\hline IEP Years & -- & -0.04 & -0.02 & -- & $0.10+$ & $0.12+$ & -- & 0.08 & 0.05 & -- & $-0.15 * *$ & -0.11 \\
\hline$R^{2}$ & 0.01 & 0.00 & 0.01 & 0.00 & 0.01 & 0.01 & 0.01 & 0.01 & 0.01 & 0.02 & 0.02 & 0.03 \\
\hline
\end{tabular}

\begin{tabular}{|c|c|c|c|c|c|c|c|c|c|c|c|c|}
\hline & \multicolumn{3}{|c|}{ Self-Concept } & \multicolumn{3}{|c|}{ Educational Attainment } & \multicolumn{3}{|c|}{ School Belonging } & \multicolumn{3}{|c|}{ Peer Relationships } \\
\hline & Model 1 & Model 2 & Model 3 & Model 1 & Model 2 & Model 3 & Model 1 & Model 2 & Model 3 & Model 1 & Model 2 & Model 3 \\
\hline Last IEP & $-0.12 *$ & -- & -0.08 & $-0.13+$ & -- & -0.11 & $-0.15^{* *}$ & -- & $-0.14+$ & -0.07 & -- & -0.08 \\
\hline IEP Years & -- & $-0.11+$ & -0.08 & -- & -0.07 & -0.04 & -- & -0.06 & -0.01 & -- & -0.01 & 0.02 \\
\hline$R^{2}$ & 0.01 & 0.01 & 0.02 & 0.00 & 0.00 & 0.01 & 0.01 & 0.00 & 0.01 & 0.00 & 0.00 & 0.00 \\
\hline
\end{tabular}

Individualized Education Program. Source: U.S. Department of Education, National Center for Education Statistics (NCES), Early

Childhood Longitudinal Study, Kindergarten Class of 1998-99 (ECLS-K: 1998), Kindergarten Through Eighth Grade Full Sample

Restricted-Use Data File. 


\section{Table S4.}

Separate and combined effects of IEP years (duration) and last IEP (timing) on outcomes from the ECLS-K: 2011 (n = 2,430) without covariate adjustment.

\begin{tabular}{|c|c|c|c|c|c|c|c|c|c|c|c|c|}
\hline & \multicolumn{12}{|c|}{ ECLS-K: 2011} \\
\hline & \multicolumn{3}{|c|}{ Victimization } & \multicolumn{3}{|c|}{ Social Anxiety } & \multicolumn{3}{|c|}{ Behavioral Engagement } & \multicolumn{3}{|c|}{ Peer Support } \\
\hline & Model 1 & Model 2 & Model 3 & Model 1 & Model 2 & Model 3 & Model 1 & Model 2 & Model 3 & Model 1 & Model 2 & Model 3 \\
\hline Last IEP & $0.10 * *$ & & 0.04 & 0.06 & & 0.02 & $-0.19 * * *$ & & $-0.14 * * *$ & $-0.12 * * *$ & & -0.05 \\
\hline IEP Years & & $0.12 * * *$ & $0.10 * *$ & & $0.07 * *$ & $0.07+$ & & $-0.16 * * *$ & $-0.10 * *$ & & $-0.15 * * *$ & $-0.12 * * *$ \\
\hline \multirow[t]{3}{*}{$R^{2}$} & 0.01 & 0.01 & 0.01 & 0.00 & 0.01 & 0.01 & 0.02 & 0.02 & 0.03 & 0.01 & 0.02 & 0.02 \\
\hline & \multicolumn{3}{|c|}{ Loneliness } & \multicolumn{3}{|c|}{ School Belonging } & \multicolumn{3}{|c|}{ Grit } & \multicolumn{3}{|c|}{ School Worries } \\
\hline & Model 1 & Model 2 & Model 3 & Model 1 & Model 2 & Model 3 & Model 1 & Model 2 & Model 3 & Model 1 & Model 2 & Model 3 \\
\hline Last IEP & $0.11 * *$ & & 0.05 & $-0.06+$ & & -0.02 & $-0.13 * * *$ & & $-0.10 * *$ & $0.10 * *$ & & $0.09 *$ \\
\hline IEP Years & & $0.13 * * *$ & $0.10 * *$ & & $-0.07 * *$ & -0.06 & & $-0.10 * * *$ & -0.05 & & $0.05^{*}$ & 0.01 \\
\hline$R^{2}$ & 0.01 & 0.01 & 0.01 & 0.00 & 0.00 & 0.00 & 0.01 & 0.01 & 0.01 & 0.01 & 0.00 & 0.01 \\
\hline
\end{tabular}

Individualized Education Program. Source: U.S. Department of Education, National Center for Education Statistics (NCES), ECLS-K

Kindergarten Class of 2010-2011 (ECLS-K: 2011), Kindergarten Through Fifth Grade Full Sample Restricted-Use Data File. 


\section{Table S5.}

Unweighted sample estimates and listwise proportion of missing data before multiple imputation and weighting procedures in the ECLS-K: $1998(N=17,120)$ and in the ECLS-K: $2011(N=$ $17,130)$.

\begin{tabular}{|c|c|c|c|c|}
\hline & \multicolumn{2}{|c|}{$\begin{array}{c}\text { ECLS-K: } 1998 \\
\text { Unimputed }\end{array}$} & \multicolumn{2}{|c|}{$\begin{array}{c}\text { ECLS-K: } 2011 \\
\text { Unimputed }\end{array}$} \\
\hline & $\%$ Missing & $\%$ or $\mathrm{M}(\mathrm{SD})$ & $\%$ Missing & $\%$ or $\mathrm{M}(\mathrm{SD})$ \\
\hline \multicolumn{5}{|l|}{ Predictor Variables } \\
\hline K Approaches & 9.7 & $2.99(0.63)$ & 16.8 & $2.95(0.68)$ \\
\hline K Externalizing & 14.1 & $1.61(0.63)$ & 19.0 & $1.60(0.62)$ \\
\hline $\mathrm{K}$ Internalizing & 10.9 & $1.53(0.52)$ & 19.8 & $1.46(0.49)$ \\
\hline K Achievement & 16.8 & $21.33(7.40)$ & 14.0 & $44.89(10.77)$ \\
\hline Ever IEP & 0.0 & 15.9 & 0.0 & 19.8 \\
\hline IEP Years & 0.0 & $1.86(1.07)$ & 0.0 & $2.61(1.68)$ \\
\hline Last IEP & 0.0 & $3.39(1.39)$ & 0.0 & $4.39(1.81)$ \\
\hline LD Services & 5.0 & 7.1 & 9.2 & 6.1 \\
\hline SLI Services & 5.0 & 6.5 & 9.1 & 8.2 \\
\hline ED Services & 5.0 & 0.8 & 9.2 & 1.1 \\
\hline ASD Services & 5.0 & 1.3 & 9.2 & 3.4 \\
\hline LI Services & 5.0 & 1.1 & 9.1 & 1.4 \\
\hline Male & 0.0 & 51.2 & 0.2 & 51.2 \\
\hline Race/Ethnicity & 0.2 & & 0.2 & \\
\hline White & & 57.0 & & 47.1 \\
\hline Black & & 14.0 & & 12.9 \\
\hline Hispanic & & 17.3 & & 25.5 \\
\hline Asian & & 7.5 & & 8.8 \\
\hline Other & & 4.2 & & 5.4 \\
\hline SES & 4.5 & $0.03(0.80)$ & 11.2 & $-0.05(0.82)$ \\
\hline \multicolumn{5}{|l|}{ Outcome Variables } \\
\hline Peer Victim & -- & -- & 34.5 & $1.98(0.92)$ \\
\hline Social Anxiety & -- & -- & 34.5 & $2.15(1.16)$ \\
\hline Behavioral Engage. & -- & -- & 34.4 & $4.30(0.55)$ \\
\hline
\end{tabular}




\begin{tabular}{lcccc} 
Peer Support & -- & -- & 34.4 & $4.04(0.86)$ \\
Loneliness & -- & -- & 34.5 & $1.67(0.94)$ \\
Belonging & 45.7 & $3.07(0.55)$ & 34.4 & $3.27(0.57)$ \\
Grit & -- & -- & 34.4 & $4.17(0.70)$ \\
Worries & -- & -- & 34.4 & $2.28(0.70)$ \\
Reading Comp. & 46.0 & $2.54(0.74)$ & -- & -- \\
Math Competency & 46.0 & $2.64(0.89)$ & -- & -- \\
Internalizing & 46.0 & $2.04(0.54)$ & -- & -- \\
Locus of Control & 46.1 & $-0.00(0.62)$ & -- & -- \\
Self-Concept & 46.1 & $0.00(0.69)$ & -- & -- \\
Educ Attainment & 54.3 & $5.30(1.29)$ & -- & -- \\
Peer Relationships & 45.7 & $3.07(0.55)$ & -- & -- \\
Auxiliary Variables & & & & \\
Young Mom & 19.8 & 8.5 & 28.5 & 10.7 \\
Single Parent & 10.0 & 14.0 & 25.7 & 27.5 \\
Pre-K/Head Start & 14.3 & 15.6 & 11.4 & 80.2 \\
Achieve. $8^{\text {th }} / 5^{\text {th }}$ & 46.2 & $156.76(23.02)$ & 34.4 & $127.83(15.66)$ \\
K Interpersonal & 11.9 & $2.98(0.63)$ & 22.8 & $3.00(0.64)$ \\
Mom Education & 6.0 & $4.29(1.79)$ & 11.2 & $4.60(1.90)$ \\
Premature Birth & 15.3 & 16.6 & 27.3 & 19.8 \\
\hline
\end{tabular}

Note: $\mathrm{M}=$ Mean, $\mathrm{SD}=$ Standard deviation. IEP = Individualized Education Program; $\mathrm{LD}=$ Learning Disability; SLI = Speech or Language Impairment; ED = Emotional Disturbance; ASD $=$ Autism Spectrum Disorder; LI = Low Incidence disability. Two auxiliary variables used in the multiple imputation procedures differed in the ECLS-K: 1998 and 2011 datasets, which is why their estimates differ in this table. Parents were asked whether the child had been enrolled in Head Start (yes/no) in the ECLS-K: 1998, but in the ECLS-K: 2011, parents were asked whether their child had received pre-kindergarten childcare (yes/no). Academic achievement (average of math and reading scores) at the final wave of data collection was also included as an auxiliary variable in imputation procedures. This was $8^{\text {th }}$ grade achievement in the ECLS-K: 1998 , and $5^{\text {th }}$ grade achievement in the ECLS-K: 2011. Source: U.S. Department of Education, National Center for Education Statistics (NCES), Early Childhood Longitudinal Study, Kindergarten Class of 1998-99 (ECLS-K: 1998), Kindergarten Through Eighth Grade Full Sample RestrictedUse Data File, and ECLS-K Kindergarten Class of 2010-2011 (ECLS-K: 2011), Kindergarten Through Fifth Grade Full Sample Restricted-Use Data File. 
Table S6.

Unweighted full samples and weighted subsamples mean values following multiple imputation procedures.

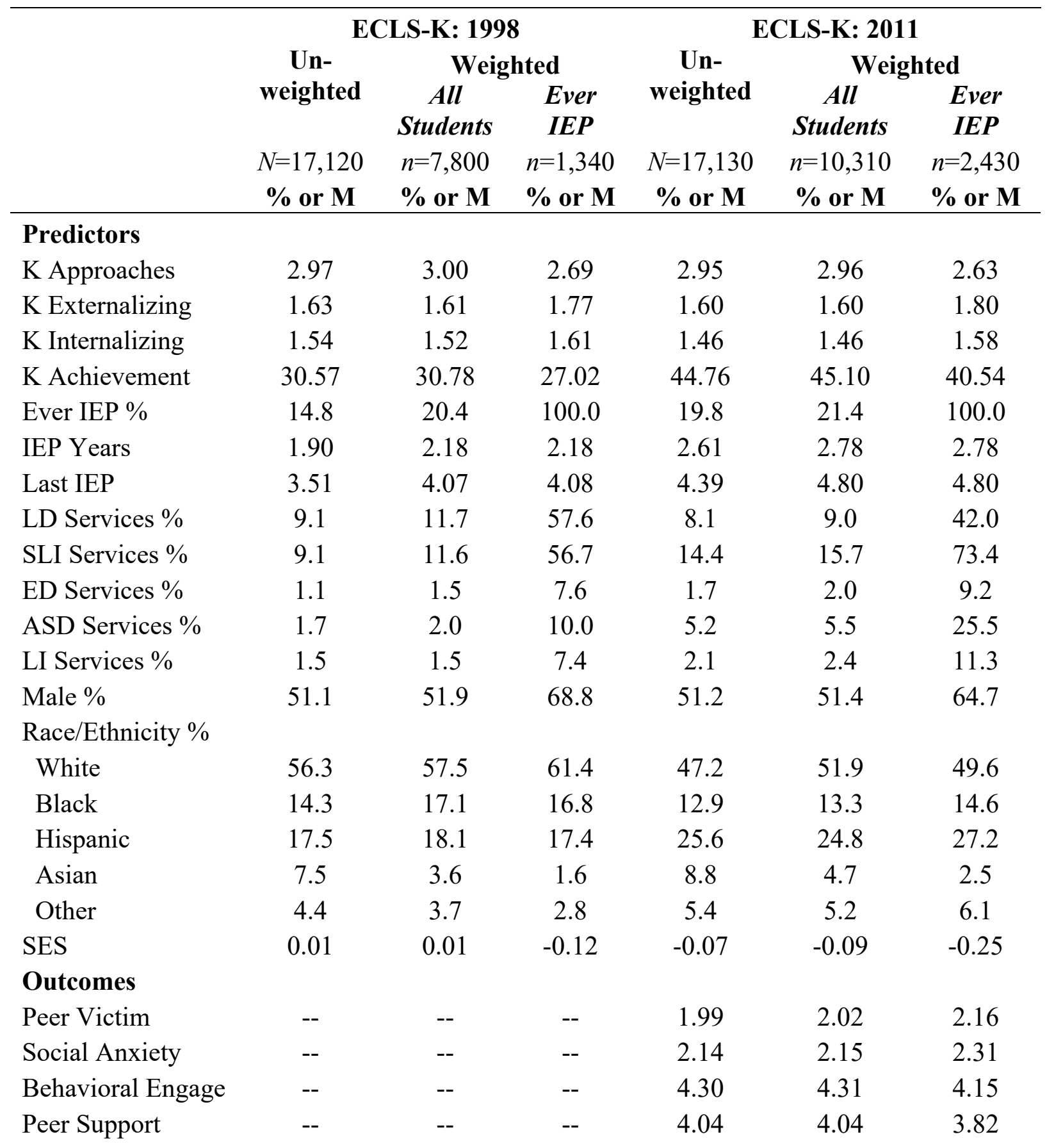




\begin{tabular}{lcccccc} 
Loneliness & -- & -- & -- & 1.67 & 1.69 & 1.86 \\
School Belonging & 3.06 & 3.06 & 2.93 & 3.27 & 3.26 & 3.17 \\
Grit & -- & -- & -- & 4.18 & 4.18 & 4.01 \\
School Worries & -- & -- & -- & 2.28 & 2.28 & 2.42 \\
Reading Comp. & 2.52 & 2.53 & 2.42 & -- & -- & -- \\
Math Competency & 2.62 & 2.60 & 2.57 & -- & -- & -- \\
Internalizing & 2.05 & 2.03 & 2.10 & -- & -- & -- \\
Locus of Control & -0.03 & -0.03 & -0.25 & -- & -- & -- \\
Self-Concept & -0.02 & -0.01 & -0.17 & -- & -- & -- \\
Educ Attainment & 5.17 & 5.12 & 4.60 & -- & -- & -- \\
Peer Relationships & 3.78 & 3.78 & 3.56 & -- & -- & -- \\
Auxiliary Vars. & & & & & & \\
Young Mom \% & 11.8 & 11.7 & 15.9 & 11.5 & 11.1 & 13.3 \\
Single Parent \% & 14.6 & 30.4 & 17.2 & 28.6 & 28.3 & 32.8 \\
Pre-K/Head Start & 16.6 & 17.5 & 21.5 & 80.0 & 80.5 & 79.9 \\
Achieve. $8^{\text {th }} 5^{\text {th }}$ & 154.74 & 153.30 & 137.64 & 127.81 & 127.69 & 117.10 \\
K Interpersonal & 2.96 & 3.00 & 2.82 & 2.98 & 3.00 & 2.78 \\
Mom Education & 4.25 & 4.30 & 3.93 & 4.56 & 4.55 & 4.21 \\
Premature Birth \% & 16.8 & 16.9 & 19.6 & 19.8 & 19.6 & 24.2 \\
\hline
\end{tabular}

Note: $\%$ or $\mathrm{M}=$ Percent or mean pooled across $m=40$ imputations. Auxiliary vars $=$ variables used in multiple imputation procedures but not in regression analyses. IEP $=$ Individualized Education Program; $\mathrm{LD}=$ Learning Disability; $\mathrm{SLI}=$ Speech or Language Impairment; $\mathrm{ED}=$ Emotional Disturbance; ASD = Autism Spectrum Disorder; LI = Low Incidence disability. Source: U.S. Department of Education, National Center for Education Statistics (NCES), Early Childhood Longitudinal Study, Kindergarten Class of 1998-99 (ECLS-K: 1998), Kindergarten Through Eighth Grade Full Sample Restricted-Use Data File, and ECLS-K Kindergarten Class of 2010-2011 (ECLS-K: 2011), Kindergarten Through Fifth Grade Full Sample Restricted-Use Data File. 
Table S7.

Regression of ECLS-K: $19988^{\text {th }}$ grade self-reported outcomes on IEP characteristics among SWD with interactions between IEP characteristics and disability type $(\mathrm{n}=1,340)$.

\begin{tabular}{lcccc}
\hline & $\begin{array}{c}\text { Reading } \\
\text { Competency }\end{array}$ & $\begin{array}{c}\text { Math } \\
\text { Competency }\end{array}$ & Internalizing & $\begin{array}{c}\text { Locus of } \\
\text { Control }\end{array}$ \\
\hline IEP Avg & 0.12 & 0.07 & -0.16 & -0.09 \\
LD Services & 0.02 & -0.03 & 0.02 & -0.10 \\
SLI Services & 0.18 & 0.05 & 0.03 & -0.06 \\
ED Services & -0.21 & -0.16 & -0.14 & -0.25 \\
ASD Services & 0.23 & 0.09 & -0.07 & 0.24 \\
LI Services & 0.04 & 0.17 & 0.23 & -0.10 \\
LD*IEP & $-0.23+$ & -0.03 & 0.08 & 0.04 \\
SLI*IEP & -0.02 & 0.08 & $0.25+$ & -0.10 \\
ED*IEP & 0.01 & 0.06 & 0.28 & 0.03 \\
ASD*IEP & -0.02 & 0.06 & -0.03 & -0.01 \\
LI*IEP & -0.06 & -0.21 & -0.08 & 0.13 \\
K Approaches & 0.03 & $0.16+$ & -0.01 & 0.04 \\
K Externalizing & 0.02 & 0.02 & 0.02 & -0.04 \\
K Internalizing & -0.01 & -0.03 & 0.07 & 0.06 \\
K Achievement & $0.21 * * *$ & 0.06 & -0.09 & $0.17 * *$ \\
Male & $-0.21 *$ & 0.17 & $-0.48 * * *$ & 0.13 \\
Black NH & 0.20 & $0.42^{* *}$ & 0.06 & -0.17 \\
Hispanic & -0.05 & 0.12 & 0.00 & -0.14 \\
Asian & 0.36 & 0.02 & 0.22 & -0.42 \\
Other & -0.12 & -0.29 & -0.04 & -0.02 \\
SES & $0.14+$ & 0.08 & $-0.22 * *$ & $0.22^{* * *}$ \\
$R-S q u a r e$ & 0.14 & 0.09 & 0.12 & 0.15 \\
\hline
\end{tabular}


(continued)

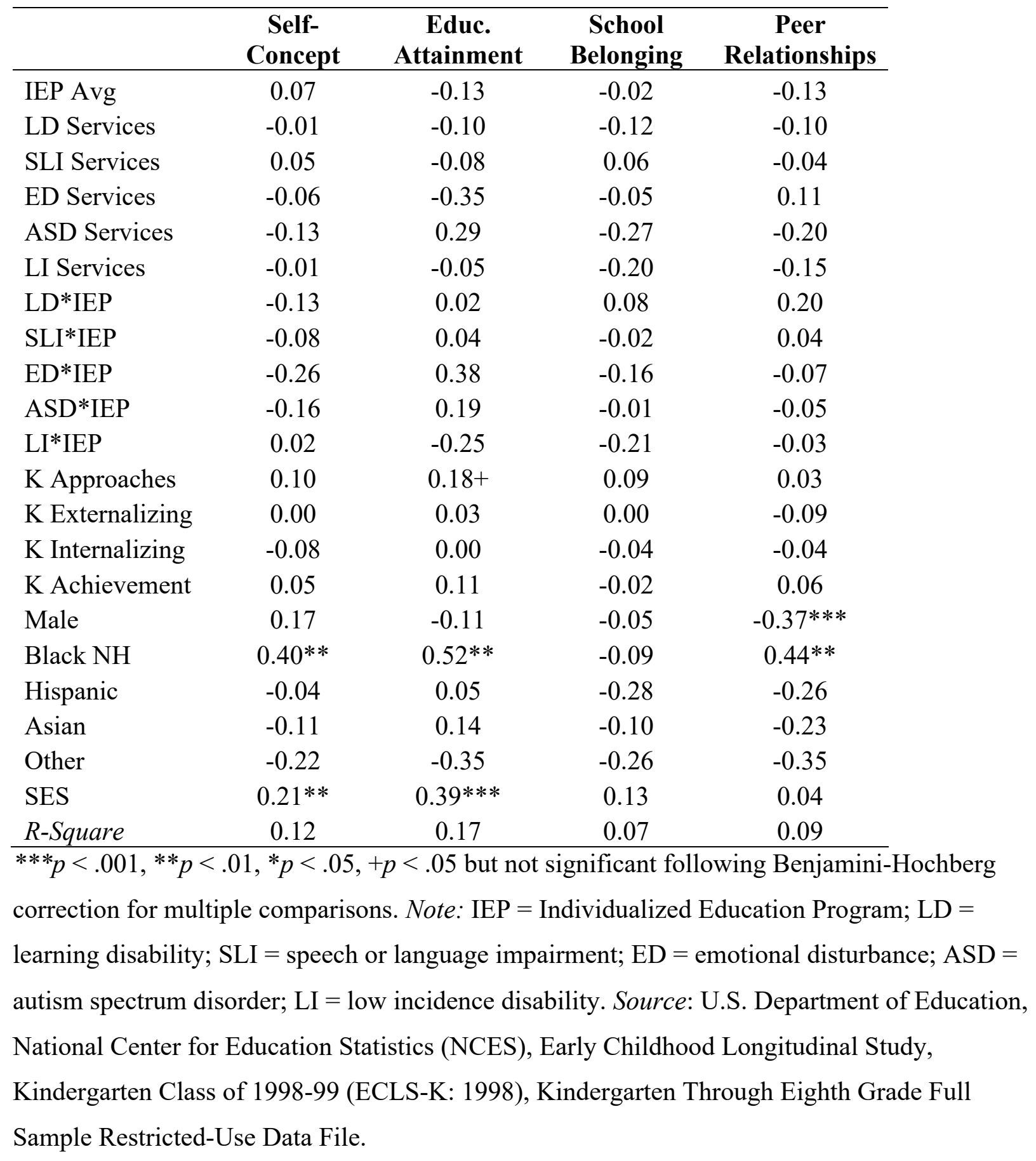


Table S8.

Regression of ECLS-K: $20115^{\text {th }}$ grade self-reported outcomes on IEP characteristics among

SWD with interactions between IEP characteristics and disability type $(\mathrm{n}=2,430)$.

\begin{tabular}{lcccc}
\hline & $\begin{array}{c}\text { Peer } \\
\text { Victimization }\end{array}$ & $\begin{array}{c}\text { Social } \\
\text { Anxiety }\end{array}$ & $\begin{array}{c}\text { Peer } \\
\text { Support }\end{array}$ & $\begin{array}{c}\text { Behavioral } \\
\text { Engagement }\end{array}$ \\
\hline IEP Avg & 0.03 & 0.09 & -0.02 & -0.12 \\
LD Services & -0.16 & -0.03 & 0.15 & -0.08 \\
SLI Services & 0.02 & 0.05 & 0.07 & 0.09 \\
ED Services & 0.20 & 0.13 & -0.15 & -0.31 \\
ASD Services & 0.03 & 0.08 & -0.15 & -0.11 \\
LI Services & -0.02 & 0.02 & -0.01 & -0.12 \\
LD*IEP & 0.07 & -0.07 & -0.09 & 0.08 \\
SLI*IEP & 0.01 & -0.07 & -0.05 & 0.01 \\
ED*IEP & -0.06 & 0.01 & -0.03 & 0.13 \\
ASD*IEP & 0.02 & 0.02 & -0.01 & -0.08 \\
LI*IEP & 0.01 & 0.07 & 0.03 & -0.04 \\
K Approaches & -0.08 & -0.05 & $0.15 * * *$ & $0.12 * *$ \\
K Externalizing & $0.14 * * *$ & $0.08+$ & -0.02 & 0.02 \\
K Internalizing & $-0.07 *$ & -0.01 & -0.02 & -0.04 \\
K Achievement & -0.07 & $-0.08+$ & 0.03 & 0.05 \\
Male & -0.10 & $-0.38 * * *$ & 0.02 & $-0.20 * * *$ \\
Black NH & 0.10 & $-0.30 * *$ & -0.14 & -0.06 \\
Hispanic & $-0.30 * * *$ & $-0.20 * *$ & 0.04 & $-0.16+$ \\
Asian & -0.01 & $-0.23+$ & $-0.30+$ & $-0.49 * * *$ \\
Other & 0.05 & -0.09 & 0.01 & -0.21 \\
SES & $-0.13 * * *$ & $-0.11 * *$ & $0.09 *$ & $0.11 * *$ \\
$R$-Square & 0.08 & 0.07 & 0.07 & 0.10 \\
\hline
\end{tabular}


(continued)

\begin{tabular}{|c|c|c|c|c|}
\hline & Grit & $\begin{array}{c}\text { School } \\
\text { Worries }\end{array}$ & Loneliness & $\begin{array}{c}\text { School } \\
\text { Belonging }\end{array}$ \\
\hline IEP Avg & -0.06 & -0.05 & -0.07 & -0.01 \\
\hline LD Services & -0.03 & 0.13 & -0.04 & 0.07 \\
\hline SLI Services & 0.04 & -0.15 & -0.07 & 0.07 \\
\hline ED Services & -0.29 & 0.28 & 0.14 & -0.21 \\
\hline ASD Services & -0.16 & -0.05 & 0.15 & -0.06 \\
\hline LI Services & -0.12 & 0.07 & 0.02 & -0.02 \\
\hline LD*IEP & 0.01 & -0.07 & 0.09 & 0.01 \\
\hline SLI*IEP & 0.01 & 0.06 & 0.11 & -0.01 \\
\hline ED*IEP & 0.09 & 0.02 & 0.02 & 0.01 \\
\hline ASD*IEP & -0.04 & 0.06 & 0.04 & -0.02 \\
\hline LI*IEP & -0.02 & 0.00 & 0.02 & -0.01 \\
\hline K Approaches & $0.13 * * *$ & -0.06 & -0.02 & 0.07 \\
\hline K Externalizing & 0.03 & 0.01 & $0.08+$ & -0.06 \\
\hline K Internalizing & -0.03 & -0.02 & 0.03 & -0.02 \\
\hline K Achievement & -0.02 & $-0.15 * * *$ & -0.03 & 0.02 \\
\hline Male & -0.09 & $-0.22 * * *$ & $-0.27 * * *$ & -0.04 \\
\hline Black NH & 0.08 & -0.03 & -0.19 & 0.12 \\
\hline Hispanic & -0.12 & 0.12 & $-0.21 * *$ & 0.06 \\
\hline Asian & -0.24 & -0.16 & -0.18 & -0.21 \\
\hline Other & -0.13 & 0.23 & -0.10 & 0.11 \\
\hline SES & $0.09 *$ & $-0.11 * *$ & $-0.12 * *$ & $0.09 *$ \\
\hline$R$-Square & 0.05 & 0.09 & 0.05 & 0.04 \\
\hline \multicolumn{5}{|c|}{$* * * p<.001, * * p<.01,{ }^{*} p<.05,+p<.05$ but not significant following Benjamini-Hochberg } \\
\hline \multirow{2}{*}{\multicolumn{5}{|c|}{$\begin{array}{l}\text { learning disability; SLI = speech or language impairment; ED = emotional disturbance; ASD = } \\
\text { autism spectrum disorder; LI = low incidence disability. Source: U.S. Department of Education, }\end{array}$}} \\
\hline & & & & \\
\hline \multicolumn{5}{|c|}{ National Center for Education Statistics (NCES), Early Childhood Longitudinal Study, } \\
\hline \multicolumn{5}{|c|}{ Kindergarten Class of 2010-11 (ECLS-K: 2011), Kindergarten Through Fifth Grade Full Sample } \\
\hline \multicolumn{5}{|c|}{ Restricted-Use Data File. } \\
\hline
\end{tabular}




\section{Stata Code}

$* * * * * * * * * * * * * * * * * * * * *$

$* * * *$ ECLS-K: $1998 * * * *$

$* * * * * * * * * * * * * * * * * * * * *$

keep childid c7cw0 c1_7fc0 c2_7fc0 u2riep u4riep u5riep u6riep f7riep gender race t1learn tlextern t1 intern t1 interp p1hmafb r1_kage p1numsib p2marsta wkmomed wksesl p1hsever p1 premat c1rscale c1mscale c7r4rscl c 7r4mscl c7sdqrdc c7sdqmtc c7sdqint c7locus c7concpt c7howfar c7fitin c7closcl c7clostc c7enjoy c7safe c7clsfr c7clslik c7clsfel e*prmdis e*1rndis $\mathrm{e}^{*}$ emtprb e*spchln $\mathrm{e}^{*}$ mntrtr $\mathrm{e}^{*}$ blnvsl $\mathrm{e}^{*}$ deafhh $\mathrm{e}^{*}$ hlthim $\mathrm{e}^{*}$ physim $\mathrm{e}^{*}$ mltim $\mathrm{e}^{*}$ dfblnd $\mathrm{e}^{*}$ devdly $\mathrm{e}^{*}$ autism $\mathrm{e}^{*}$ brain

**Recoding**

*Covariates

//gender

recode gender $(-9=)(2=0)$, gen (male)

//fall $\mathrm{K}$ behavior

clonevar learn $1=\mathrm{t}$ 1learn if $\mathrm{t} 1$ learn $>0$

clonevar interp $1=\mathrm{t} 1$ interp if $\mathrm{t} 1$ interp $>0$

clonevar extern $1=\mathrm{t} 1$ extern if $\mathrm{t} 1$ extern $>0$

clonevar intern $1=\mathrm{t}$ lintern if $\mathrm{t} 1$ intern $>0$

//Achievement

recode $\mathrm{c} 7 \mathrm{r} 4 \mathrm{rscl}(-9=).(-1=),. \operatorname{gen}(\operatorname{read} 7)$

recode c $7 \mathrm{r} 4 \mathrm{mscl}(-9=).(-1=$.$) , gen (math7)$

gen achieve $7=(\operatorname{read} 7+$ math 7$) / 2$

recode c1rscale $(-9=)(-1=)$, gen $($ read 1$)$

recode c1mscale $(-9=)(-1=$.), gen (math1)

gen achieve $1=(\operatorname{read} 1+$ math 1$) / 2$

foreach var of varlist learn1 interp1 extern1 intern1 achieve1 achieve7 \{

egen $z^{\prime} \operatorname{var}^{\prime}=\operatorname{std}\left({ }^{\prime} v^{\prime} r^{\prime}\right)$

\}

$/ /$ race

tab race, missing

rename race race_og

recode race_og $(-9=).(4=3)(5=4)(6=4)(7=5)(8=5)$, gen(race)

label define race 1 "White" 2 "Black" 3 "Hispanic" 4 "Asian" 5 "Other", replace

label values race race

//mom age

clonevar youngma $=\mathrm{p} 1 \mathrm{hmafb}$ if $\mathrm{p} 1 \mathrm{hmafb}>0$ 
$/ /$ single

recode p2marsta $(1=0)(5=0)(2=1)(3=1)(4=1)(-9=).(7=$.), gen (single)

$/ /$ pre-k

clonevar headst $=\mathrm{p} 1$ hsever if $\mathrm{p} 1 \mathrm{hsever}>0$

//Maternal ed

clonevar momed $=$ wkmomed if wkmomed $>0$

//SES

clonevar ses $=$ wksesl if wksesl $>-9$

//premature birth

recode p1premat $(-9=).(-8=).(-7=).(2=0)$, gen(premat)

*Key Predictors

//Special Ed

recode u2riep $(-9=)$. $(2=0)$, gen(iep2)

recode u4riep $(-9=$.) $(-8=$.) $(-1=$.) $(2=0)$, gen(iep4)

recode u5riep $(-9=$.) $(-8=$.) $(-1=)(2=0)$, gen $($ iep5 $)$

recode u6riep $(-9=$.) $(-8=$.) $(-1=)(2=0)$, gen $($ iep6)

recode f7riep $(-9=)(-8=).(-1=)(2=0)$, gen $($ iep 7$)$

egen sped_dos $=$ rowtotal(iep2 iep4 iep5 iep6 iep7)

replace sped_dos $=$. if iep2 $==. \&$ iep $4==$. \& iep $5==$. \& iep6 $==$. \& iep $7==$.

gen sped_rec $=1$ if iep2 $==1$

replace sped_rec $=2$ if iep $4==1$

replace sped rec $=3$ if iep $5==1$

replace sped_rec $=4$ if iep $6==1$

replace sped_rec $=5$ if iep $7==1$

label define timing 1 "Kindergarten" 2 "First" 3 "Second" 4 "Third" 5 "Fourth" 6 "Fifth"

label values sped_rec timing

gen eversped $=0$

replace eversped $=1$ if iep2==1 | iep $4==1 \mid$ iep5 $==1 \mid$ iep6==1 | iep7==1

replace eversped $=$. if iep $2==$. \& iep $4==$. \& iep $5==$. \& iep6 $==$. \& iep $7==$.

//Disability type

foreach var of varlist $\mathrm{e}^{*}$ lrndis $\mathrm{e}^{*}$ emtprb $\mathrm{e}^{*}$ spchln $\mathrm{e}^{*}$ mntrtr $\mathrm{e}^{*}$ blnvsl $\mathrm{e}^{*}$ deafhh $\mathrm{e}^{*}$ hlthim $\mathrm{e}^{*}$ physim $\mathrm{e}^{*}$ mltim $\mathrm{e}^{*}$ dfblnd $\mathrm{e}^{*}$ devdly $\mathrm{e}^{*}$ autism $\mathrm{e}^{*}$ brain \{

recode 'var' $(-9=$.) $(-8=).(-1=$.) $(2=0)$, gen ('var'r $)$ 
//ever

gen everlrndis $=($ e21rndisr $==1 \mid$ e4lrndisr $==1 \mid$ e51rndisr $==1 \mid$ e61rndisr $==1 \mid$ e7lrndisr $==1)$ replace everlrndis $=$. if e21rndisr $==$. \& e4lrndisr $==$. \& e5lrndisr $==$. \& e6lrndisr $==$. \& e 7lrndisr $==$. gen everemtprb $=($ e2emtprbr $==1 \mid$ e4emtprbr= $=1 \mid$ e5emtprbr $==1 \mid$ e6emtprbr $==1 \mid$

e7emtprbr==1)

replace everemtprb $=$. if e2emtprbr $==$. \& e4emtprbr $==$. \& e5emtprbr $==$. \& e6emtprbr $==$. \& e7emtprbr $==$.

gen everspchln $=($ e2spchlnr==1 | e4spchlnr==1 | e5spchlnr==1 | e6spchlnr==1 | e7spchlnr==1) replace everspchln $=$. if e2spchlnr $==. \&$ e 4 spchlnr $==. \&$ e5spchlnr $==. \&$ e6spchlnr $==. \&$ e7spchlnr $==$. gen evermntrtr $=($ e 2 mntrtrr $==1 \mid$ e4mntrtrr==1 | e5mntrtrr==1 | e6mntrtrr $==1 \mid$ e 7 mntrtrr==1) replace evermntrtr $=$. if e 2 mntrtrr $==. \&$ e 4 mntrtrr $==. \&$ e 5 mntrtrr $==. \&$ e 6 mntrtrr $==. \&$ e 7 mntrtrr $==$. gen everasddev $=($ e2autismr $==1 \mid$ e4autismr $==1 \mid$ e5autismr $==1$ | e6autismr==1 | e7autismr==1 | e2devdlyr==1 | e4devdlyr==1 | e5devdlyr==1 | e6devdlyr==1 | e7devdlyr==1) replace everasddev $=$. if e2autismr $==$. \& e4autismr $==$. \& e5autismr $==$. \& e6autismr $==$. \& e7autismr $==. \&$ e 2devdlyr $==$. \& e4devdlyr $==$. \& e5devdlyr $==. \&$ e6devdlyr $==. \&$ e7devdlyr $==$. gen everlowinc $=(\mathrm{e} 2 \mathrm{~b} \ln v \operatorname{sir}==1 \mid$ e4blnvs1r $==1 \mid$ e 5 blnvslr $==1 \mid$ e6blnvslr $==1 \mid$ e 7 blnvslr $==1 \mid$ e2deafhhr==1 | e4deafhhr==1 | e5deafhhr==1 | e6deafhhr==1 | e7deafhhr==1 | e2physimr==1 | e4physimr $==1 \mid$ e 5 physimr $==1 \mid$ e6physimr $==1 \mid$ e 7 physimr $==1 \mid$ e2mltimr $==1 \mid$ e4mltimr==1 | e5mltimr $==1 \mid$ e6mltimr $==1$ | e 7 mltimr==1 | e2mltimr==1 | e4mltimr==1 | e 5mltimr==1 | e6mltimr==1 | e7mltimr==1 | e2brainr==1 | e4brainr==1 | e5brainr==1 | e6brainr==1 | e7brainr $==1$ ) replace everlowinc $=$. if e2blnvslr $==$. \& e4blnvslr $==$. \& e 5blnvslr $==$. \& e6blnvslr $==$. \& e7blnvslr $==. \&$ e2deafhhr $==$. \& e4deafhhr==. \& e5deafhhr $==$. \& e6deafhhr $==. \&$ e7deafhhr== $\&$ e2physimr $==. \&$ e4physimr $==$. \& e 5 physimr $==$. \& e6physimr $==. \&$ e 7 physimr $==. \&$ e 2 mltimr $==. \&$ e4mltimr $==. \&$ e 5 mltimr $==. \&$ e 6 mltimr $==. \&$ e 7 mltimr $==. \&$ e 2 mltimr $==. \&$ e4mltimr $==. \&$ e 5 mltimr $==$. \& e6mltimr $==$. \& e 7 mltimr $==$. \& e 2 brainr $==$. \& e4brainr $==$. \& e5brainr $==$. \& e6brainr $==$. \& e 7 brainr $==$.

*Outcome variables

//Perceived Interest/Competence in Reading recode c7sdqrdc $(-9=)(-1=$.$) , gen(rcomp)$

//Perceived Interest/Competence in Math recode c 7 sdqmtc $(-9=)(-1=$.), gen (mcomp)

//Internalizing Behavior Subscale recode c7sdqint $(-9=)(-1=$.), gen(intern)

//Locus of Control recode c7locus $(-9=$.) $(-1=$.), gen(locus) 


\author{
//Self-Concept \\ recode c7concpt $(-9=).(-1=$.$) , gen (concept)$ \\ //How far do you think you will go in school? \\ recode c7howfar $(-9=)(-8=).(-1=$.$) , gen(attain)$ \\ //School Belongingness \\ recode c7fitin $(-9=)(-1=)$, gen(fitin) \\ recode c7closcl $(-9=)(-1=)$, gen $($ closcl $)$ \\ recode c7clostc $(-9=)(-1=)$, gen $($ lostc $)$ \\ recode c7enjoy $(-9=)(-1=)$, gen(enjoy) \\ recode c 7 safe $(-9=$.) $(-1=$.), gen (safe) \\ alpha fitin closcl lostc enjoy safe, gen(belong) \\ //Peer Relationships \\ recode c 7 clsfr $(-9=)(-1=$.), gen (clsfr) \\ recode c7clslik $(-9=)(-1=)$, gen (clslik) \\ recode c7clsfel $(-9=)(-1=$.$) , gen (clsfel)$ \\ alpha clsfr clslik clsfel, gen(peers)
}

***Impute data***

mdesc male learn 1 extern1 intern 1 interp1 achieve1 youngma single headst achieve7 momed ses premat rcomp mcomp intern locus concept attain belong peers race sped_rec sped_dos lrndis spchln everlrndis everspchln everemtprb everasddev everlowinc if eversped $\sim=$.

drop if eversped $==$.

mi set mlong

mi register imputed male learn1 extern 1 intern 1 interp 1 achieve1 youngma single headst achieve 7 momed ses premat rcomp mcomp intern locus concept attain belong peers race sped_rec sped_dos lrndis spchln everlrndis everspchln everemtprb everasddev everlowinc eversped

mi impute chained (pmm, knn(10)) rcomp mcomp intern locus concept attain belong peers eversped achieve7 momed ses learn1 interp1 extern1 intern1 achieve1 male youngma single premat headst race lrndis spchln everlrndis everspchln everemtprb everasddev everlowinc, $\operatorname{add}(40) \operatorname{rseed}(53421)$ dots

replace everlrndis $=0$ if eversped $=0$

replace everspchln $=0$ if eversped $=0$

replace everemtprb $=0$ if eversped $=0$

replace everasddev $=0$ if eversped $==0$

replace everlowinc $=0$ if eversped $=0$ 


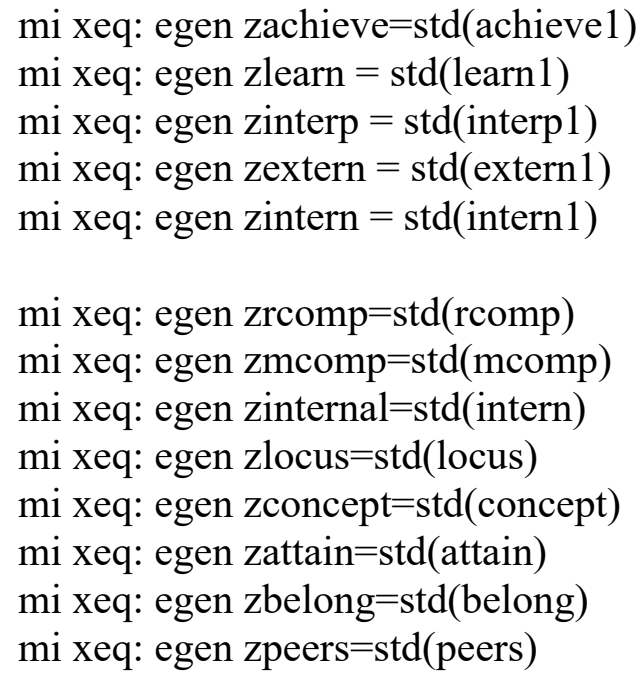

** Gen Ed Sample 
*1) Ever IEP

foreach var of varlist zrcomp zmcomp zinternal zlocus zconcept zattain zbelong zpeers \{

mi estimate: regress 'var' i.eversped [pweight $=\mathrm{c} 1 \_7 \mathrm{fc} 0$ ] // Regressions

regress 'var' i.eversped [pweight $=\mathrm{c} 1$ _ $7 \mathrm{fc} 0]$ if_mi_m $==7 / /$ R-squared

\}

*2) Ever IEP + full

foreach var of varlist zrcomp zmcomp zinternal zlocus zconcept zattain zbelong zpeers \{

mi estimate: regress 'var' i.eversped zlearn zextern zintern zachieve i.male i.race ses

[pweight $\left.=\mathrm{c} 1 \_7 \mathrm{fc} 0\right] / /$ Regression

regress 'var' i.eversped zlearn zextern zintern zachieve i.male i.race ses [pweight $=\mathrm{c} 1 \_7 \mathrm{fc} 0$ ] if _mi_m==7//R-squared $\bar{\xi}$

*3) Ever services

foreach var of varlist zrcomp zmcomp zinternal zlocus zconcept zattain zbelong zpeers \{

mi estimate: regress 'var' i.everlrndis i.everspchln i.everemtprb i.everasddev i.everlowinc

[pweight $\left.=\mathrm{c} 1 \_7 \mathrm{fc} 0\right] / /$ Regression

regress 'var' i.everlrndis i.everspchln i.everemtprb i.everasddev i.everlowinc [pweight $=\mathrm{c} 1 \_7 \mathrm{fc} 0$ ]

if_mi_m==7 // R-squared

\}

*4) Ever services + full

foreach var of varlist zrcomp zmcomp zinternal zlocus zconcept zattain zbelong zpeers \{

mi estimate: regress 'var' i.everlrndis i.everspchln i.everemtprb i.everasddev i.everlowinc zlearn zextern zintern zachieve i.male i.race ses [pweight $\left.=\mathrm{c} 1 \_7 \mathrm{fc} 0\right] / /$ Regression

regress 'var' i.everlrndis i.everspchln i.everemtprb i.everasddev i.everlowinc zlearn zextern zintern zachieve i.male i.race ses [pweight $\left.=\mathrm{c} 1 \_7 \mathrm{fc} 0\right]$ if_mi_m==7// R-squared

\}

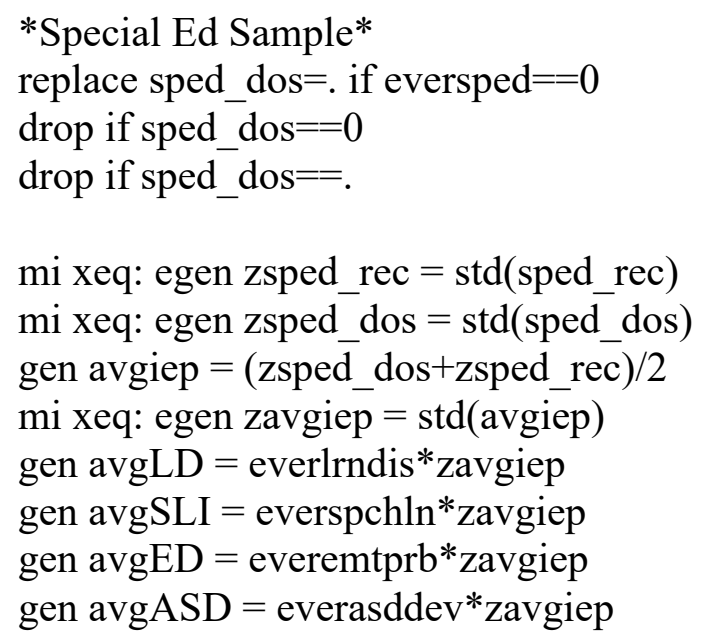


gen $\operatorname{avgLI}=$ everlowinc*zavgiep

*Analyses

//descriptives

mi estimate: mean learn1 extern1 intern1 interp1 achieve1 achieve 7 momed ses rcomp mcomp intern locus concept attain belong peers sped_dos sped_rec [pweight $=\mathrm{c} 1$ _ $7 \mathrm{fc} 0$ ]

mi estimate: prop male youngmom single headst premat race everlrndis everspchln everemtprb everasddev everlowinc [pweight $\left.=\mathrm{c} 1 \_7 \mathrm{fc} 0\right]$

//correlations

corr sped_dos sped_rec everlrndis everspchln everemtprb everasddev everlowinc rcomp mcomp intern locus concept attain belong peers male white black hisp asian other ses learn1 extern1 intern 1 interp1 achieve1 youngmom single headst achieve7 momed premat if_mi_m==7 \& $\mathrm{c} 1 \_7 \mathrm{fc} 0 \sim=. \& \mathrm{c} 1 \_7 \mathrm{fc} 0>0$

*1) Last IEP

*2) IEP Years

*3) Average of two

*4) Average + full

*5) Average + full + services

foreach var of varlist zrcomp zmcomp zinternal zlocus zconcept zattain zbelong zpeers \{

// Regressions

mi estimate: regress 'var' zsped_rec [pweight $\left.=\mathrm{c} 1 \_7 \mathrm{fc} 0\right]$

mi estimate: regress 'var' zsped_dos [pweight $\left.=\mathrm{c} 1 \_7 \mathrm{fc} 0\right]$

mi estimate: regress 'var' zavgiep [pweight $\left.=\mathrm{c} 1 \_7 \overline{f c} 0\right]$

mi estimate: regress 'var' zavgiep zlearn zextern zintern zachieve i.male i.race ses

[pweight $=\mathrm{c} 1 \_7 \mathrm{fc} 0$ ]

mi estimate: regress 'var' zavgiep i.everlrndis i.everspchln i.everemtprb i.everasddev

i.everlowinc zlearn zextern zintern zachieve i.male i.race ses [pweight $=\mathrm{c} 1$ _ $7 \mathrm{fc} 0$ ]

//R-Squared

regress 'var' zsped_rec [pweight $\left.=\mathrm{c} 1 \_7 \mathrm{fc} 0\right]$ if _mi_m $==7$

regress 'var' zsped_dos [pweight $\left.=\mathrm{c}_{-}{ }_{-} 7 \mathrm{fc} 0\right]$ if $\_\mathrm{mi} \mathrm{m}==7$

regress 'var' zavgiep [pweight $\left.=\mathrm{c} 1 \_7 \overline{\mathrm{fc}} 0\right]$ if $\_\mathrm{mi} \overline{\mathrm{m}}==7$

regress 'var' zavgiep zlearn zextern zintern zachieve i.male i.race ses [pweight $=\mathrm{c} 1$ _ $7 \mathrm{fc} 0$ ] if mi_m $==7$

regress 'var' zavgiep i.everlrndis i.everspchln i.everemtprb i.everasddev i.everlowinc zlearn zextern zintern zachieve i.male i.race ses [pweight $\left.=\mathrm{c} 1 \_7 \mathrm{fc} 0\right]$ if_mi_m==7

\}

** Specific Disabilities

*1) Average + interactions

*2) model $5+$ interactions

foreach var of varlist zrcomp zmcomp zinternal zlocus zconcept zattain zbelong zpeers \{ 


\begin{abstract}
// Regressions ses [pweight $=\mathrm{c} 1 \_7 \mathrm{fc} 0$ ]

//R-Squared

\}

** Dosage/Recency knockout

$* * * * * * * * * * * * * * * * * * * * *$

$* * * *$ ECLS-K: $2011 * * * *$

$* * * * * * * * * * * * * * * * * * * * *$
\end{abstract}

mi estimate: regress 'var' zavgiep i.everlrndis i.everspchln i.everemtprb i.everasddev

i.everlowinc avgLD avgSLI avgED avgASD avgLI [pweight $=\mathrm{c} 1$ 7fc0]

mi estimate: regress 'var' zavgiep i.everlrndis i.everspchln i.everemtprb i.everasddev

i.everlowinc avgLD avgSLI avgED avgASD avgLI zlearn zextern zintern zachieve i.male i.race

regress 'var' zavgiep i.everlrndis i.everspchln i.everemtprb i.everasddev i.everlowinc avgLD avgSLI avgED avgASD avgLI [pweight $\left.=\mathrm{c} 1 \_7 \mathrm{fc0}\right]$ if_mi $\mathrm{m}==7$

regress 'var' zavgiep i.everlrndis i.everspchln i.everemtprb i.everasddev i.everlowinc avgLD avgSLI avgED avgASD avgLI zlearn zextern zintern zachieve i.male i.race ses

[pweight=c1_7fc0] if_mi_m==7

foreach var of varlist zrcomp zmcomp zinternal zlocus zconcept zattain zbelong zpeers \{

mi estimate: regress 'var' zsped_rec zsped_dos [pweight $\left.=\mathrm{c} 1 \_7 \mathrm{fc} 0\right] / /$ Regressions

regress 'var' zsped_rec zsped_dos [pweight $\left.=\mathrm{c} 1 \_7 \mathrm{fc} 0\right]$ if_mi_m $==7 / / \mathrm{R}-$ Squared

keep childid x_chsex_r x_raceth_r x 1 tchapp x1tchper x1tchext x1tchint x1rscalk5 x1mscalk5 x9rscalk5 x9mscalk5 p1oldmom p1curmar x12carepk x1numsib x12par1ed_i x12ses1 p1premat t2iep t4iep t6iep t7iepx g8iepx g9iepx c9teased c9liesabt c9pushch c9excldch c9wrythk c9wrydtlk c9afrdntlk c9hapthgs c9hapattn c9hapnbhd c9tryhrd c9wrkhrd c9pardis c9payatt c91stncl c9kidbtr c9kidply c9kidhap c9kidhlpx c9friend c9helpmn c9lonely c9lftout c9alone c9fitin c9closcl c9clostc c9enjoy c9safe c9finish c9trymst c9wkgoal c9wkhdqt c9wksetdo c9tryimprv c9wrytst c9hardfin c9ashame c9wrywel c9wryfin w9c9p_20 e*prmdis e*spchln $\mathrm{e}^{*}$ Irndis $\mathrm{e}^{*}$ emtprb $\mathrm{e}^{*}$ mntrtr $\mathrm{e}^{*}$ devdly $\mathrm{e}^{*}$ blnvsl $\mathrm{e}^{*}$ deafhh $\mathrm{e}^{*}$ orthim $\mathrm{e}^{*}$ hlthim $\mathrm{e}^{*}$ autism $\mathrm{e}^{*}$ brain $\mathrm{e}^{*}$ dfblnd $\mathrm{e}^{*}$ mltim $\mathrm{e}^{*}$ adhd
**Recoding**
*Covariates
//gender
recode $x \_c h s e x \_r(-9=).(2=0)$, gen (male)
//fall K behavior
clonevar learn $1=x 1$ tchapp if $x 1$ tchapp $>0$
clonevar interp $1=x 1$ tchper if $x 1$ tchper $>0$
clonevar extern $1=x 1$ tchext if $x 1$ tchext $>0$
clonevar intern $1=x 1$ tchint if $x 1$ tchint $>0$ 


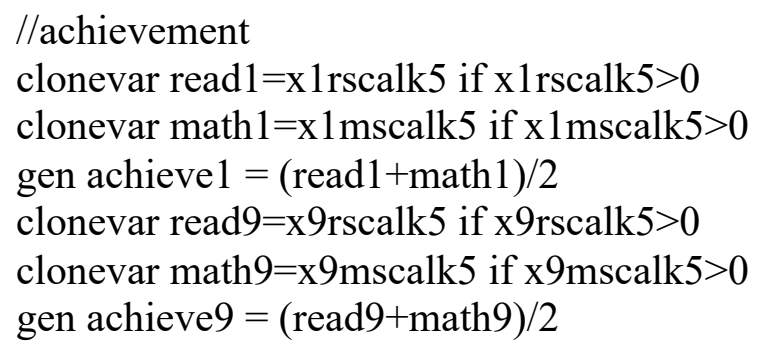


recode g8iepx $(-9=$.) $(2=0)$, gen(iep8)

recode g9iepx $(-9=$.) $(2=0)$, gen(iep9)

egen sped_dos $=$ rowtotal(iep2 iep4 iep6 iep7 iep8 iep9)

replace sped_dos $=$. if iep2 $==. \&$ iep $4==$. \& iep6 $==$. \& iep $7==. \&$ iep $8==. \&$ iep $9==$.

gen sped_rec $=1$ if iep $2==1$

replace sped_rec $=2$ if iep $4==1$

replace sped_rec $=3$ if iep6 $==1$

replace sped_rec $=4$ if iep $7==1$

replace sped_rec $=5$ if iep $8==1$

replace sped_rec $=6$ if iep9 $==1$

label define timing 1 "Kindergarten" 2 "First" 3 "Second" 4 "Third" 5 "Fourth" 6 "Fifth"

label values sped_rec timing

gen eversped $=0$

replace eversped $=1$ if iep2==1 | iep4 $==1 \mid$ iep6==1 | iep7==1 | iep8 $==1 \mid$ iep9==1

replace eversped $=$. if iep $2==$. \& iep $4==. \&$ iep $6==. \&$ iep $7==. \&$ iep $8==$. \& iep $9==$.

//Disability Type

${ }^{*} \mathrm{e}^{*}$ spchln $\mathrm{e}^{*}$ lrndis $\mathrm{e}^{*}$ emtprb e*mntrtr e*devdly e*blnvsl e*deafhh $\mathrm{e}^{*}$ orthim $\mathrm{e}^{*}$ hlthim e*autism $\mathrm{e}^{*}$ brain $\mathrm{e}^{*}$ dfblnd $\mathrm{e}^{*}$ mltim $\mathrm{e}^{*}$ adhd

foreach var of varlist $\mathrm{e}^{*}$ lrndis $\mathrm{e}^{*}$ emtprb $\mathrm{e}^{*} \operatorname{spchln} \mathrm{e}^{*}$ mntrtr $\mathrm{e}^{*}$ blnvsl $\mathrm{e}^{*}$ deafhh $\mathrm{e}^{*}$ hlthim $\mathrm{e}^{*}$ orthim $\mathrm{e}^{*}$ mltim $\mathrm{e}^{*}$ dfblnd $\mathrm{e}^{*}$ devdly $\mathrm{e}^{*}$ autism $\mathrm{e}^{*}$ brain $\mathrm{e}^{*}$ adhd \{

recode 'var' $(-9=).(-8=).(-1=).(2=0)$, gen( 'var'r)

\}

//ever

gen everlrndis $=($ e21rndisr $==1 \mid$ e4lrndisr $==1 \mid$ e61rndisr $==1 \mid$ e 71 rndisr $==1 \mid$ e81rndisr $==1 \mid$

e91rndisr==1)

replace everlrndis $=$. if e21rndisr $==. \&$ e4lrndisr $==. \&$ e6lrndisr $==. \&$ e 71 rndisr $==. \&$ e8lrndisr $==$. \& e91rndisr $==$.

gen everemtprb $=($ e2emtprbr $==1 \mid$ e4emtprbr==1 | e6emtprbr==1 | e7emtprbr==1 |

e8emtprbr==1 | e9emtprbr==1)

replace everemtprb $=$. if e2emtprbr $==$. \& e4emtprbr $==. \&$ e6emtprbr $==$. \& e7emtprbr $==$. \& e8emtprbr $==$. \& e9emtprbr $==$.

gen everspchln $=($ e2spchlnr==1 | e4spchlnr==1 | e6spchlnr==1 | e7spchlnr==1 | e8spchlnr==1 | e9spchlnr==1)

replace everspchln $=$. if e2spchlnr $==. \&$ e 4 spchlnr $==. \&$ e 6 spchlnr $==. \&$ e 7 spchlnr $==. \&$ e8spchlnr $==. \&$ e9spchlnr $==$.

gen evermntrtr $=($ e 2 mntrtrr $==1 \mid$ e4mntrtrr $==1 \mid$ e6mntrtrr $==1 \mid$ e 7 mntrtrr $==1 \mid$ e8mntrtrr $==1 \mid$

e9mntrtrr==1)

replace evermntrtr $=$. if e 2 mntrtrr $==. \&$ e 4 mntrtrr $==. \&$ e 6 mntrtrr $==. \&$ e 7 mntrtrr $==. \&$ e8mntrtrr $==. \&$ e9mntrtrr $==$. 
gen everasddev $=($ e2autismr $==1 \mid$ e4autismr $==1 \mid$ e6autismr $==1 \mid$ e7autismr $==1 \mid$ e8autismr $==1 \mid$ e9autismr==1 | e2devdlyr==1 | e4devdlyr==1 | e6devdlyr==1 | e7devdlyr==1 | e8devdlyr==1 | e9devdlyr $==1$ ) replace everasddev $=$. if e2autismr $==. \&$ e4autismr $==. \&$ e6autismr $==. \&$ e7autismr $==. \&$ e8autismr $==. \&$ e9autismr $==. \&$ e2devdlyr $==. \&$ e4devdlyr $==. \&$ e6devdlyr $==. \&$ e7devdlyr $==$. $\&$ e8devdlyr $==$. \& e9devdlyr $==$.

gen everlowinc $=($ e2blnvslr $==1 \mid$ e4blnvslr $==1 \mid$ e6blnvslr $==1 \mid$ e7blnvslr $==1 \mid$ e8blnvslr $==1 \mid$ e9blnvslr==1 | e2deafhhr==1 | e4deafhhr==1 | e6deafhhr==1 | e7deafhhr==1 | e8deafhhr==1 | e9deafhhr==1 | e2orthimr==1 | e4orthimr==1 | e6orthimr==1 | e7orthimr==1 | e8orthimr==1 | e9orthimr $==1$ | e2mltimr==1 | e4mltimr==1 | e6mltimr $==1$ | e7mltimr==1 | e8mltimr==1 | e9mltimr==1 | e2brainr==1 | e4brainr==1 | e6brainr==1 | e7brainr==1 | e8brainr==1 | e9brainr $==1$ ) replace everlowinc $=$. if e $2 \mathrm{~b} \ln v \operatorname{sir}==. \&$ e4blnvslr $==. \&$ e6blnvslr $==. \&$ e $7 \mathrm{~b} \ln v \operatorname{sir}==. \&$ e8blnvslr $==. \&$ e9blnvslr $==$. \& e2deafhhr $==$. \& e4deafhhr $==$. \& e6deafhhr $==$. \& e7deafhhr $==$. $\&$ e8deafhhr $==. \&$ e9deafhhr $==$. \& e2orthimr $==$. \& e4orthimr $==$. \& e6orthimr $==$. \& e7orthimr $==$. \& e8orthimr $==$. \& e9orthimr $==$. \& e2mltimr $==$. \& e4mltimr $==$. \& e6mltimr $==$. \& e 7 mltimr $==$. \& e8mltimr $==$. \& e9mltimr $==$. \& e2brainr $==$. \& e4brainr $==$. \& e6brainr $==$. \& e7brainr $==$. \& e8brainr $==. \&$ e9brainr $==$.

*Outcome variables

//Peer victimization foreach var of varlist c9teased c9liesabt c9pushch c9excldch \{ clonevar 'var'n = 'var' if 'var'>0

\} alpha c9teasedn c9liesabtn c9pushchn c9excldchn, gen(victim) // a =.81

//Social anxiety/fear of negative evaluation foreach var of varlist c9wrythk c9wrydtlk c9afrdntlk \{ clonevar 'var'n $=$ 'var' if 'var'>0 \} alpha c9wrythkn c9wrydtlkn c9afrdntlkn, gen( $\operatorname{socanx}) / / \mathrm{a}=.88$

//Life satisfaction foreach var of varlist c9hapthgs c9hapattn c9hapnbhd \{ clonevar 'var'n = 'var' if 'var'>0 \} alpha c9hapthgsn c9hapattnn c9hapnbhdn, gen(lifesat) // a =.54 -- maybe exclude this one?

//Behavioral engagement foreach var of varlist c9tryhrd c9wrkhrd c9pardis c9payatt c91stncl \{ clonevar 'var'n = 'var' if 'var'>0 \} alpha c9tryhrdn c9wrkhrdn c9pardisn c9payattn c91stncln, gen(beheng) $/ / \mathrm{a}=.73$ 
//Peer social support

foreach var of varlist c9kidbtr c9kidply c9kidhap c9kidhlpx c9friend c9helpmn \{

clonevar 'var'n = 'var' if 'var'>0

\} alpha c9kidbtrn c9kidplyn c9kidhapn c9kidhlpxn c9friendn c9helpmnn, gen(peersupp) // a $=.87$

//Loneliness

foreach var of varlist c9lonely c91ftout c9alone \{

clonevar 'var'n = 'var' if 'var'>0

\}

alpha c9lonelyn c9lftoutn c9alonen, gen(lonely) // a = .89

//School belonging

foreach var of varlist c9fitin c9closcl c9clostc c9enjoy c9safe \{

clonevar 'var'n = 'var' if 'var'>0

\}

alpha c9fitinn c9closcln c9clostcn c9enjoyn c9safen, gen(belong) $/ / \mathrm{a}=.70$

//Grit

foreach var of varlist c9finish c9trymst c9wkgoal c9wkhdqt c9wksetdo c9tryimprv \{

clonevar 'var'n = 'var' if 'var'>0

\} alpha c9finishn c9trymstn c9wkgoaln c9wkhdqtn c9wksetdon c9tryimprvn, gen(grit) // a = .83

//Worry/stress about school

foreach var of varlist c9wrytst c9hardfin c9ashame c9wrywel c9wryfin \{

clonevar 'var'n = 'var' if 'var'>0

\}

alpha c9wrytstn c9hardfinn c9ashamen c9wryweln c9wryfinn, gen(schworry) $/ / \mathrm{a}=.71$

$* * *$ Impute $* * *$

drop if eversped $==$.

mi set mlong

mi register imputed male learn 1 extern 1 intern 1 interp1 achieve1 race youngma single headst achieve9 wkmomed wksesl premat victim socanx lifesat beheng peersupp lonely belong grit schworry eversped lrndis spchln everlrndis everspchln everemtprb everasddev everlowinc mi impute chained (pmm, knn(10)) male learn 1 extern 1 intern 1 interp1 achieve 1 race youngma single headst achieve9 wkmomed wksesl premat victim socanx lifesat beheng peersupp lonely belong grit schworry eversped lrndis spchln everlrndis everspchln everemtprb everasddev everlowinc, add(40) rseed(53421) dots

mi xeq: egen $z$ achieve $=\operatorname{std}($ achieve 1$)$ 


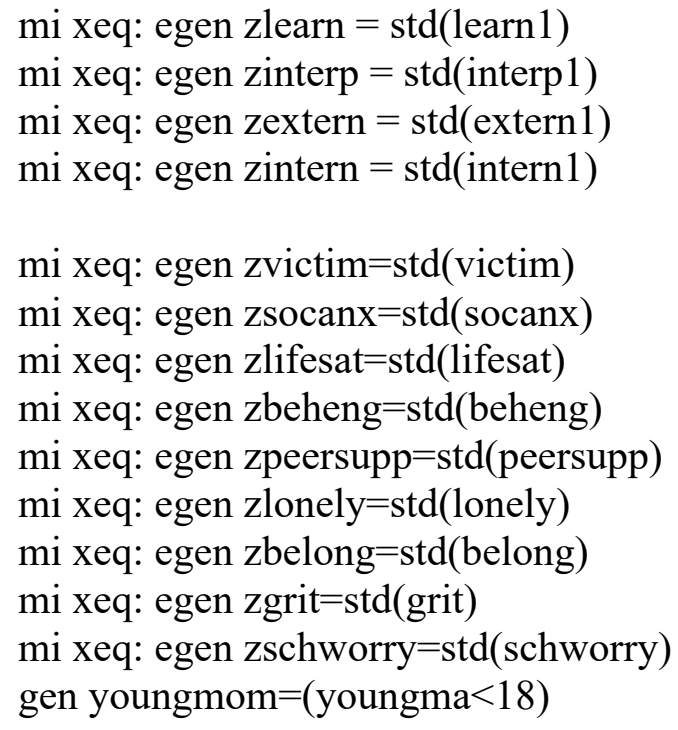


corr eversped victim socanx beheng peersupp lonely belong grit schworry male white black hisp asian other wksesl learn1 extern1 intern1 interp1 achieve1 youngmom single headst achieve9 wkmomed premat if_mi $m==7 \&$ w9c9p_20 =.\& w9c9p_20>0

\section{*Regressions \\ ** Gen Ed Sample}

*1) Ever IEP

foreach var of varlist zvictim zsocanx zbeheng zpeersupp zlonely zbelong zgrit zschworry \{ mi estimate: regress 'var' i.eversped [pweight $\left.=w 9 c 9 p \_20\right] / /$ Regression regress 'var' i.eversped [pweight $\left.=w 9 c 9 p \_20\right]$ if_mi_m==7 // R-squared \}

*2) Ever IEP + full foreach var of varlist zvictim zsocanx zbeheng zpeersupp zlonely zbelong zgrit zschworry \{ mi estimate: regress 'var' i.eversped zlearn zextern zintern zachieve i.male i.race wksesl [pweight=w9c9p_20] // Regression regress 'var' i.eversped zlearn zextern zintern zachieve i.male i.race wksesl [pweight=w9c9p_20] if_mi_m==7// R-squared \}

*3) Ever services foreach var of varlist zvictim zsocanx zbeheng zpeersupp zlonely zbelong zgrit zschworry \{ mi estimate: regress 'var' i.everlrndis i.everspchln i.everemtprb i.everasddev i.everlowinc [pweight=w9c9p_20] // Regression regress 'var' i.everlrndis i.everspchln i.everemtprb i.everasddev i.everlowinc [pweight=w9c9p_20] if_mi_m==7// R-squared \}

*4) Ever services + full foreach var of varlist zvictim zsocanx zbeheng zpeersupp zlonely zbelong zgrit zschworry \{ mi estimate: regress 'var' i.everlrndis i.everspchln i.everemtprb i.everasddev i.everlowinc zlearn zextern zintern zachieve i.male i.race wksesl [pweight=w9c9p_20] // Regression regress 'var' i.everlrndis i.everspchln i.everemtprb i.everasddev i.everlowinc zlearn zextern zintern zachieve i.male i.race wkses1 [pweight=w9c9p_20] if_mi_m==7 // R-squared

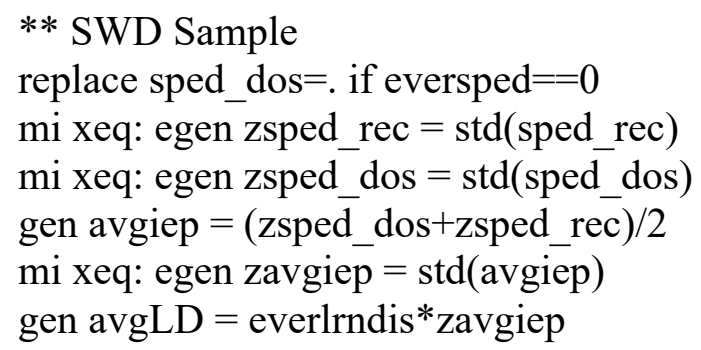


gen avgSLI $=$ everspchln*zavgiep

gen avgED = everemtprb*zavgiep

gen avgASD = everasddev*zavgiep

gen $\operatorname{avgLI}=$ everlowinc $*$ zavgiep

*1) Last IEP

*2) IEP Years

*3) Average of two

*4) Average + full

*5) Average + full + services

foreach var of varlist zvictim zsocanx zbeheng zpeersupp zlonely zbelong zgrit zschworry \{

// Regressions

mi estimate: regress 'var' zsped_rec [pweight=w9c9p_20]

mi estimate: regress 'var' zsped_dos [pweight $=$ w9c9p_20]

mi estimate: regress 'var' zavgiep [pweight=w9c9p_20]

mi estimate: regress 'var' zavgiep zlearn zextern zintern zachieve i.male i.race wksesl

[pweight=w9c9p_20]

mi estimate: regress 'var' zavgiep i.everlrndis i.everspchln i.everemtprb i.everasddev

i.everlowinc zlearn zextern zintern zachieve i.male i.race wksesl [pweight $=w 9 c 9 p \_20$ ]

// R-squared

regress 'var' zsped_rec [pweight $\left.=w 9 \mathrm{c} 9 \mathrm{p} \_20\right]$ if _mi_m $==7$

regress 'var' zsped_dos [pweight $=$ w9c9p_20] if_mi $\mathrm{m}==7$

regress 'var' zavgiep [pweight $\left.=\mathrm{w} 9 \mathrm{c} 9 \mathrm{p} \_20\right]$ if $\mathrm{mi}$ - $\mathrm{m}==7$

regress 'var' zavgiep zlearn zextern zintern zachieve i.male i.race wksesl [pweight=w9c9p_20] if_mi_m==7

regress 'var' zavgiep i.everlrndis i.everspchln i.everemtprb i.everasddev i.everlowinc zlearn

zextern 'var' zachieve i.male i.race wksesl [pweight $=$ w9c9p_20] if_mi_m==7

\}

** Specific Disabilities

*1) Average + interactions

*2) model $5+$ interactions

foreach var of varlist zvictim zsocanx zbeheng zpeersupp zlonely zbelong zgrit zschworry \{

// Regressions

mi estimate: regress 'var' zavgiep i.everlrndis i.everspchln i.everemtprb i.everasddev

i.everlowinc avgLD avgSLI avgED avgASD avgLI [pweight=w9c9p_20]

mi estimate: regress 'var' zavgiep i.everlrndis i.everspchln i.everemtprb i.everasddev

i.everlowinc avgLD avgSLI avgED avgASD avgLI zlearn zextern zintern zachieve i.male i.race wksesl [pweight=w9c9p_20]

// R-squared

regress 'var' zavgiep i.everlrndis i.everspchln i.everemtprb i.everasddev i.everlowinc avgLD avgSLI avgED avgASD avgLI [pweight=w9c9p_20] if_mi_m==7 
regress 'var' zavgiep i.everlrndis i.everspchln i.everemtprb i.everasddev i.everlowinc avgLD avgSLI avgED avgASD avgLI zlearn zextern zintern zachieve i.male i.race wksesl [pweight=w9c9p_20] if_mi_m==7 \}

** Dosage/Recency knockout foreach var of varlist zvictim zsocanx zbeheng zpeersupp zlonely zbelong zgrit zschworry \{ mi estimate: regress 'var' zsped_rec zsped_dos [pweight=w9c9p_20]// Regressions regress 'var' zsped_rec zsped_dos [pweight $\left.=w 9 c 9 p \_20\right]$ if_mi_m $==7 / / \mathrm{R}-\mathrm{Squared}$ \} 